\title{
Cognitive-behavioural treatment for subacute and chronic neck pain (Review)
}

\author{
Monticone M, Cedraschi C, Ambrosini E, Rocca B, Fiorentini R, Restelli M, Gianola S,
} Ferrante S, Zanoli G, Moja L

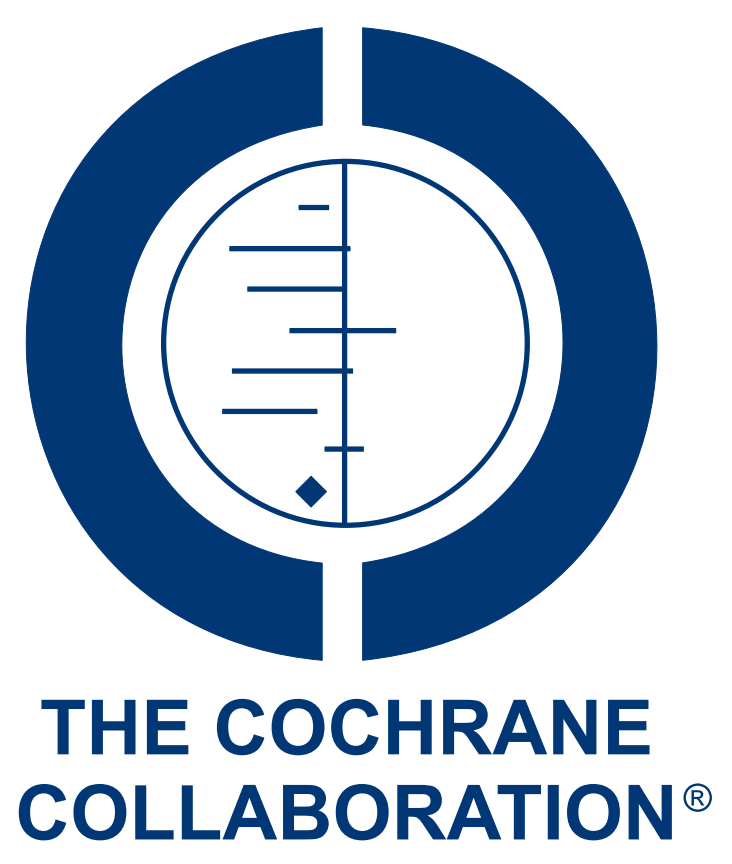

This is a reprint of a Cochrane review, prepared and maintained by The Cochrane Collaboration and published in The Cochrane Library 2015, Issue 5

http://www.thecochranelibrary.com

\section{WILEY}

Cognitive-behavioural treatment for subacute and chronic neck pain (Review)

Copyright @ 2015 The Cochrane Collaboration. Published by John Wiley \& Sons, Ltd. 
TABLE OF CONTENTS

HEADER . . . . . . . . . . . . . . . . . . . . . . . . . . . . . . . . . . . . . . .

ABSTRACT . . . . . . . . . . . . . . . . . . . . . . . . . . . . . . . . . . . . . . 1

PLAIN LANGUAGE SUMMARY . . . . . . . . . . . . . . . . . . . . . . . . . . . . . . . . . . . . . . . 2

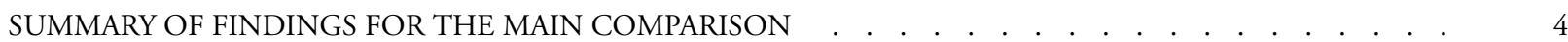

BACKGROUND . . . . . . . . . . . . . . . . . . . . . . . . . . . . . . . . . . . . . . . . . 6

OBJECTIVES . . . . . . . . . . . . . . . . . . . . . . . . . . . . . . . . . . . . . . . . . . . . . . .

METHODS . . . . . . . . . . . . . . . . . . . . . . . . . . . . . . . . . . . . . . . . .

RESULTS . . . . . . . . . . . . . . . . . . . . . . . . . . . . . . . . . . . . . . . . . . .

Figure 1. . . . . . . . . . . . . . . . . . . . . . . . . . . . . . . . . . . . . . 12

Figure 2. . . . . . . . . . . . . . . . . . . . . . . . . . . . . . . . . . . 14

Figure 3. . . . . . . . . . . . . . . . . . . . . . . . . . . . . . . . . . . . . . .

Figure 4. . . . . . . . . . . . . . . . . . . . . . . . . . . . . . . . . . . . . . 16

Figure 5. . . . . . . . . . . . . . . . . . . . . . . . . . . . . . . . . . . 16

Figure 6. . . . . . . . . . . . . . . . . . . . . . . . . . . . . . . . . . . . . . 17

Figure $7 . \quad$. . . . . . . . . . . . . . . . . . . . . . . . . . . . . . . . . . . 17

Figure 8. . . . . . . . . . . . . . . . . . . . . . . . . . . . . . . . . . . . . . 18

Figure 9. . . . . . . . . . . . . . . . . . . . . . . . . . . . . . . . . . . . . . 18

Figure 10. . . . . . . . . . . . . . . . . . . . . . . . . . . . . . . . . . . . . 19

Figure 11. . . . . . . . . . . . . . . . . . . . . . . . . . . . . . . . . . . . . . 19

Figure 12. . . . . . . . . . . . . . . . . . . . . . . . . . . . . . . . . . . . . . 19

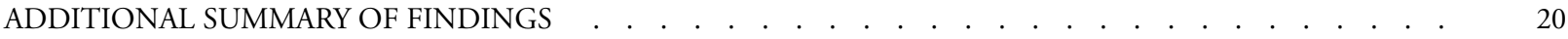

DISCUSSION . . . . . . . . . . . . . . . . . . . . . . . . . . . . . . . . . . . . . . . . . . 22

AUTHORS' CONCLUSIONS . . . . . . . . . . . . . . . . . . . . . . . . . . . . . . . . . . . . . . .

ACKNOWLEDGEMENTS . . . . . . . . . . . . . . . . . . . . . . . . . . . . . . . . . . . 24

REFERENCES . . . . . . . . . . . . . . . . . . . . . . . . . . . . . . . . . . . . . . 24

CHARACTERISTICS OF STUDIES . . . . . . . . . . . . . . . . . . . . . . . . . . . . . . . . . . . . .

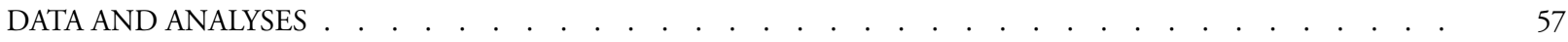

Analysis 1.1. Comparison 1 CBT versus other types of treatment (subacute NP), Outcome 1 Pain (short-term follow-up). 58

Analysis 1.2. Comparison 1 CBT versus other types of treatment (subacute NP), Outcome 2 Disability (short-term followup)

Analysis 2.1. Comparison 2 CBT versus no treatment (chronic NP), Outcome 1 Pain (short-term follow-up). . . . . 60

Analysis 2.2. Comparison 2 CBT versus no treatment (chronic NP), Outcome 2 Disability (short-term follow-up). . $\quad 61$

Analysis 2.3. Comparison 2 CBT versus no treatment (chronic NP), Outcome 3 Kinesiophobia (short-term follow-up). 61

Analysis 2.4. Comparison 2 CBT versus no treatment (chronic NP), Outcome 4 Distress (short-term follow-up). . . 62

Analysis 2.5. Comparison 2 CBT versus no treatment (chronic NP), Outcome 5 Quality of life (short-term follow-up). 63

Analysis 3.1. Comparison 3 CBT versus other types of treatment (chronic NP), Outcome 1 Pain (short-term follow-up). 63

Analysis 3.2. Comparison 3 CBT versus other types of treatment (chronic NP), Outcome 2 Pain (intermediate-term followup)

Analysis 3.3. Comparison 3 CBT versus other types of treatment (chronic NP), Outcome 3 Disability (short-term followup).

Analysis 3.4. Comparison 3 CBT versus other types of treatment (chronic NP), Outcome 4 Disability (intermediate-term follow-up).

Analysis 3.5. Comparison 3 CBT versus other types of treatment (chronic NP), Outcome 5 Kinesiophobia (intermediateterm follow-up).

Analysis 3.6. Comparison 3 CBT versus other types of treatment (chronic NP), Outcome 6 Depression (short-term followup)

Analysis 3.7. Comparison 3 CBT versus other types of treatment (chronic NP), Outcome 7 Depression (intermediate-term follow-up).

Analysis 3.8. Comparison 3 CBT versus other types of treatment (chronic NP), Outcome 8 Coping (short-term followup).

Cognitive-behavioural treatment for subacute and chronic neck pain (Review)

Copyright @ 2015 The Cochrane Collaboration. Published by John Wiley \& Sons, Ltd. 
Analysis 3.9. Comparison 3 CBT versus other types of treatment (chronic NP), Outcome 9 Coping (intermediate-term follow-up).

Analysis 4.1. Comparison 4 CBT in addition to another intervention versus the other intervention alone (chronic NP),

Outcome 1 Pain (short-term follow-up). . . . . . . . . . . . . . . . . . . . . . . . . . .

Analysis 4.2. Comparison 4 CBT in addition to another intervention versus the other intervention alone (chronic NP),

Outcome 2 Disability (short-term follow-up). . . . . . . . . . . . . . . . . . . . . . . . 72

ADDITIONAL TABLES . . . . . . . . . . . . . . . . . . . . . . . . . . . . . . . . . . . 72

APPENDICES . . . . . . . . . . . . . . . . . . . . . . . . . . . . . . . . . . . . . . 73

CONTRIBUTIONS OF AUTHORS . . . . . . . . . . . . . . . . . . . . . . . . . . . . . . . . . . . . . . .

DECLARATIONS OF INTEREST . . . . . . . . . . . . . . . . . . . . . . . . . . . . . . . . . . . . . . 86

SOURCES OF SUPPORT . . . . . . . . . . . . . . . . . . . . . . . . . . . . . . . . . . . . . . . . . . . . . 86

DIFFERENCES BETWEEN PROTOCOL AND REVIEW . . . . . . . . . . . . . . . . . . . . . . 86

NOTES . . . . . . . . . . . . . . . . . . . . . . . . . . . . . . . . . . . . . . . . . 87 


\title{
[Intervention Review] \\ Cognitive-behavioural treatment for subacute and chronic neck pain
}

\author{
Marco Monticone ${ }^{1}$, Christine Cedraschi ${ }^{2}$, Emilia Ambrosini ${ }^{1,3}$, Barbara Rocca ${ }^{1}$, Roberta Fiorentini ${ }^{1}$, Maddalena Restelli ${ }^{1}$, Silvia \\ Gianola $^{4}$, Simona Ferrante ${ }^{3}$, Gustavo Zanoli ${ }^{5}$, Lorenzo Moja ${ }^{6}$ \\ ${ }^{1}$ Physical Medicine and Rehabilitation Unit, Scientific Institute of Lissone (Milan), Institute of Care and Research, Salvatore Maugeri \\ Foundation, IRCCS, Milan, Italy. ${ }^{2}$ Multidisciplinary Pain Centre, Division of Clinical Pharmacology and Toxicology \& Division \\ of General Medical Rehabilitation, Geneva University Hospitals, Geneva, Switzerland. ${ }^{3}$ Neuroengineering and Medical Robotics \\ Laboratory, Department of Electronics, Information and Bioengineering, Politecnico di Milano, Milan, Italy. ${ }^{4}$ Clinical Epidemiology \\ Unit, IRCCS Galeazzi Orthopaedic Institute, Milan, Italy. ${ }^{5}$ Casa di Cura SM Maddalena - University of Ferrara, Occhiobello (RO) - \\ Ferrara, Italy. ${ }^{6}$ Department of Biomedical Sciences for Health, University of Milan, Milan, Italy
}

Contact address: Marco Monticone, Physical Medicine and Rehabilitation Unit, Scientific Institute of Lissone (Milan), Institute of Care and Research, Salvatore Maugeri Foundation, IRCCS, Milan, Italy. marco.monticone@fsm.it.

Editorial group: Cochrane Back Group.

Publication status and date: New, published in Issue 5, 2015.

Review content assessed as up-to-date: 20 November 2014.

Citation: Monticone M, Cedraschi C, Ambrosini E, Rocca B, Fiorentini R, Restelli M, Gianola S, Ferrante S, Zanoli G, Moja L. Cognitive-behavioural treatment for subacute and chronic neck pain. Cochrane Database of Systematic Reviews 2015, Issue 5. Art. No.: CD010664. DOI: 10.1002/14651858.CD010664.pub2.

Copyright (C) 2015 The Cochrane Collaboration. Published by John Wiley \& Sons, Ltd.

\section{A B S T R A C T}

\section{Background}

Although research on non-surgical treatments for neck pain (NP) is progressing, there remains uncertainty about the efficacy of cognitive-behavioural therapy (CBT) for this population. Addressing cognitive and behavioural factors might reduce the clinical burden and the costs of NP in society.

\section{Objectives}

To assess the effects of CBT among individuals with subacute and chronic NP. Specifically, the following comparisons were investigated: (1) cognitive-behavioural therapy versus placebo, no treatment, or waiting list controls; (2) cognitive-behavioural therapy versus other types of interventions; (3) cognitive-behavioural therapy in addition to another intervention (e.g. physiotherapy) versus the other intervention alone.

\section{Search methods}

We searched CENTRAL, MEDLINE, EMBASE, CINAHL, PsycINFO, SCOPUS, Web of Science, and PubMed, as well as ClinicalTrials.gov and the World Health Organization International Clinical Trials Registry Platform up to November 2014. Reference lists and citations of identified trials and relevant systematic reviews were screened.

\section{Selection criteria}

We included randomised controlled trials that assessed the use of CBT in adults with subacute and chronic NP.

Cognitive-behavioural treatment for subacute and chronic neck pain (Review)

Copyright @ 2015 The Cochrane Collaboration. Published by John Wiley \& Sons, Ltd. 


\section{Data collection and analysis}

Two review authors independently assessed the risk of bias in each study and extracted the data. If sufficient homogeneity existed among studies in the pre-defined comparisons, a meta-analysis was performed. We determined the quality of the evidence for each comparison with the GRADE approach.

\section{Main results}

We included 10 randomised trials (836 participants) in this review. Four trials (40\%) had low risk of bias, the remaining $60 \%$ of trials had a high risk of bias.

The quality of the evidence for the effects of CBT on patients with chronic NP was from very low to moderate. There was low quality evidence that CBT was better than no treatment for improving pain (standard mean difference (SMD) $-0.58,95 \%$ confidence interval (CI) -1.01 to -0.16 ), disability (SMD $-0.61,95 \%$ CI -1.21 to -0.01 ), and quality of life (SMD $-0.93,95 \%$ CI -1.54 to -0.31 ) at shortterm follow-up, while there was from very low to low quality evidence of no effect on various psychological indicators at short-term follow-up. Both at short- and intermediate-term follow-up, CBT did not affect pain (SMD -0.06, 95\% CI -0.33 to 0.21, low quality, at short-term follow-up; MD -0.89, 95\% CI -2.73 to 0.94 , low quality, at intermediate-term follow-up) or disability (SMD -0.10, $95 \%$ CI -0.40 to 0.20 , moderate quality, at short-term follow-up; SMD -0.24, 95\% CI-0.54 to 0.07, moderate quality, at intermediate-term follow-up) compared to other types of interventions. There was moderate quality evidence that CBT was better than other interventions for improving kinesiophobia at intermediate-term follow-up (SMD $-0.39,95 \%$ CI -0.69 to $-0.08, \mathrm{I}^{2}=0 \%$ ). Finally, there was very low quality evidence that CBT in addition to another intervention did not differ from the other intervention alone in terms of effect on pain (SMD - $0.36,95 \%$ CI -0.73 to 0.02 ) and disability (SMD -0.10, 95\% CI -0.56 to 0.36) at short-term follow-up.

For patients with subacute NP, there was low quality evidence that CBT was better than other interventions at reducing pain at shortterm follow-up (SMD - $0.24,95 \%$ CI -0.48 to 0.00 ), while no difference was found in terms of effect on disability (SMD - $0.12,95 \%$ CI -0.36 to 0.12 ) and kinesiophobia.

None of the included studies reported on adverse effects.

\section{Authors' conclusions}

With regard to chronic neck pain, CBT was found to be statistically significantly more effective for short-term pain reduction only when compared to no treatment, but these effects could not be considered clinically meaningful. When comparing both CBT to other types of interventions and CBT in addition to another intervention to the other intervention alone, no differences were found. For patients with subacute NP, CBT was significantly better than other types of interventions at reducing pain at short-term follow-up, while no difference was found for disability and kinesiophobia. Further research is recommended to investigate the long-term benefits and risks of CBT including for the different subgroups of subjects with NP.

\section{PLAIN LANGUAGE SUMMARY}

\section{Cognitive-behavioural treatment for neck pain}

\section{Background}

Neck pain (NP) is defined as pain, muscle tension, or stiffness localized in the neck and may originate from many structures, including the spine or soft tissues. Risk factors include age, gender, a history of pain, poor posture, repetitive strain, and social and psychological factors.

NP is experienced by people of all ages and both genders and is an important cause of medical expenses, work absenteeism, and disability. Current management of NP includes a range of different treatments such as reassurance, education, promotion of a timely return to normal activities, appropriate use of painkillers, and exercises.

There remains uncertainty about the efficacy of cognitive-behavioural therapy (CBT) for these patients. CBT is a psychological technique that encompasses a wide set of interventions conducted by health professionals. It includes cognitive and behavioural modifications of specific activities to reduce the impact of pain as well as physical and psychosocial disability and to overcome dangerous barriers to physical and psychosocial recovery.

\section{Review Question}

Cognitive-behavioural treatment for subacute and chronic neck pain (Review)

Copyright ( 2015 The Cochrane Collaboration. Published by John Wiley \& Sons, Ltd. 
We therefore reviewed the evidence about the effect of CBT on pain, disability, psychological factors, and quality of life among patients with subacute and chronic NP. Specifically, we compared CBT versus no treatment, CBT versus other types of interventions, and CBT in addition to another intervention (e.g. physiotherapy) versus the other intervention alone.

\section{Study Characteristics}

We examined the research published up to November 2014. We included 10 randomised trials (836 participants). Two studies included subjects with subacute NP (337 participants), while the other eight studies included participants with chronic NP (499 participants). CBTwas compared to no treatment (225 participants) or to other types of treatments (506 participants), or combined with another intervention (e.g. physiotherapy) and compared to the other intervention alone (200 participants). The interventions were carried out at primary and secondary health care centres.

\section{Key Results}

With regard to chronic NP, CBT was statistically significantly better than no treatment at improving pain, disability, and quality of life, but these effects could not be considered clinically meaningful. No differences between CBT and other types of interventions (e.g. medication, education, physiotherapy, manual therapy, and exercises) were found in terms of pain and disability; there was moderate quality evidence that CBT was better than other interventions in improving fear of movement. Also, there was very low quality evidence that CBT added to another intervention was no better at improving pain and disability than the other intervention alone .

For subacute NP, there was low quality evidence that CBT was statistically significantly better than other types of interventions (e.g. manual therapy or education) for improving pain, but this effect was not clinically relevant. No difference was found in terms of disability and fear of movement.

None of the included studies reported on whether any adverse effects related to cognitive-behavioural therapy were observed.

\section{Quality of the Evidence}

The quality of evidence in this review ranged between "very low" and "moderate". Therefore, the review results should be interpreted with caution. More high quality randomised trials are needed to address short and long term benefits of cognitive-behavioural therapy in subacute and chronic neck pain, and its effectiveness compared with other treatments, and to better understand which patients may benefit most from this type of intervention. 


\section{SUMMARY OF FINDINGSFOR THE MAINCOMPARISON [Explanation]}

\section{Cognitive-behavioural treatment compared to other types of treatment for chronic neck pain at intermediate follow-up}

Patient or population: chronic neck pain

Settings: primary and secondary health care centres

Intervention: cognitive-behavioural treatment

Comparison: other types of treatment

\begin{tabular}{|c|c|c|c|c|c|}
\hline \multirow[t]{3}{*}{ Outcomes } & \multicolumn{2}{|c|}{ Illustrative comparative risks $(95 \% \mathrm{CI})$} & \multirow{3}{*}{$\begin{array}{l}\text { No of Participants } \\
\text { (studies) }\end{array}$} & \multirow{3}{*}{$\begin{array}{l}\text { Quality of the evidence } \\
\text { (GRADE) }\end{array}$} & \multirow[t]{3}{*}{ Comments } \\
\hline & Assumed risk & Corresponding risk & & & \\
\hline & Other types of treatment & $\begin{array}{l}\text { Cognitive-behavioural treat- } \\
\text { ment }\end{array}$ & & & \\
\hline $\begin{array}{l}\text { Pain } \\
\text { Numerical Rating Scale, from } \\
0 \text { (no pain) to } 10 \text { (maximum } \\
\text { pain) }\end{array}$ & $\begin{array}{l}\text { The mean pain ranged across } \\
\text { control groups from 4.3-7.0 } \\
\text { points. }\end{array}$ & $\begin{array}{l}\text { The mean pain in the CBT } \\
\text { group was } \mathbf{0 . 8 9} \text { lower ( } 2.73 \\
\text { lower to } 0.94 \text { higher). }\end{array}$ & $\begin{array}{l}168 \\
\text { (2 studies) }\end{array}$ & $\begin{array}{l}\oplus \oplus \bigcirc \bigcirc \\
\text { low }^{1,2}\end{array}$ & No effect was found. \\
\hline $\begin{array}{l}\text { Disability } \\
\text { Neck Disability Index, } \\
\text { from } 0 \text { (no disability) to } 100 \\
\text { (maximal disability) }\end{array}$ & $\begin{array}{l}\text { *The intermediate follow-up } \\
\text { for the most representative } \\
\text { study (Vonk 2009) was } 26.5 \\
\text { (SD 13.9). }\end{array}$ & $\begin{array}{l}\text { The estimated mean disabil- } \\
\text { ity in the CBT group was } 3 \text {. } \\
\mathbf{3 5} \text { lower (7.53 lower to } 0.98 \\
\text { higher). }\end{array}$ & $\begin{array}{l}168 \\
\text { (2 studies) }\end{array}$ & $\begin{array}{l}\oplus \oplus \oplus \bigcirc \\
\text { moderate }^{1}\end{array}$ & No effect was found. \\
\hline $\begin{array}{l}\text { Kinesiophobia } \\
\text { Tampa Scale for Kinesiopho- } \\
\text { bia, from } 17 \text { (no fear) to } 68 \text { ( } \\
\text { maximal fear) }\end{array}$ & $\begin{array}{l}\text { *The intermediate follow-up } \\
\text { for the most representative } \\
\text { study (Vonk 2009) was } 34.3 \\
\text { (SD 8.3). }\end{array}$ & $\begin{array}{l}\text { The estimated mean kinesio- } \\
\text { phobia in the CBT group was } \\
\mathbf{3 . 2 6} \text { lower ( } 5.76 \text { to } 0.67 \\
\text { lower). }\end{array}$ & $\begin{array}{l}168 \\
\text { (2 studies) }\end{array}$ & $\begin{array}{l}\oplus \oplus \oplus \bigcirc \\
\text { moderate }^{1}\end{array}$ & $\begin{array}{l}\text { The effect was not clinically } \\
\text { relevant. A } 25 \% \text { relative im- } \\
\text { provement is considered as a } \\
\text { clinically important treatment } \\
\text { effect for all secondary out- } \\
\text { comes }\end{array}$ \\
\hline
\end{tabular}

*Of the included trials for this outcome, we chose the study that is a combination of the most representative study population and has the largest weighting in the overall result in Revman (Vonk 2009). The reported data represent the intermediate follow-up mean in the control group of this study.

Cl: Confidence interval; CBT: cognitive-behavioural therapy. 
GRADE Working Group grades of evidence

High quality: Further research is very unlikely to change our confidence in the estimate of effect.

Moderate quality: Further research is likely to have an important impact on our confidence in the estimate of effect and may change the estimate.

Low quality: Further research is very likely to have an important impact on our confidence in the estimate of effect and is likely to change the estimate.

Very low quality: We are very uncertain about the estimate.

${ }^{1}$ Serious imprecision (i.e. total number of participants $<200$ for each outcome; an optimal information size of 300 was computed considering a $\alpha$ of 0.05 , a $\beta$ of 0.2 , and an effect size of 0.3 standard deviations).

2 Unexplained heterogeneity $\left(1^{2}=72 \%\right)$ 


\section{B A C K G R O U N D}

Neck pain (NP) is frequently experienced by people of all ages and both genders (Hogg-Johnson 2008). One-year prevalence ranges from $12.1 \%$ to $71.5 \%$ in the general population, and from $27.1 \%$ to $47.8 \%$ among the employed (Hogg-Johnson 2008). One-year prevalence of chronic NP, ranges from $1.7 \%$ to $11.5 \%$ in the general population; chronic NP is responsible for most of the social and economic costs of this condition (Cotè 2008).

Although research on non-surgical treatments for NP is progressing (e.g. reassurance, education, promotion of a timely return to normal activities, appropriate use of painkillers, and supervised exercises (Hoving 2001, Binder 2006; Hurwitz 2008)), there remains uncertainty about the efficacy of cognitive-behavioural treatment (CBT) for this population. Addressing cognitive and behavioural factors might reduce the clinical burden and the costs of NP in society.

\section{Description of the condition}

NP is defined as pain, muscle tension, or stiffness localized below the superior nuchal line and above the scapula line from the back, and below the superior nuchal line and the external occipital protuberance line and above the superior border of the clavicle and the suprasternal notch from the side (Guzman 2008).

NP may originate from many structures in the cervical region, including the spine or soft tissues, and its aetiology is multifactorial (Binder 2007; Croft 2001). Factors that contribute to its development include age, gender, a history of NP, the occurrence of other musculoskeletal problems (e.g. low back pain), poor posture, repetitive strain, poor self-rated health, and social and psychological factors (Binder 2007; Croft 2001). Also, prognosis appears to be influenced by several factors such as age, prior NP episodes, and poor psychological health (Carroll 2008).

Research conducted over the past decade links persistent NP to psychological factors, including cognitive distress, anxiety, and depressed mood (Linton 2000b). These psychological factors may play a role in the chronicity of symptoms and may contribute to a downward spiral of increasing avoidance, disability, and pain (Ariens 2001; Foster 2003).

\section{Description of the intervention}

CBT is a psychological management strategy that may be helpful for subacute and chronic NP by treating the associated psychological and behavioural factors as described above, and can be used alone or in conjunction with other therapeutic modalities such as exercise or physical modalities). Cognitive-behavioural treatment may be delivered by a variety of health professionals such as psychologists, medical doctors, physiotherapists, occupational therapists, teams devoted to the management of chronic pain, and rehabilitative teams. It encompasses a wide set of interventions that include cognitive reconditioning (e.g. cognitive restructuring, imagery, attention diversion, relaxation techniques) and behavioural modifications of specific activities (e.g. operant treatment, pacing, graded exposure approaches) to modify and/or reduce the impact of pain and physical and psychosocial disability and to overcome barriers to physical and psychosocial recovery (Turk 1984; Vlaeyen 2000; Pincus 2002; Butler 2006; Morley 2011). A main assumption of these interventions is that pain and pain disability are influenced not only by somatic pathology, but also by psychological and social factors (e.g. patients' attitudes and beliefs, psychological distress, illness behaviours). Consequently, the treatment of persistent pain is primarily focused not on removing an underlying organic pathology, but on the reduction of disability through modification of environmental contingencies and cognitive processes (Main 2008).

Little evidence is available to establish whether different CBT methods differentially affect subgroups of patients with specific attributes, but it has been suggested that treatment efficacy may be improved by matching treatments to patient characteristics (Vlaeyen 2005).

\section{How the intervention might work}

Under the supervision of psychologists or health professionals specifically trained in CBT, the intervention works by means of modifying maladaptive and dysfunctional thoughts (e.g. catastrophising, kinesiophobia) and improving mood (e.g. anxiety and depression), leading to gradual changes in cognition and illness behaviour. Patients are progressively educated to view their pain and the related disability as something that can be self-managed rather than as a serious disease that requires ongoing intervention. Processing of internal and external stimuli is central to cognitivebehavioural approaches, in order to change behaviours through a direct influence on cognitions as well as emotional and psychological responses (Vlaeyen 2005).

Cognitive relearning is based on accepting pain, developing awareness of the problem, and seeking a means of coping with frightening thoughts and mood alterations. Participants are assisted in transferring attention from incorrect and erratic thoughts and fears to adaptive thought patterns,increasing the level of activity by means of pacing, and graded exposure to situations they had previously avoided. Acquisition or re-acquisition of coping strategies is strongly encouraged and promoted through communication between the health professional and the patient, and the definition of realistic and meaningful goals is provided (Turk 1984; Vlaeyen 2000; Pincus 2002; Butler 2006; Morley 2011). As functional outcomes may rely in part on patient self-management and active participation in the recovery process, the identification of cognitive and behavioural factors amenable to change and of treatment strategies favouring these changes is of considerable interest (Pincus 2006; Hazard 2012). 


\section{Why it is important to do this review}

CBT is commonly used in the management of persistent low-back pain to reduce disability through modification of cognitive processes and maladaptive pain behaviours (Henschke 2010). However, it is still debated whether treating cognitive and behavioural factors in patients with subacute and chronic NP can actually lead to clinically meaningful changes in disability, dysfunctional thoughts, pain and quality of life.

This systematic review is particularly topical, as growing attention is devoted to cognitive-behavioural interventions for spinal disorders, including subacute and chronic NP. The main aim of conservative interventions for subacute and chronic NP should not only be targeted at treating "pain" or "physical dysfunction" but should also attempt to modify maladaptive cognitions and illness behaviours, which are significant barriers to recovery.

\section{O B JECT IVES}

The objective of this systematic review was to determine whether cognitive-behavioural therapy is more effective than other treatments for subacute and chronic neck pain. The following comparisons were investigated:

1. Cognitive-behavioural therapy versus placebo, no treatment, or waiting list controls.

2. Cognitive-behavioural therapy versus other types of interventions.

3. Cognitive-behavioural therapy in addition to another intervention (e.g. physiotherapy) versus the other intervention alone.

\section{METHODS}

\section{Criteria for considering studies for this review}

\section{Types of studies}

Only randomised controlled trials (RCTs) were included.

\section{Types of participants}

RCTs were included if they examined adult participants (male and female) with a clinical diagnosis of subacute NP (i.e. a documented history of pain lasting for at least one month and not longer than three months) or chronic NP (i.e. a documented history of pain lasting for at least three months), irrespective of the presence of radiculopathy or whiplash injury.
When an RCT recruited participants suffering from pain in different body regions, it was automatically excluded if results for neck pain were not presented separately.

When an RCT recruited participants with both subacute and chronic NP, it was considered eligible only if data for participants with subacute and chronic NP were presented separately.

\section{Types of interventions}

RCTs were included if they analysed one or more types of CBT. CBT encompasses a wide set of interventions, including cognitive reconditioning and behavioural modifications of specific activities with the aim of modifying or reducing the impact of pain and physical and psychosocial disability (Turk 1984; Vlaeyen 2000; Pincus 2002; Butler 2006; Morley 2011). Only trials that specified the use of treatment based on cognitive-behavioural principles were considered eligible. Simple psychologically-oriented pain management strategies were not considered true cognitivebehavioural treatments.

We expected high variability in the type of CBT provided (i.e., cognitive, respondent or operant treatments and varying modalities of administration), and we anticipated uncertainty about what was actually done as practical intervention. Doubts about the types and treatment characteristics of CBT were resolved through discussion, by contacting the authors of the study for additional information, or by finding a process paper associated with the study that provided further information.

\section{Types of outcome measures}

To be considered eligible for inclusion in this review, trials must have reported on at least one of the outcomes described in the following sections. Outcomes measured closest to four weeks were considered short-term follow-up, outcomes measured closest to 6 months were considered intermediate-term follow-up, and outcomes measured closest to one year were considered long-term follow-up.

\section{Primary outcomes}

The primary outcome chosen for this review was pain, expressed by means of a visual analogue scale (VAS) or a numerical rating scale (NRS; Huskinson 1974).

We reasoned that pain was a participant-centred outcome that had better responsiveness, particularly in subacute participants, compared with disability. Furthermore, we expected trials in this field to have limited length of follow-up, prohibiting assessment of disability improvement.

\section{Secondary outcomes}

We also included the following secondary outcomes. 
- Disability (e.g. 10-item Neck Disability Index (NDI; Vernon 1991); 20-Item Neck Pain and Disability Scale (NPDS; Wheeler 1999)).

- Psychological indicators, such as fear of pain,

kinesiophobia, catastrophising, coping strategies, anxiety, depression (e.g. Tampa Scale for Kinesiophobia (Kori 1990); Pain Catastrophising Scale (Sullivan 1995)).

- Global improvement or perceived recovery (overall improvement, proportion of participants recovered, subjective improvement of symptoms).

- Quality of life (e.g.Short-Form Health Survey

Questionnaire (SF-36; Ware 1992)).

- Return to work/absenteeism (e.g. estimated by and the proportion of participants returned to work, the number of days of sick leave).

- Satisfaction with treatment (e.g. Global Perceived Effect (GPE)).

- Adverse events.

- Reduction in frequency or number of medications used.

\section{Search methods for identification of studies}

We used the search strategy recommended by the Cochrane Back Review Group (Furlan 2009). Study design filters for identifying RCTs were combined with search terms for "neck pain" and "CBT". No language or date restrictions were applied to the searches.

\section{Electronic searches}

We searched the following databases from inception to November 20 and 21, 2014:

- Cochrane Central Register of Controlled Trials

(CENTRAL, which includes the Back Review Group Trials

Register; The Cochrane Library, Issue 10, October 2014)

- MEDLINE (OvidSP, 1946 to November Week 2 2014)

and MEDLINE In-Process \& Other Non-Indexed Citations

(OvidSP, November 19, 2014)

- EMBASE (OvidSP, 1980 to 2014 Week 46)

- CINAHL (EBSCO, 1981 to November 2014)

- PsycINFO (OvidSP, 2002 to November Week 32014 )

- SCOPUS (Elsevier)

- Web of Science (Thomas Reuters)

- PubMed

- ClinicalTrials.gov

- World Health Organization International Clinical Trials Registry Platform (WHO ICTRP)

Searches were previously run in July 2013. For the November 2014 search, the clinical trials registries were added and PubMed was searched to identify studies not in MEDLINE using the strategy recommended by Duffy 2014. The search strategies are reported in Appendix 1.

\section{Searching other resources}

We screened the reference lists of all included studies and systematic reviews pertinent to this topic. We did not contact experts to inquire about other potentially relevant studies.

\section{Data collection and analysis}

\section{Selection of studies}

Five teams of two authors each (MM and CC; EA and LM; BR and RF; MR and SG; SF and GZ) independently screened the citations identified in the literature search for inclusion on the basis of title and abstract, discarding any that did not meet the inclusion criteria. We retrieved all potentially relevant articles for an assessment of the full text. The two members of each team screened articles independently and. consensus meetings were held to resolve disagreements concerning the inclusion of RCTs. If disagreements persisted, another review author (LM) was consulted. We documented excluded studies in the 'Characteristics of excluded studies' table and provided a reason for exclusion for each. Review authors who were authors of trials being considered were excluded from eligibilitydecisions about their own studies.

\section{Data extraction and management}

Review authors used a customised data extraction form, which were piloted before use. Two authors (RF and MR) independently documented the following information.

- Methods: study design, randomisation and allocation procedures.

- Participants: patient population, source, and setting; inclusion criteria; number of participants; age; gender; duration of NP; type, symptoms, and characteristics of pain; baseline functional status or level of impairment; method of diagnosisof NP.

- Interventions: description of interventions given to each treatment group, including duration, type, frequency and cointerventions. If reported, we documented the background of the person providing the intervention (e.g. psychologist, medical doctor, occupational therapist, physiotherapist, physiotherapy/ occupational therapy assistant, family). If more than two intervention groups were included in the study, we noted the method of including these groups in any subsequent analysis.

- Outcomes: primary and secondary outcomes relevant to this review in the following domains:

- Pain intensity.

- NP-specific functional status.

- Psychological indicators (e.g. catastrophising, fear of pain/movement, mood disorders).

- Global improvement.

- Qualify of life. 
- Return to work or resumption of previous level of participation.

o Satisfaction with treatment.

- Adverse events.

- Reduction in frequency or number of medications

used.

The two review authors resolved any data extraction discrepancies through discussion. When disagreement persisted, a third review author (EA) resolved the disagreement.

Measures of effect and estimates of variability were extracted in the form of follow-up (post-intervention) measurements or change scores from baseline in all intervention and control groups. Where possible, follow-up measures were entered into the meta-analyses. The clinical relevance of each included trial was assessed by two review authors (MM and SG). A list of five questions has been recommended to facilitate decisions about the applicability of results to other populations (Furlan 2009; Malmivaara 2006;Appendix 2). A clinically important treatment effect (i.e. the smallest change in score of the construct that participants perceive as important) for our primary outcome (pain) was achieved if improvement of at least 2.5 points was seen on a 0 to 10 VAS/NRS scale. A $25 \%$ relative improvement was taken as a clinically important treatment effect for all secondary outcomes (Cleland2008; Young2009; Young2010). We collected data on adverse events, including types, rates, severity and duration of harmful events.

\section{Assessment of risk of bias in included studies}

Two review authors (EA and $\mathrm{MM}$ ) independently assessed the risk of bias of each included RCT using the 12 criteria recommended by the Cochrane Back Review Group (Furlan 2009). These are an expansion of the criteria described in the Cochrane Handbook for Systematic Reviews of Interventions (Higgins 2011).

For each criterion, we assessed each study as being at "low risk", "high risk", or "unclear risk" of bias, and reported the ratings in the 'Risk of bias' table. We defined studies as having a low risk of bias if they met six or more criteria in the absence of other obvious serious methodological weakness, whereas we considered studies satisfying fewer than six criteria or with serious weakness as having a high risk of bias. We considered serious methodological weakness based on recommendations made in the Cochrane Handbook (Higgins 2011): (1) a dropout rate greater than 50\% at the follow-up measurement point of interest; (2) clinically relevant baseline differences for one or more primary outcomes, indicating unsuccessful randomisation; or (3) unacceptable adherence to the CBT program (defined as $<50 \%$ adherence in supervised programs). Risk of bias was not used to select trials for inclusion. The criteria and the instructions for performing these assessments are provided in Appendix 3.

The review authors could not be blinded to study authors, institution, and journal because the review authors who performed the risk of bias assessments were familiar with the literature. Review authors who were authors on included studies were excluded from risk of bias decisions about their own studies.

We produced a 'Risk of bias' table, graph and summary figure to illustrate potential biases within each of the included studies.

\section{Measures of treatment effect}

We considered separately the effects of CBT for populations with subacute and chronic NP.

We analysed the data using Review Manager 5 (Revman). We assessed the treatment effects for dichotomized outcomes using the risk ratio (RR), and for continuous outcomes we used the mean difference (MD) or the standardised mean difference (SMD) when the outcome was measured using different instruments, along with 95\% confidence intervals. For dichotomous outcomes, an RR below 1 indicated that CBT resulted in greater improvement than the comparison therapy. For continuous outcomes, a negative effect size indicated that CBT was more beneficial than the comparison therapy, meaning that participants had better pain relief and showed better improvement in functional status.

\section{Unit of analysis issues}

We anticipated that most trials randomised at the participant level. However, when we identified a cluster RCT, we included it, and when possible, we extracted effect measures and standard errors from an analysis that took clustering into account. When this was not possible, we extracted the number of clusters and estimated the intracluster correlation coefficient to inform a reliable analysis. When this was not possible, we disregarded the clustering if it made a modest contribution to the combined analysis and investigated the effect of this in a sensitivity analysis.

\section{Dealing with missing data}

For included studies, we extracted levels of and reasons for attrition. Missing data were treated according to whether data were 'missing at random' or 'not missing at random'. In relation to the former, we analysed available data and ignored missing data. For studies that reported a mean difference but no standard deviation (SD) or other statistic that could be used to compute the SD via appropriate methods, as outlined in Higgins 2011, we used imputation (Furlan 2009). For each outcome, we imputed missing SDs as the pooled SD from all other trials in the same meta-analysis by treatment group. This is considered to be a safe method of analysis, provided that most studies in a meta-analysis do not have missing SDs. When the proportion of trials missing parameter variability data for a particular outcome was high (>20\%), or when data were not missed at random, imputation methods were not appropriate, and we conducted analyses using only available data (i.e. we did not impute missing data), and implications were discussed in the text. 


\section{Assessment of heterogeneity}

Between-trial statistical heterogeneity was assessed using the $\mathrm{I}^{2}$ statistic and the $\mathrm{Chi}^{2}$ test. For the meta-analyses, we used a fixedeffect model if trials were sufficiently homogeneous (i.e. $\mathrm{I}^{2}<25 \%$ ) and a random-effects model if trials presented moderate levels of heterogeneity (i.e. $\mathrm{I}^{2}>25 \%$ but $<75 \%$ ). If considerable betweengroup statistical heterogeneity was detected (i.e. $\mathrm{I}^{2}>75 \%$ ), we did not perform a meta-analysis.

\section{Assessment of reporting biases}

We used funnel plots to explore the likelihood of reporting biases when at least 10 studies were included in a meta-analysis and studies were not of similar size. First, we assessed funnel plot asymmetry visually, integrating visual inspection with the use of formal tests for funnel plot asymmetry. For continuous outcomes, we used the test proposed by Egger 1997, and for dichotomous outcomes, we used the test proposed by Harbord 2006. When asymmetry was detected in any of these tests or was suggested by visual assessment, we discussed possible explanations (such as publication bias, poor methodological quality, true heterogeneity, artefact, or chance) on the basis of available information (Higgins 2011) and performed sensitivity analyses to consider implications of the review findings. Funnel plots were interpreted cautiously as they could be misleading. We also checked for inconsistencies between the information presented in clinical trial registries and that provided in published reports of trials. Review authors who were authors of trials were excluded from decisions about their own studies.

\section{Data synthesis}

The results from individual trials were combined when possible through a meta-analysis. The main analysis was performed irrespective of the presence/absence of participants with cervical radiculopathy or whiplash injury. This pooling of the data was dependent on the level of heterogeneity of retrieved studies.

Regardless of whether available homogeneous data were sufficient to allow review authors to quantitatively summarise the data, we assessed the overall quality of the evidence for each outcome. To accomplish this, we used the GRADE approach, as recommended in the Cochrane Handbook (Higgins 2011) and adapted in the updated Cochrane Back Review Group method guidelines (Furlan 2009). The quality of the evidence on a specific outcome was based on the performance of studies against five factors: study design and limitations, consistency of results, directness (generalisability), precision (sufficient data) and reporting of results across all studies that measured that particular outcome. The quality starts at high when high-quality RCTs provide results for the outcome and is reduced by one level for each of the factors not met.

We prepared the 'Summary of findings' tables following the published guidelines from the Cochrane Collaboration (Higgins 2011). Only outcomes measuring pain, disability, and fear avoidance (i.e. kinesiophobia) were included in the 'Summary of find- ings' tables. Two separate tables were included, each of them reporting the most important comparison for the two categories of subjects (subacute and chronic NP). For each category, the most important comparison was selected based on the number of studies included in the meta-analysis and on the time point of the followup (the longer the follow-up, the more preferred the comparison). We used GRADEpro (GRADEpro) to prepare the GRADE tables and the 'Summary of findings' tables.

High-quality evidence: Consistent findings have been noted among at least $75 \%$ of RCTs with no limitations on study design; with consistent, direct and precise data; and with no known or suspected publication biases. Further research is unlikely to change the estimate or our confidence in the results.

Moderate-quality evidence: One of the domains is not met. Further research is likely to have an important impact on our confidence in the estimate of effect and may change the estimate.

Low-quality evidence: Two of the domains are not met. Further research is very likely to have an important impact on our confidence in the estimate of effect and is likely to change the estimate. Very low-quality evidence: Three of the domains are not met. We are very uncertain about the results.

No evidence: No RCTs are identified that addressed this outcome.

\section{Subgroup analysis and investigation of heterogeneity}

Subgroup analyses were planned but not conducted due to insufficient numbers of studies in each pairwise comparison. For a description of the original plans for subgroup analyses please refer to the 'Difference between protocol and review' paragraph.

\section{Sensitivity analysis}

Studies with substantial missing data $(>20 \%$ of treated participants excluded from the final analysis) were excluded in a sensitivity analysis to allow investigation of any bias they could confer on the results.

\section{R E S U L T S}

\section{Description of studies}

See: Characteristics of included studies; Characteristics of excluded studies

\section{Results of the search}

The search strategy identified 780 references from CENTRAL, 666 from MEDLINE, 2530 from EMBASE, 310 from CINAHL, 384 from SCOPUS, 203 from Web of Knowledge, and 90 from PsycINFO. 770 of these publications were duplications, resulting 
in a total of 4193 unique titles. After screening the titles and abstracts, full text copies of 64 trials and 17 reviews were retrieved. The reference lists of the reviews were checked but did not result in the identification of any further relevant studies. After reviewing the full text of the 64 selected trials, we agreed on the inclusion of 10 RCTs (Dunne 2012; Gustavsson 2006; Monticone 2012; Pato 2010; Pool 2010; Robinson 2013; Soderlund 2001; Taimela 2000; Vonk 2009; Wicksell 2008). There was no need to contact the authors to resolve doubts about the types and treatment characteristics of CBT. All of the included studies were considered eligible for inclusion in the meta-analysis.

Figure 1 shows the flow diagram of the review. 
Figure I. Flow diagram

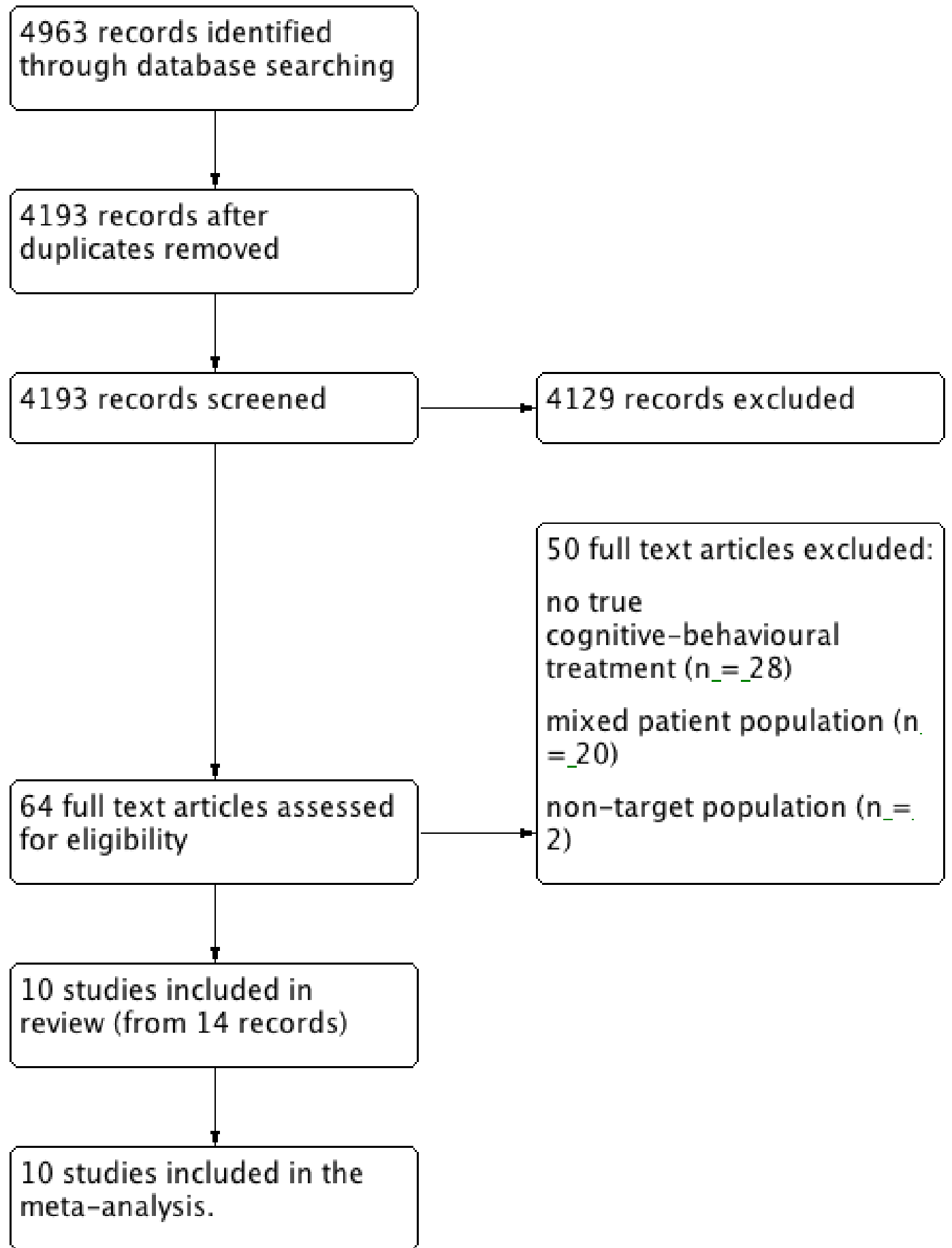




\section{Included studies}

Two studies (Pool 2010; Robinson 2013) included subjects with subacute NP, while the other eight studies included participants with chronic NP. Four studies (Dunne 2012; Robinson 2013; Taimela 2000; Wicksell 2008) compared some type of cognitive behavioural treatment to no treatment (225 recruited subjects in total). Specifically, Dunne at al (Dunne 2012) included 10 weekly 1-hour sessions of individually trauma-focused cognitive behavioural therapy based on the Australian Guidelines for the Treatment of Acute Stress Disorder and Posttraumatic Stress Disorder (cognitive strategies, coping self-talk, cognitive restructuring, psychoeducation, anxiety management strategies, and relapse prevention strategies); Robinson et al (Robinson 2013) provided an educational booklet (information on anatomical and neurological aspects of whiplash injury and pain) plus three biweekly skill training sessions (including strategies to cope with anxiety and stress, pain management, and relaxation), pacing, and graded exposure therapy sessions (imaginal and in vivo desensitization) in a one-on-one format; Taimela et al (Taimela 2000) planned 24 treatments, two sessions per week, 45 minutes each, during 12 weeks and included cervicothoracic stabilization, relaxation training, behavioural support, eye fixation exercises and seated wobble-board training; Wicksell et al (Wicksell 2008) planned 10 individual sessions (60 minutes each) over a period of 8 weeks, with the aim of increasing psychological flexibility by means of pain education, values assessment, shifting perspective, exposure, acceptance, and defusion. Five other studies (Gustavsson 2006; Pool 2010; Robinson 2013; Taimela 2000; Vonk 2009) compared some type of cognitive behavioural treatment to other kinds of treatment (506 recruited subjects in total): Gustavsson et al (Gustavsson 2006) planned seven 1.5-hour sessions, over a period of 7 weeks, addressing applied relaxation training, coping strategies, body awareness exercises and theoretical information about anatomy, aetiology, and physiology of pain and stress, and pain and stress management; Pool et al (Pool 2010) provided a maximum of 18 sessions (30 minutes each) of a behavioural graded activity program, the core elements of which were decrease in pain behaviour and increase in "healthy" behaviour, improvement of function, and no focus on pain reduction, where the patient is responsible for the treatment and has an active role; Vonk et al (Vonk 2009) planned up to 18 treatments (30 minutes each) of behaviour graded activity, including pain and pain-related beliefs management, pacing and graded exposure to exercises. The last three studies (Monticone 2012; Pato 2010; Soderlund 2001) compared some type of cognitive behavioural treatment in addition to another treatment to that treatment alone (200 recruited subjects in total): Monticone et al (Monticone 2012) planned 10 sessions consisting of exercises and CBT based on correct re-learning, cognitive reconditioning, and physical and psychosocial recovery to modify mistaken fears, catastrophising beliefs, and inappropriate thinking; Pato et al (Pato 2010) planned twice weekly sessions for 8 weeks and focused on pain aspects, teaching control of pain, stress reduction, and chronic pain management techniques such as imagery, cognitive therapy for stressful situations, progressive muscle relaxation training, and application of guided mastery for stress/ pain management; Soderlund et al (Soderlund 2001) planned 12 individual sessions including learning of basic physical and psychological skills (cognitive awareness, coping strategies management, and relaxation training), application and generalization of these basic skills in everyday activities (behaviour re-learning), and a phase for maintenance of these skills. Two studies (Robinson 2013; Taimela 2000) were included in two different comparisons since they randomised the participants into three groups: an experimental group receiving cognitive behavioural treatment; a notreated group receiving only an information booklet; and a control group receiving some other kind of intervention.

There were four studies (Dunne 2012; Pato 2010; Robinson 2013; Wicksell 2008) that specifically involved a clinical psychologist in the CBT, and four studies (Monticone 2012; Pool 2010; Taimela 2000; Vonk 2009) that involved other healthcare professionals (physiotherapists) specifically trained in CBT. In the two remaining studies (Gustavsson 2006; Soderlund 2001), the level of expertise of the healthcare professionals delivering CBT was not adequately described.

\section{Risk of bias in included studies}

The final results of the risk of bias assessment are shown in Figure 2. Four studies (40\%) had a low risk of bias, meeting six or more of the criteria (Gustavsson 2006; Monticone 2012; Pool 2010; Vonk 2009). All studies were described as randomised, but only three studies (30\%) used a clearly described and adequate randomisation procedure in combination with adequate concealment of treatment allocation. Eight studies (80\%) had similar timing of outcome measurements between groups and seven studies (70\%) were free of selective reporting. Seven studies $(70 \%)$ had an acceptable drop-out rate, four studies (40\%) reported acceptable compliance, and in only two studies (20\%) were co-interventions avoided or similar between groups. In most of the studies (90\%), groups were similar at baseline, and in six studies (60\%) an intention-to-treat analysis was performed. In all of the studies, the blinding of participants, and consequently of outcome assessors (as the outcome measures included in the meta-analysis were patientreported), was inadequate. Finally, none of the studies reported adequate blinding of care providers. 
Figure 2. Risk of bias summary: review authors' judgements about each risk of bias item for each included study.

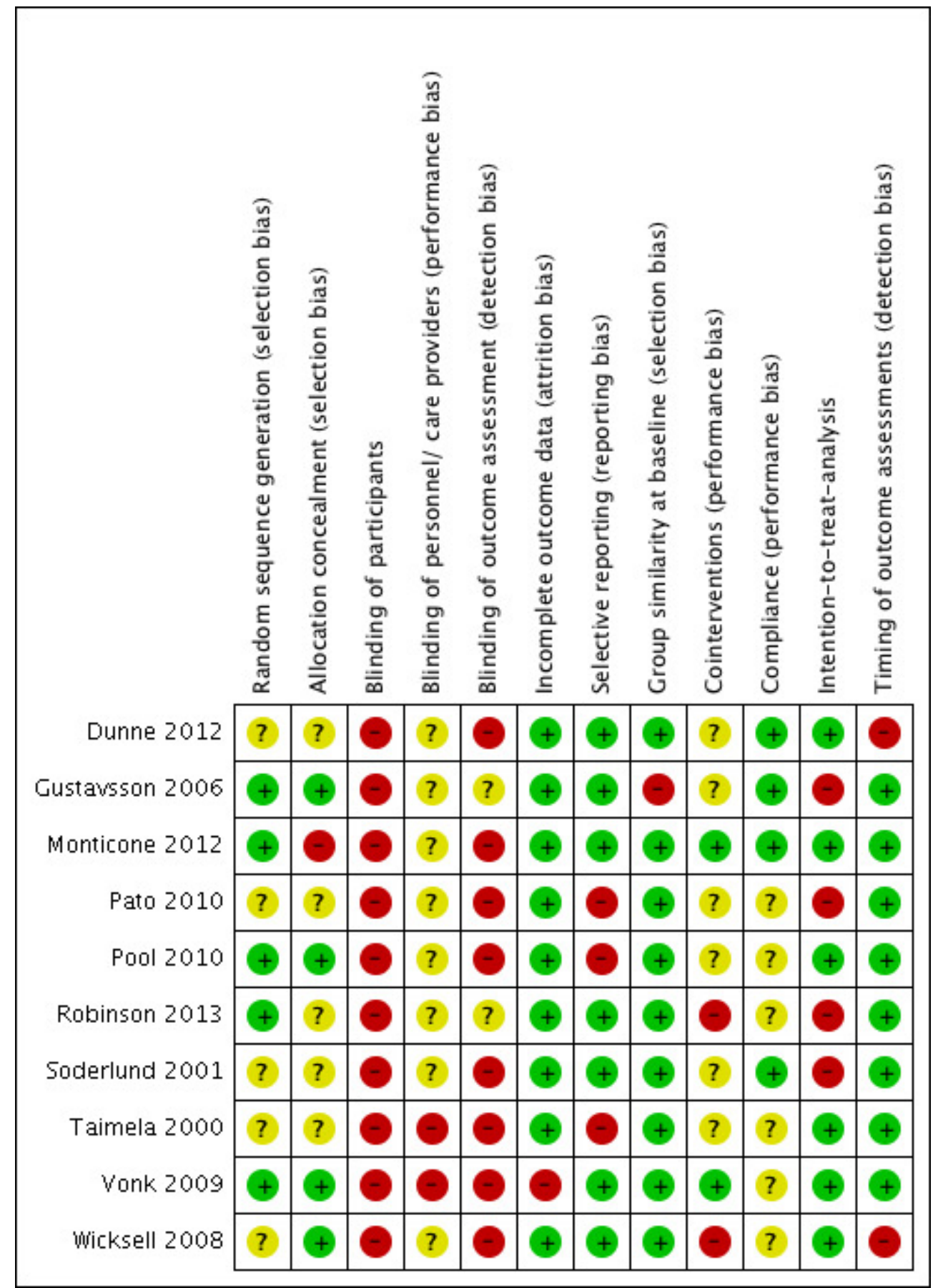


At short-term follow-up, only one study lost more than $20 \%$ of patients (Vonk 2009), while at intermediate-term follow-up there were two studies (Gustavsson 2006; Vonk 2009), who lost more than $20 \%$ of participants. However, since the percentages of dropouts in the two groups were similar, we assumed these data were "missing at random", and thus we analysed available data and ignored missing data.

Four studies performed per-protocol analyses (Gustavsson 2006; Pato 2010; Robinson 2013; Soderlund 2001), while the other six performed intention-to-treat analyses. However, among the studies that performed intention-to-treat analyses, only two (Dunne 2012; Wicksell 2008) described the method used to deal with missing data.

\section{Clinical relevance}

The clinical relevance scores for each trial are presented in Table 1. All of the 10 RCTs were found to have moderate to high clinical relevance (a score of three out of five or greater). The majority of studies could be easily assessed in terms of applicability to other populations because they provided sufficient descriptions of the included patients (100\%), provided sufficient descriptions of the interventions applied (90\%), measured appropriate outcome measures (100\%), and treatment benefits outweighed the potential harms (100\%). In no studies did the size of the effect reach a clinically important difference. These findings indicate that, while most studies were found to have moderate to high clinical relevance scores, the overall relevance was limited by the small size of the effect.

\section{Effects of interventions}

See: Summary of findings for the main comparison Cognitivebehavioural treatment compared to other types of treatment for chronic neck pain at intermediate follow-up; Summary of findings 2 Cognitive-behavioural treatment compared to other types of treatment for subacute neck pain at short-term follow-up See: Summary of findings for the main comparison; Summary of findings 2.

Given that each pairwise comparison included a limited number of RCTs, we decided to not formally assess publication bias, and we did not perform a subgroup analysis or a sensitivity analysis.

\section{Effects of CBT in patients with subacute NP}

Two studies, one with high risk of bias (Robinson 2013) and one with low risk of bias (Pool 2010), evaluated the effects of CBT on patients with subacute NP. In one study, 191 patients were randomly assigned to 3 treatment groups: one performing a type of CBT ( $\mathrm{n}=70)$, one receiving only an information booklet (no treatment; $n=57$ ), and one being involved in a didactic discussion (other type of intervention; $\mathrm{n}=64$; Robinson 2013). The shortterm effects ( 6 weeks) of the three interventions were compared. In the other study, the effects of CBT both at short- (13 weeks) and long-term follow-up (52 weeks) were compared to those of manual therapy; 146 patients with subacute NP were included (Pool 2010).

The results of these two studies were combined in a meta-analysis comparing the effects of CBT versus other interventions at shortterm follow-up (see Summary of findings 2). This meta-analysis included a total of 265 subacute NP patients and showed that there was low quality evidence that $\mathrm{CBT}$ is better than other interventions for improving pain (SMD - $0.24,95 \%$ CI -0.48 to 0.00 , $\mathrm{I}^{2}=7 \%$, p-value $\left.=0.05\right)$; see Analysis 1.1 ; Figure 3 ), while no difference was found in terms of disability (SMD - $0.12,95 \% \mathrm{CI}$ -0.36 to $0.12, \mathrm{I}^{2}=0 \%$, p-value $=0.31$; see Analysis 1.2 ; Figure 4 ).

Figure 3. Forest plot of comparison: I CBT versus other types of treatment (subacute NP), outcome: I.I Pain (short-term follow-up).

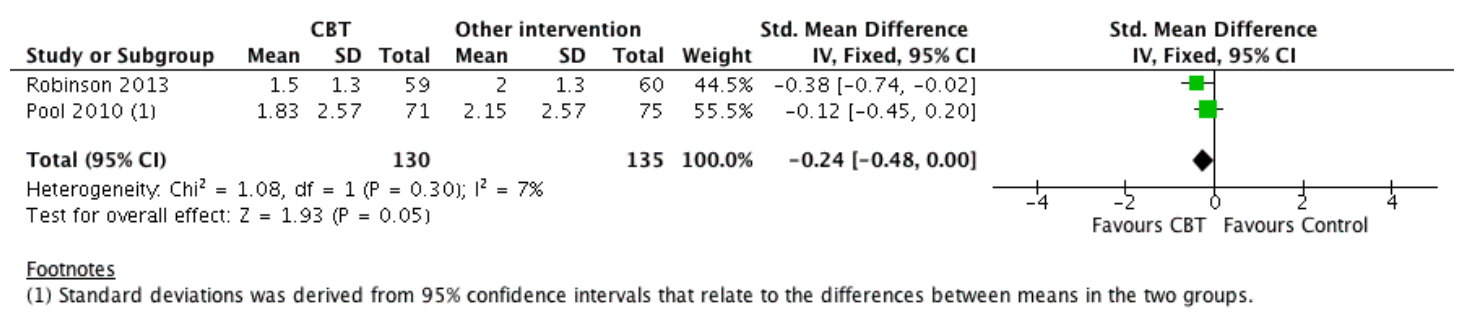

Cognitive-behavioural treatment for subacute and chronic neck pain (Review) 
Figure 4. Forest plot of comparison: I CBT versus other types of treatment (subacute NP), outcome: 1.2 Disability (short-term follow-up).

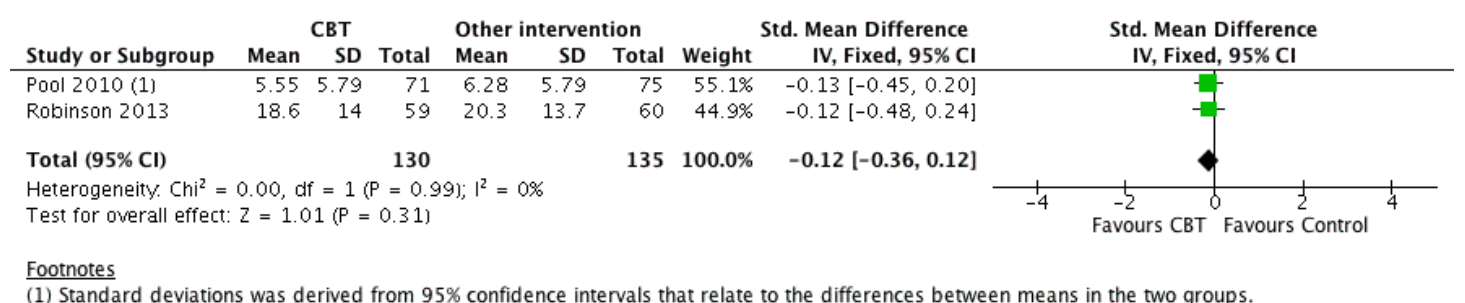

Futhermore, Robinson et al. (Robinson 2013) observed that the CBT group outperformed the no treatment group in terms of pain and disability ( (mean pain severity: possible range 0 to $6, \mathrm{MD}$ $-0.80,95 \%$ CI -1.27 to -0.33 ); Neck Disability Index: possible range 0 to $100, \mathrm{MD}-5.80,95 \% \mathrm{CI}-10.52$ to -1.08$)$. Finally, Pool et al. (Pool 2010) showed that at long-term follow-up, CBT was better than manual therapy at improving pain and disability (Numerical Rating Scale: possible range 0 to 10 , MD 0.99, 95\% CI 0.15 to 1.83 ; Neck Disability Index: possible range 0 to 50 , MD 2.42, 95\% CI 0.52 to 4.32). For other outcomes (such as Tampa Scale of Kinesiophobia or the Pain Coping and Cognition List), there was no significant difference between groups.

\section{Cognitive Behavioural Treatment versus no}

\section{treatment in patients with chronic NP}

For this comparison, only post-treatment (short-term) data were available because after the treatment period, most studies allowed the waiting list controls to receive the interventions or did not perform the follow-up assessment. A total of 89 chronic patients were included in three studies with high risk of bias comparing cognitive behavioural treatment to no treatment (Dunne 2012; Taimela 2000; Wicksell 2008). There is low quality evidence that CBT is better than no treatment at improving pain in the short term $\left(\mathrm{SMD}-0.58,95 \% \mathrm{CI}-1.01\right.$ to $-0.16, \mathrm{I}^{2}=0 \%, \mathrm{p}$-value $=$ 0.007; see Analysis 2.1; Figure 5). The outcome was downgraded from high to low quality due to serious imprecision (total number of participants $<300$ ) and serious limitation in the design and implementation ( $>25 \%$ of studies with high risk of bias).

Figure 5. Forest plot of comparison: 2 CBT versus no treatment (chronic NP), outcome: 2.I Pain (shortterm follow-up).

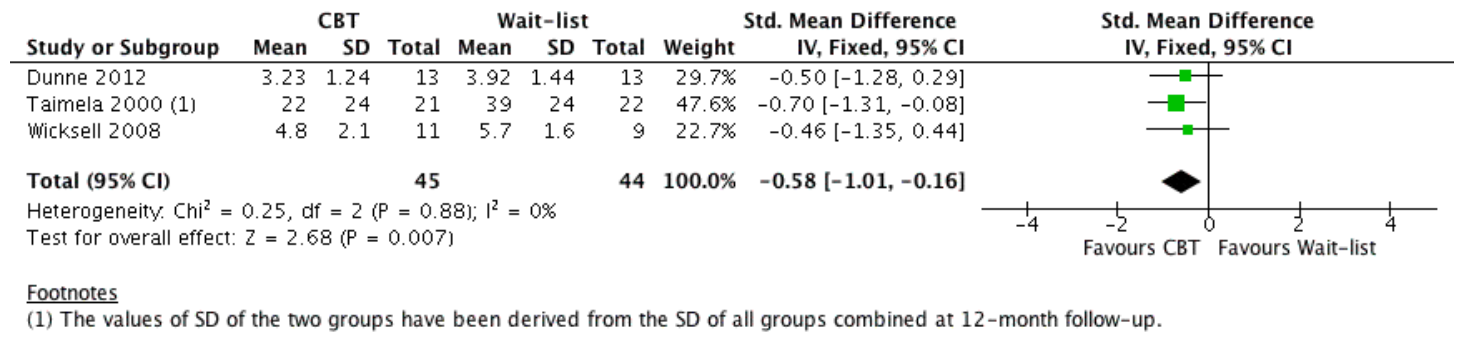

Two of these RCTs $(\mathrm{N}=46)$ also measured disability and psychological indicators, such as kinesiophobia, distress, and quality of life. There is low quality evidence that CBT had a significant positive benefit for disability (SMD $-0.61,95 \%$ CI -1.21 to -0.01 , $\mathrm{I}^{2}=0 \%$, p-value $=0.05$; see Analysis 2.2 ; Figure 6 ), and quality of life (SMD -0.93, 95\% CI - 1.54 to $-0.31, \mathrm{I}^{2}=0 \%$, $\mathrm{p}$-value $=0.003$; see Analysis 2.5). Finally, CBT compared to no treatment had no effect on kinesiophobia (measured on the Tampa Scale for Kinesiophobia: possible range 17 to 68, random-effects, MD -6.69, $95 \% \mathrm{CI}-13.91$ to $0.53, \mathrm{I}^{2}=72 \%$, p-value $=0.07$; see Analysis 2.3; very low quality), and distress (SMD -0.41, 95\% CI -0.99 to $0.18, \mathrm{I}^{2}=0 \%$, p-value $=0.17$; see Analysis 2.4 ; low quality). The same reasons for downgrading the evidence on pain to low 
quality were applied for the other outcomes. Kinesiophobia was additionally downgraded to very low quality due to unexplained heterogeneity $\left(\mathrm{I}^{2}>25 \%\right)$.

Figure 6. Forest plot of comparison: 2 CBT versus no treatment (chronic NP), outcome: 2.2 Disability (short-term follow-up).

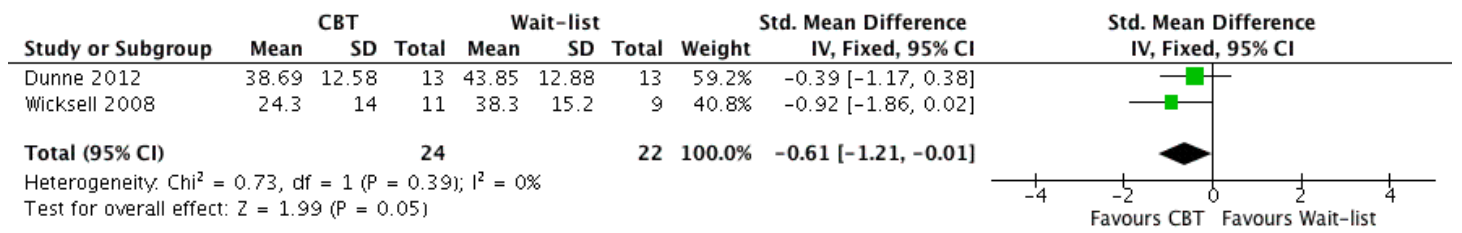

\section{Cognitive Behavioural treatments versus other treatments in patients with chronic NP}

A total of 212 chronic NP patients were included in three studies that compared cognitive behavioural treatment with other types of interventions. Two RCTs (Gustavsson 2006; Vonk 2009) had a low risk of bias, and one (Taimela 2000) had a high risk of bias. In terms of pain at short-term follow-up, there is low quality evidence that CBT does not differ in effectiveness from other types of interventions (SMD -0.06, 95\% CI - 0.33 to $0.21, \mathrm{I}^{2}=0 \%$, pvalue $=0.65$; see Analysis 3.1; Figure 7). The outcome was down- graded from high to low quality due to serious imprecision (total number of participants $<300$ ) and serious limitation in the design and implementation ( $>25 \%$ of studies with high risk of bias). Two out of three studies $(\mathrm{N}=168)$ confirm this result at intermediateterm (5-6 months) follow-up (measured on the Numerical Rating Scale: possible range from 0 to 10 , random-effects, MD -0.89 , $95 \%$ CI -2.73 to $0.94, \mathrm{I}^{2}=72 \%$, p-value $=0.34$; see Analysis 3.2; Figure 8). In this case, the outcome was downgraded to low quality due to serious imprecision and unexplained heterogeneity $\left(I^{2}>25 \%\right)$.

Figure 7. Forest plot of comparison: 3 CBT versus other types of treatment (chronic NP), outcome: 3. I Pain (short-term follow-up).

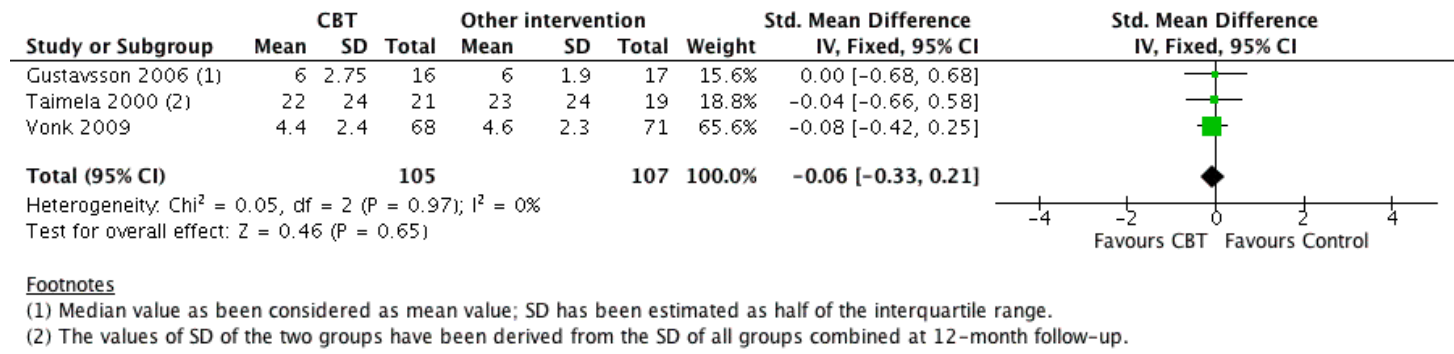


Figure 8. Forest plot of comparison: 3 CBT versus other types of treatment (chronic NP), outcome: 3.2 Pain (intermediate-term follow-up).

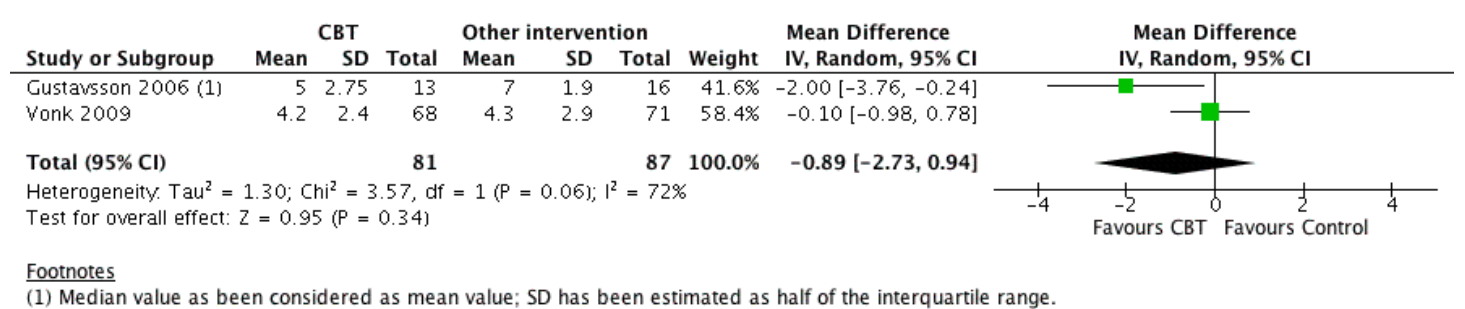

Two studies $(\mathrm{N}=168)$ also evaluated the effect of CBT on secondary outcome measures. Concerning disability, there is moderate quality evidence of no difference between the effectiveness of CBT and other interventions both at short-term (SMD -0.10, $95 \%$ CI -0.40 to $0.20, \mathrm{I}^{2}=0 \%$, p-value $=0.52$; see Analysis 3.3; Figure 9) and intermediate-term follow-up (SMD -0.24, 95\% CI -0.54 to $0.07, \mathrm{I}^{2}=0 \%$, p-value $=0.13$; see Analysis 3.4; Figure 10). There is moderate quality evidence that CBT is better than other interventions at decreasing kinesiophobia at intermediateterm follow-up (SMD -0.39, 95\% CI -0.69 to $-0.08, \mathrm{I}^{2}=0 \%$, $\mathrm{p}$-value $=0.01$; see Analysis 3.5). Also, there is moderate quality evidence that CBT is better than other interventions at improving depression (SMD $-0.43,95 \%$ CI -0.74 to $-0.12, \mathrm{I}^{2}=0 \%$, $\mathrm{p}$ - value $=0.006$; see Analysis 3.6), while there is low quality evidence that CBT is no more effective than other interventions to improve coping ability at short-term follow-up (random-effects, SMD $-0.28,95 \%$ CI -0.72 to $0.16, \mathrm{I}^{2}=33 \%$, p-value $=0.21$; see Analysis 3.8). At intermediate-term follow-up, no benefit of CBT was found for decreasing depression (SMD - $0.29,95 \%$ 0.60 to $0.01, \mathrm{I}^{2}=0 \%$, p-value $=0.06$; see Analysis 3.7; moderate quality) or improving coping (random-effects, SMD -0.07, 95\% CI -0.84 to $0.71, \mathrm{I}^{2}=73 \%$, p-value $=0.87$; see Analysis 3.9; low quality). For all secondary outcomes but coping, the quality of the evidence was downgraded from high to moderate due to serious imprecision. Coping was additionally downgraded to low quality due to unexplained heterogeneity $\left(\mathrm{I}^{2}>25 \%\right)$.

Figure 9. Forest plot of comparison: 3 CBT versus other types of treatment (chronic NP), outcome: 3.3 Disability (short-term follow-up).

\begin{tabular}{|c|c|c|c|c|c|c|c|c|c|c|c|}
\hline \multirow[b]{2}{*}{ Study or Subgroup } & \multicolumn{3}{|c|}{ CBT } & \multicolumn{3}{|c|}{ Other intervention } & \multicolumn{2}{|r|}{ Std. Mean Difference } & \multirow{2}{*}{\multicolumn{3}{|c|}{$\begin{array}{l}\text { Std. Mean Difference } \\
\text { IV, Fixed, } 95 \% \mathrm{CI}\end{array}$}} \\
\hline & Mean & SD & Total & Mean & SD & Total & Weight & IV, Fixed, 95\% CI & & & \\
\hline Vonk 2009 & 22.1 & 15.2 & 68 & 24 & 12.9 & 71 & $82.9 \%$ & $-0.13[-0.47,0.20]$ & & & \\
\hline $\begin{array}{l}\text { Heterogeneity. } \mathrm{Chi}^{2}= \\
\text { Test for overall effect: }\end{array}$ & $\begin{array}{l}0.25, \mathrm{df} \\
Z=0.64\end{array}$ & $\begin{array}{l}=1(\mathrm{P} \\
+(\mathrm{P}=\end{array}$ & $\begin{array}{l}=0.62 \\
0.521\end{array}$ & $2) ; 1^{2}=0$ & & & & & -4 & $\begin{array}{ccc}-2 & 0 & \frac{1}{2} \\
\text { Favours CBT } & \text { Favours Control }\end{array}$ & $\frac{1}{4}$ \\
\hline
\end{tabular}


Figure 10. Forest plot of comparison: 3 CBT versus other types of treatment (chronic NP), outcome: 3.4 Disability (intermediate-term follow-up).

\begin{tabular}{lrrrrrrrrr} 
& \multicolumn{3}{c}{ CBT } & \multicolumn{3}{c}{ Other intervention } & \multicolumn{2}{c}{ Std. Mean Difference } & Std. Mean Difference \\
IV, Fixed, 95\% CI
\end{tabular}

\section{Behavioural treatments in addition to another treatment versus the other treatment alone in patients with chronic NP}

For this comparison, only post-treatment (short-term) data were available for meta-analysis, since intermediate- and long-term follow-up data were each available from only one RCT. A total of 185 chronic NP patients were included in three studies of cognitive behavioural treatment in addition to other type of interventions compared to the other intervention alone. One RCT (Monticone 2012) had a low risk of bias and two RCTs (Pato 2010; Soderlund
2001) had a high risk of bias. At short-term follow-up, there is very low quality evidence that CBT in addition to another intervention compared to the other intervention alone has no benefit for decreasing pain (random-effects, SMD - 0.36, 95\% CI -0.73 to $0.02, \mathrm{I}^{2}=37 \%$, p-value $=0.07$; see Analysis 4.1 ; Figure 11 ) and disability (random-effects, SMD $-0.10,95 \%$ CI -0.56 to 0.36 , I $2=57 \%$, p-value $=0.68$; see Analysis 4.2; Figure 12). Both outcomes were downgraded to very low quality due to serious imprecision (total number of participants $<300$ ), serious limitation in the design and implementation ( $>25 \%$ of studies with high risk of bias), and unexplained heterogeneity ( $\left.\mathrm{I}^{2}>25 \%\right)$.

Figure I I. Forest plot of comparison: 4 CBT in addition to another intervention versus the other intervention alone (chronic NP), outcome: 4.I Pain (short-term follow-up).

\begin{tabular}{|c|c|c|c|c|c|c|c|c|c|}
\hline Study or Subgroup & \multicolumn{3}{|c|}{ CBT+ other intervention } & \multicolumn{3}{|c|}{ Other intervention } & \multicolumn{2}{|r|}{ Std. Mean Difference } & $\begin{array}{l}\text { Std. Mean Difference } \\
\text { IV, Random, } 95 \% \mathrm{CI}\end{array}$ \\
\hline Monticone 2012 & 2.32 & 2.34 & 40 & 3.78 & 2.3 & 40 & $39.6 \%$ & $-0.62[-1.07,-0.17]$ & $\rightarrow-$ \\
\hline Pato 2010 & 32 & 24 & 40 & 41 & 26 & 33 & $38.1 \%$ & $-0.36[-0.82,0.11]$ & - \\
\hline Soderlund 2001 (1) & 3.7 & 2.3 & 16 & 3.4 & 2.4 & 16 & $22.3 \%$ & $0.12[-0.57,0.82]$ & $\Gamma$ \\
\hline Total $(95 \% \mathrm{CI})$ & & & 96 & & & 89 & $100.0 \%$ & $-0.36[-0.73,0.02]$ & \\
\hline \multicolumn{10}{|c|}{ 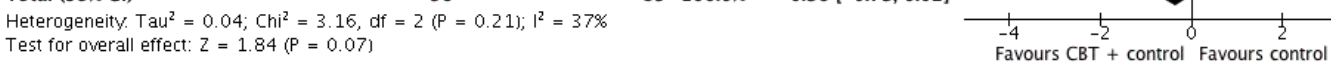 } \\
\hline
\end{tabular}

Figure 12. Forest plot of comparison: 4 CBT in addition to another intervention versus the other intervention alone (chronic NP), outcome: 4.2 Disability (short-term follow-up).

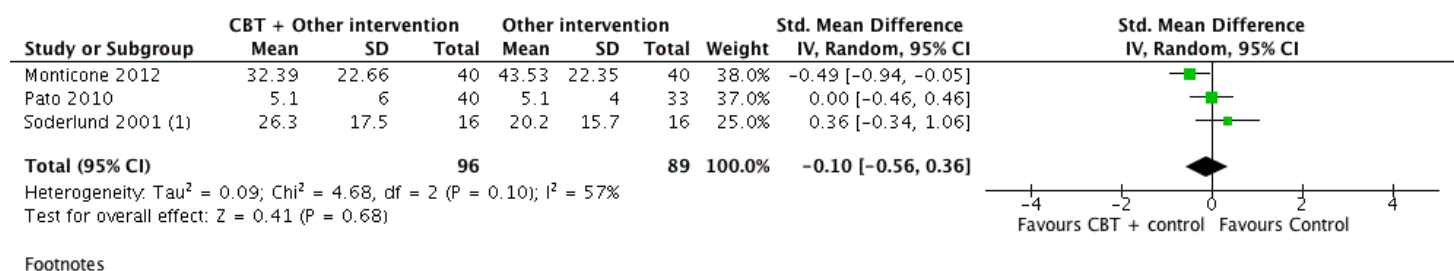

Footnotes

(1) Scores at 3-month follow-up have been reported. 
ADDITIONAL SUMMARY OF FINDINGS[Explanation]

Cognitive-behavioural treatment compared to other types of treatment for subacute neck pain at short-term follow-up

Patient or population: subacute neck pain

Settings: primary and secondary health care centres

Intervention: cognitive-behavioural treatment

Comparison: other types of treatment

\begin{tabular}{|c|c|c|c|c|c|}
\hline \multirow[t]{3}{*}{ Outcomes } & \multicolumn{2}{|c|}{ Illustrative comparative risks (95\% CI) } & \multirow{3}{*}{$\begin{array}{l}\text { No of Participants } \\
\text { (studies) }\end{array}$} & \multirow{3}{*}{$\begin{array}{l}\text { Quality of the evidence } \\
\text { (GRADE) }\end{array}$} & \multirow[t]{3}{*}{ Comments } \\
\hline & Assumed risk & Corresponding risk & & & \\
\hline & Other types of treatment & $\begin{array}{l}\text { Cognitive-behavioural treat- } \\
\text { ment }\end{array}$ & & & \\
\hline $\begin{array}{l}\text { Pain } \\
\text { Numerical Rating Scale, from } \\
0 \text { (no pain) to } 10 \text { (maximum } \\
\text { pain) }\end{array}$ & $\begin{array}{l}{ }^{*} \text { The short-term follow-up for } \\
\text { the most representative study } \\
\text { (Pool 2010) was } 2.15 \text { (SD } 2 . \\
57 \text { ). }\end{array}$ & $\begin{array}{l}\text { The estimated mean pain in } \\
\text { the CBT group was } 0.62 \text { lower } \\
(1.23 \text { lower to } 0.00) \text {. }\end{array}$ & 265 (2 study) & $\begin{array}{l}\oplus \oplus \bigcirc \bigcirc \\
\text { low }^{1,2}\end{array}$ & $\begin{array}{l}\text { The effect was not clinically } \\
\text { relevant. A clinically important } \\
\text { treatment effect on } 0-10 \text { pain } \\
\text { scale is about } 2.5 \text { points }\end{array}$ \\
\hline $\begin{array}{l}\text { Disability } \\
\text { Neck Disability Index, } \\
\text { from } 0 \text { (no disability) to } 50 \\
\text { (maximal disability) }\end{array}$ & $\begin{array}{l}{ }^{*} \text { The short-term follow-up for } \\
\text { the most representative study } \\
\text { (Pool 2010) was } 6.28 \text { (SD } 5 . \\
\text { 79). }\end{array}$ & $\begin{array}{l}\text { The estimated mean disabil- } \\
\text { ity in the CBT group was } 0 \text {. } \\
69 \text { lower ( } 2.08 \text { lower to } 0.69 \\
\text { higher). }\end{array}$ & 265 (2 study) & $\begin{array}{l}\oplus \oplus \bigcirc \bigcirc \\
\text { low }^{1,2}\end{array}$ & No effect was found. \\
\hline $\begin{array}{l}\text { Kinesiophobia } \\
\text { various scales }\end{array}$ & $\begin{array}{l}\text { *The short-term follow-up for } \\
\text { the most representative study } \\
\text { (Pool 2010) was not reported. } \\
\text { The other study (Robinson } \\
\text { 2013) reported a short-term } \\
\text { follow-up of } 105.7 \text { (139.2) } \\
\text { Outcome measure: Fear }\end{array}$ & $\begin{array}{l}\text { No difference was found in- } \\
\text { dividually by the two studies. } \\
\text { A meta-analysis was not con- } \\
\text { ducted since one study (Pool } \\
\text { 2010) did not report individual } \\
\text { data. }\end{array}$ & 265 (2 study) & $\begin{array}{l}\oplus \oplus \bigcirc \bigcirc \\
\operatorname{low}^{1,2}\end{array}$ & No effect was found. \\
\hline
\end{tabular}


*Of the included trials for this outcome, we chose the study with low risk of bias (Pool 2010). The reported data represent the intermediate follow-up mean in the control group of this study. Cl: Confidence interval; CBT: cognitive-behavioural therapy.

GRADE Working Group grades of evidence

High quality: Further research is very unlikely to change our confidence in the estimate of effect.

Moderate quality: Further research is likely to have an important impact on our confidence in the estimate of effect and may change the estimate.

Low quality: Further research is very likely to have an important impact on our confidence in the estimate of effect and is likely to change the estimate.

Very low quality: We are very uncertain about the estimate.

${ }^{1}$ Serious imprecision (i.e. total number of participants < 300 for each outcome; an optimal information size of 300 was computed considering a $\alpha$ of 0.05 , a $\beta$ of 0.2 , and an effect size of 0.3 standard deviations).

${ }^{2}$ Serious limitation in the design and implementation since the estimates of the treatment effects were derived from two studies, one with high (Robinson 2013) and one with low risk of bias (Pool 2010). The study of Robinson 2013 was considered as high risk of bias since it satisfied less than six criteria, as outlined in the Methods section. 


\section{ISCUSSION}

\section{Summary of main results}

Ten RCTs were included in this systematic review. A complete risk of bias assessment was performed, and the GRADE approach was used to judge the quality of the evidence.

Overall, most of the trials were not adequately sized, did not provide intermediate- and long-term outcomes, and suffered from poor reporting of a number of methodological quality items. None of the comparisons made in this systematic review provided high quality evidence, either for or against CBT; there was very low to moderate quality evidence to support the results. Also, we were not able to estimate the probability of publication bias due to the small number of trials.

Only two studies evaluating the effects of CBT on patients with subacute NP were found (see Summary of findings 2). These studies showed that CBT was significantly better than other types of interventions (e.g. manual therapy or education) for short-term pain relief, but this effect could not be considered clinically relevant. In terms of reducing disability and fear of movement, no benefit of CBT was found at short-term. One of the two studies (Pool 2010) also evaluated the long-term effect of CBT compared to manual therapy and observed a significant positive effect of CBT in terms of pain and disability, and no difference regarding kinesiophobia. Although this study recruited 146 patients, further investigation is needed to confirm these results.

With regard to patients with chronic NP, CBT was found to be statistically significantly more effective than no treatment for shortterm pain relief, decreasing disability, and improving quality of life, but these effects could not be considered clinically meaningful. No differences were found regarding psychological indicators (e.g. kinesiophobia and distress). There was no difference between CBT and other types of interventions for relieving pain or decreasing disability at short- and intermediate-term follow-up; however, at intermediate-term follow-up, CBT was better than other interventions $\mathrm{t}$ improving kinesiophobia, and at short-term followup it was better at improving depression. When comparing CBT plus another intervention to the other intervention alone, no differences were found for the effectiveness on short-term pain relief or disability, and no data regarding psychological indicators could be pooled (see Summary of findings for the main comparison).

\section{Overall completeness and applicability of evidence}

Our results suggest that it is not possible to modify pain intensity and disability associated with subacute and chronic NP to a clinically meaningful level in the short-term using CBT. In the intermediate- and long-term, CBT had no effect at all on chronic NP, while a significant but not clinically meaningful improvement was found when comparing CBT with manual therapy for subacute NP. However this latter result needs to be considered with caution since it was derived from a single study (Pool 2010).
A large number and variety of cognitive-behavioural outcomes were measured by the included trials in this review, showing the diversity of cognitive-behavioural constructs. Apart from pain intensity and disability, psychological indicators (i.e. kinesiophobia, coping, and distress), mood symptoms (i.e. depression) and quality of life were the only other outcomes that could be pooled in meta-analyses. Among them, the only effect that was seen was a decrease in kinesiophobia among patients with chronic NP who were treated with CBT compared to those treated with another intervention, at intermediate-term follow-up. Therefore, there is still uncertainty concerning the effectiveness of CBT on kinesiophobia, coping, and distress.

Other psychological variables (e.g. anxiety and catastrophising) were measured, but only in individual studies, hampering comparisons between studies or data pooling. Even on an individual basis, no clear trends could be highlighted. No difference was found in anxiety reduction between CBT and no treatment for subacute (Robinson 2013) and chronic NP (Wicksell 2008) at short-term follow-up; however, a small significant benefit of CBT was found for this outcome compared to usual care for chronic NP at intermediate-term follow-up (Gustavsson 2006). Catastrophising was measured in only one study, which was reduced significantly more in the CBT group compared to the group assigned to conventional exercise at the end of the intervention; this effect was lost in the long term (Vonk 2009). Despite the limited evidence found in our review, musculoskeletal literature increasingly suggests that catastrophising be addressed when planning CBT interventions (Pincus 2002; Morley 2011; Monticone 2013; Monticone 2014; Vlaeyen 1995; Vlaeyen 2000). Indeed, catastrophising is considered a precursor of kinesiophobia and, as catastrophisers are expected to present increased levels of fear of movement, targeted interventions are recommended in order to achieve strong treatment effects.

Most of the studies included in this review did not involve a clinical psychologist and the experimental training was delivered by health professionals specifically trained in CBT. However, we believe that it is important to involve a clinical psychologist when planning future studies in order to enhance the quality of the intervention. We defined a clinically significant effect size for the primary outcome (pain) as an improvement of at least 2.5 points on a 0 to 10 VAS/NRS scale; regarding secondary outcomes a $25 \%$ relative improvement was considered as a clinically important treatment effect. When considering both primary and secondary outcomes, none of the included studies achieved a clinically significant size of the effect. While these outcomes are recommended for use in most NP trials, further research is needed to expand the definition of a clinically significant effect size, especially when using common outcome measures.

Considering the large number of people suffering from neck pain, it is important to evaluate not only the effectiveness of CBT compared to usual care but also its cost-effectiveness. Among the included studies, only one (Pool 2010) assessed the cost-effective- 
ness of CBT on subacute neck pain. The authors concluded that substantial investments are needed to reach a 0.95 probability that CBT is cost-effective in comparison with manual therapy for pain and disability. Further investigations, also on chronic patients, are needed to provide a final conclusion about the cost-effectiveness of CBT.

\section{Quality of the evidence}

The overall quality of the evidence of the effects of CBT on patients with chronic NP was from very low to moderate. For each outcome, there were fewer than five studies included in the metaanalysis, and in the majority of the cases there were only two. Most studies also had small sample sizes. Concerning patients with subacute NP, the quality of the evidence was low and two studies, one with high and one with low risk of bias, were included in the meta-analysis.

In order to be consistent in applying the GRADE approach to the meta-analyses, we decided to use cut-offs defined in a previous Cochrane review investigating the effect of CBT on chronic lowback pain (Henschke 2010). This means that when coming to a decision about the extent of limitations in the design and implementation, the quality of the evidence was downgraded if more than $25 \%$ of the pooled data came from studies with a high risk of bias. Concerning the imprecision of the results, we lowered our rating of the quality of the evidence if the pooled sample size was less than the the optimal information size. A value of 300 was computed considering $\alpha$ of $0.05, \beta$ of 0.2 , and an effect size of 0.3 standard deviations. None of the comparisons satisfied this second cut-off, and thus the evidence was always downgraded at least to moderate quality. Few studies reported a correct a priori calculation of the sample size, thus confirming the low rating of precision of our results. The third reason for downgrading the quality of the evidence was the presence of unexplained heterogeneity. The same cut-off defined for selecting a random-effects model was used ( ${ }^{2}$ $>25 \%$ ).

The risk of bias of the trials included in this review was high in most cases. Considering the nature of CBT, blinding of patients and care providers was not possible, reducing the quality of evidence. Many of the other criteria used to assess risk of bias were poorly reported, especially details about the randomisation procedure and concealment, compliance, and tracking of co-interventions.

The limitations found in the design and reporting of the included RCTs contributed to the overall judgment of the quality of evidence, using the GRADE approach, and served to downgrade the quality for most of the comparisons.

\section{Potential biases in the review process}

An extensive search of the most important electronic databases has been performed, and thus there is a high likelihood that all relevant studies were identified. Appropriate imputation methods were adopted when variability data were not available. The limitations of this review are mainly related to the paucity of relevant studies and to their limitations in design and reporting, being therefore outside the control of the review authors.

\section{Adverse effects}

None of the included RCTs reported on whether any adverse effects related to the intervention were observed. This made it difficult to determine whether the benefits gained from behavioural treatment are worth the potential harms. From the results of the meta-analyses, it can be seen that CBT for NP generally results in small effect sizes, if any.

\section{AUTHORS, CONCLUSIONS}

\section{Implications for practice}

CBT was shown to induce statistically significant changes in terms of pain relief and disability in subject with chronic NP only when compared to no treatment. On subacute NP, a statistically significant effect was found on pain relief but not on disability when comparing CBT to other types of interventions. However, none of these treatment effects could be considered clinically meaningful and there was no evidence on maintenance of the effects beyond the short term in either category of patients. Due to the low quality of the evidence, a conclusion about the usefulness of CBT for patients with NP cannot be derived from this review.

\section{Implications for research}

More research is recommended in order to i) investigate the longterm benefits and risks of CBT including the different subgroups of NP subjects (for example, whiplash injuries); ii) identify which psychological factors have the strongest influence on a patient's experience of NP and which of these factors can be utilised as appropriate outcome measures; iii) to promote the involvement of clinical psychologists and health professionals specifically trained in CBT in order to standardize CBT intervention; iv) to promote more specifically targeted interventions which might have the potential to achieve stronger treatment effects. Future studies should include a larger sample size, guarantee the blinding of the outcome assessors, specify the method used for randomisation and allocation concealment, extensively describe the experimental intervention, assure no or similar co-interventions between groups, and describe possible adverse effects. We suggest the exploration of benefits both in terms of pain and disability for longer followup periods (at least one year). Finally, a cost-effectiveness analysis of CBT should be included in future RCTs. 


\section{ACKNOWLEDGEMENTS}

We would like to thank Teresa Marin, previous Managing Editor of the Cochrane Back Review Group, Claire Munhall, current Managing Editor of the Cochrane Back Review Group, and Allison Kelly, Administrative Editorial Assistant of the Cochrane Back Review Group, for their assistance and support.

\section{R E F E R E N C E S}

\section{References to studies included in this review}

Dunne 2012 \{published data only\}

Dunne RL, Kenardy J, Sterling M. A randomized controlled trial of cognitive-behavioral therapy for the treatment of PTSD in the context of chronic whiplash. Clinical Journal of Pain 2012;28(9):755-65.

Gustavsson 2006 \{published data only\} Gustavsson C, von Koch L. Applied relaxation in the treatment of long-lasting neck pain: a randomized controlled pilot study. Journal of Rehabilitation Medicine 2006;38(2):100-7.

Monticone 2012 \{published data only\}

Monticone M, Baiardi P, Vanti C, Ferrari S, Nava T, Montironi $\mathrm{C}$, et al. Chronic neck pain and treatment of cognitive and behavioural factors: results of a randomised controlled clinical trial. European Spine Journal 2012;21(8): 1558-66.

Pato 2010 \{published data only\} Pato U, Di Stefano G, Fravi N, Arnold M, Curatolo M, Radanov BP, et al. Comparison of randomized treatments for late whiplash. Neurology 2010;74(15):1223-30.

Pool 2010 \{published data only\} Bosmans JE, Pool JJM, De Vet HC, Van Tulder MW, Ostelo RW. Is behavioral graded activity cost-effective in comparison with manual therapy for patients with subacute neck pain? An economic evaluation alongside a randomized clinical trial. Spine 2011;36(18):E1179-86.

* Pool JJ, Ostelo RW, Knol DL, Vlaeyen JW, Bouter LM, De Vet HC. Is a behavioral graded activity program more effective than manual therapy in patients with subacute neck pain? Results of a randomized clinical trial. Spine 2010;35(10):1017-24.

Pool JJ, Ostelo RW, Köke AJ, Bouter LM, De Vet HC. Comparison of the effectiveness of a behavioural graded activity program and manual therapy in patients with subacute neck pain: design of a randomized clinical trial. Manual Therapy 2006;11(4):297-305.

Robinson 2013 \{published data only\}

Robinson JP, Theodore BR, Dansie EJ, Wilson HD, Turk DC. The role of fear of movement in subacute whiplashassociated disorders grades I and II. Pain 2013;154(3): 393-401.
Soderlund 2001 \{published data only\}

* Soderlund A, Lindberg P. Cognitive behavioural components in physiotherapy management of chronic whiplash associated disorders (WAD) - A randomised group study. Physiotherapy Theory and Practice 2001;17(4): 229-38.

Soderlund A, Lindberg P. Cognitive behavioural components in physiotherapy management of chronic whiplash associated disorders (WAD)--a randomised group study. Giornale Italiano di Medicina del Lavoro ed Ergonomia 2007;29(1 Suppl A):A5-11.

Taimela 2000 \{published data only\} Taimela S, Takala EP, Asklöf T, Seppälä K, Parviainen S. Active treatment of chronic neck pain: a prospective randomized intervention. Spine 2000;25(8):1021-7.

\section{Vonk 2009 \{published data only\}}

Vonk F, Verhagen AP, Geilen M, Vos CJ, Koes BW. Effectiveness of behavioural graded activity compared with physiotherapy treatment in chronic neck pain: design of a randomised clinical trial [ISRCTN88733332]. BMC Musculoskeletal Disorders 2004;5(1):34.

* Vonk F, Verhagen AP, Twisk JW, Köke AJ, Luiten MW, Koes BW. Effectiveness of a behaviour graded activity program versus conventional exercise for chronic neck pain patients. European Journal of Pain 2009;13(5):533-41.

Wicksell 2008 \{published data only\}

Wicksell RK, Ahlqvist J, Bring A, Melin L, Olsson GL. Can exposure and acceptance strategies improve functioning and life satisfaction in people with chronic pain and whiplashassociated disorders (WAD)? A randomized controlled trial. Cognitive Behaviour Therapy 2008;37(3):169-82.

\section{References to studies excluded from this review}

Andersen 2008 \{published data only\}

Andersen LL, Jørgensen MB, Blangsted AK, Pedersen MT, Hansen EA, Sjøgaard G. A randomized controlled intervention trial to relieve and prevent neck/shoulder pain. Medicine and Science in Sports and Exercise 2008;40(6): 983-90.

\section{Andersen 2012 \{published data only\}} Andersen LL, Andersen CH, Sundstrup E, Jakobsen MD, Mortensen OS, Zebis MK. Central adaptation of pain perception in response to rehabilitation of musculoskeletal pain: Randomized controlled trial. Pain Physician 2012;15 (5):385-93. 
Aslan Telci 2012 \{published data only\}

Aslan Telci E, Karaduman A. Effects of three different conservative treatments on pain, disability, quality of life, and mood in patients with cervical spondylosis. Rheumatology International 2012;32(4):1033-40.

Bablis 2008 \{published data only\} Bablis P, Pollard H, Bonello R. Neuro Emotional Technique for the treatment of trigger point sensitivity in chronic neck pain sufferers: a controlled clinical trial. Chiropractic \& Osteopathy 2008;16:4.

Bergstrom 2012 \{published data only\} Bergstrom C, Jensen I, Hagberg J, Busch H, Bergstrom G. Effectiveness of different interventions using a psychosocial subgroup assignment in chronic neck and back pain patients: A 10-year follow-up. Disability and Rehabilitation 2012;34(2):110-8.

Bernaards 2008 \{published data only\}

Bernaards CM, Ariëns GA, Simons M, Knol DL, Hildebrandt VH. Improving work style behavior in computer workers with neck and upper limb symptoms. Journal of Occupational Rehabilitation 2008;18(1):87-101.

Bissett 1985 \{published data only\}

Bissett A, Mitchell KR, Major G. The cervico-brachial pain syndrome: muscle activity and pain relief. Behaviour Change 1985;2(2):129-35.

Bronfort 2012 \{published data only\}

Bronfort G, Evans R, Anderson AV, Svendsen KH, Bracha Y, Grimm RH. Spinal manipulation, medication, or home exercise with advice for acute and subacute neck pain:A randomized trial. Annals of Internal Medicine 2012;156(1): $1-10$.

Bunketorp 2006 \{published data only\}

Bunketorp L, Lindh M, Carlsson J, Stener-Victorin E. The perception of pain and pain-related cognitions in subacute whiplash-associated disorders: its influence on prolonged disability. Disability and Rehabilitation 2006;28(5):271-9.

Busch 2011 \{published data only\}

Busch H, Bodin L, Bergström G, Jensen IB. Patterns of sickness absence a decade after pain-related multidisciplinary rehabilitation. Pain 2011;152(8):1727-33.

Cramer 2012 \{published data only\} Cramer H, Lauche R, Haller H, Langhorst J, Dobos G, Berger B. Becoming aware of your body: A qualitative study on yoga for chronic neck pain patients. $B M C$ Complementary and Alternative Medicine 2012;12(Suppl 1): P393.

Cramer 2013 \{published data only\} Cramer H, Lauche R, Hohmann C, Langhorst J, Dobos G. Yoga for Chronic Neck Pain: A 12-Month Follow-Up. Pain Medicine (United States) 2013;14(4):541-8.

Cramer 2013a \{published data only\}

Cramer H, Lauche R, Hohmann C, Lüdtke R, Haller H, Michalsen A, Langhorst J, Dobos G. Randomizedcontrolled trial comparing yoga and home-based exercise for chronic neck pain. Clinical Journal of Pain 2013;29(3): 216-23.

Dehner 2009 \{published data only\} Dehner C, Elbel M, Strobel P, Scheich M, Schneider F, Krischak G, Kramer M. Grade II whiplash injuries to the neck: what is the benefit for patients treated by different physical therapy modalities?. Patient Safety in Surgery 2009; 3(1):2.

Ehrenborg 2010 \{published data only\} Ehrenborg C, Archenholtz B. Is surface EMG biofeedback an effective training method for persons with neck and shoulder complaints after whiplash-associated disorders concerning activities of daily living and pain -- a randomized controlled trial. Clinical Rehabilitation 2010;24(8):715-26.

Gale 2002 \{published data only\}

Gale G, Nussbaum D, Rothbart P, Hann B, Leung V, Kanetz G. A randomized treatment study to compare the efficacy of repeated nerve blocks with cognitive therapy for control of chronic head and neck pain. Pain Research \& Management 2002;7(4):185-9.

Gustavsson 2010 \{published data only\} Gustavsson C, Denison E, von Koch L. Self-management of persistent neck pain: A randomized controlled trial of a multi-component group intervention in primary health care. European journal of Pain 2010;14(6):630.e1-630.e11.

Gustavsson 2011 \{published data only\}

Gustavsson C, Denison E, von Koch L. Self-management of persistent neck pain: Two-year follow-up of a randomized controlled trial of a multicomponent group intervention in primary health care. Spine 2011;36(25):2105-15.

Haugli 2003 \{published data only\}

Haugli L, Steen E, Laerum E, Nygard R, Finset A. Psychological distress and employment status. Effects of a group learning programme for patients with chronic musculoskeletal pain. Psychology, Health \& Medicine 2003;8 (2):135-48.

Jensen 1995 \{published data only\} Jensen I, Nygren A, Gamberale F, Goldie I, Westerholm P, Jonsson E. The Role of the Psychologist in Multidisciplinary Treatments for Chronic Neck and Shoulder Pain - A Controlled Cost-Effectiveness Study. Scandinavian Journal of Rehabilitation Medicine 1995;27(1):19-26.

Jensen 1997 \{published data only\} Jensen IB, Dahlquist C, Nygren A, Royen E, Stenberg M. Treatment for "helpless" women suffering from chronic spinal pain: a randomized controlled 18-month follow-up study. Journal of Occupational Rehabilitation 1997;7(4): 225-38.

Jensen 1998 \{published data only\}

Jensen IB, Bodin L. Multimodal cognitive-behavioural treatment for workers with chronic spinal pain: A matched cohort study with an 18-month follow-up. Pain 1998;76 (1-2):35-44. 
Jensen 2005 \{published data only\}

Jensen IB, Bergström G, Ljungquist T, Bodin L. A 3-year follow-up of a multidisciplinary rehabilitation programme for back and neck pain. Pain 2005;115(3):273-83.

Jorgensen 2011 \{published data only\} Jørgensen MB, Faber A, Hansen JV, Holtermann A, Søgaard K. Effects on musculoskeletal pain, work ability and sickness absence in a 1-year randomised controlled trial among cleaners. BMC Public Health 2011;11:840.

Klaber 2005 \{published data only\} Klaber Moffett JA, Jackson DA, Richmond S, Hahn S, Coulton S, Farrin A, Manca A, Torgerson DJ. Randomised trial of a brief physiotherapy intervention compared with usual physiotherapy for neck pain patients: outcomes and patients' preference. BMJ 2005;330(7482):75.

Klaber 2006 \{published data only\} Moffett JK, Jackson DA, Gardiner ED, Torgerson DJ, Coulton S, Eaton S, Mooney MP, Pickering C, Green AJ, Walker LG, May S, Young S. Randomized trial of two physiotherapy interventions for primary care neck and back pain patients: 'McKenzie' vs brief physiotherapy pain management. Rheumatology 2006;45(12):1514-21.

Lindell 2008 \{published data only\}

Lindell O, Johansson SE, Strender LE. Subacute and chronic, non-specific back and neck pain: Cognitivebehavioural rehabilitation versus primary care. A randomized controlled trial. BMC Musculoskeletal Disorders 2008;9:172.

Linton 2000 \{published data only\}

Linton SJ, Andersson T. Can chronic disability be prevented? A randomized trial of a cognitive-behavior intervention and two forms of information for patients with spinal pain. Spine 2000;25(21):2825-31.

Linton 2001 \{published data only\}

Linton SJ, Ryberg M. A cognitive-behavioral group intervention as prevention for persistent neck and back pain in a non-patient population: a randomized controlled trial. Pain 2001;90(1-2):83-90.

Manca 2007 \{published data only\}

Manca A, Dumville JC, Torgerson DJ, Klaber Moffett JA, Mooney MP, Jackson DA, et al. Randomized trial of two physiotherapy interventions for primary care back and neck pain patients: cost effectiveness analysis. Rheumatology 2007;46(9):1495-501.

Marhold 2001 \{published data only\} Marhold C, Linton SJ, Melin L. A cognitive-behavioral return-to-work program: Effects on pain patients with a history of long-term versus short-term sick leave. Pain 2001;91(1-2):155-63.

McLean 2013 \{published data only\} McLean SM, Klaber Moffett JA, Sharp DM, Gardiner E. A randomised controlled trial comparing graded exercise treatment and usual physiotherapy for patients with nonspecific neck pain (the GET UP neck pain trial). Manual Therapy 2013;18(3):199-205.
Michalsen 2012 \{published data only\}

Michalsen A, Traitteur H, Lüdtke R, Brunnhuber S, Meier L, Jeitler M, Büssing A, Kessler C. Yoga for chronic neck pain: A pilot randomized controlled clinical trial. Journal of Pain 2012;13(11):1122-30.

Mongini 2012 \{published data only\}

Mongini F, Evangelista A, Milani C, Ferrero L, Ciccone G, Ugolini A, Piedimonte A, Sigaudo M, Carlino E, Banzatti E, Galassi C. An educational and physical program to reduce headache, neck/shoulder pain in a working community: a cluster-randomized controlled trial. Plos One 2012;7(1): e29637.

Persson 2001 \{published data only\} Persson LC, Lilja A. Pain, coping, emotional state and physical function in patients with chronic radicular neck pain. A comparison between patients treated with surgery, physiotherapy or neck collar - A blinded, prospective randomized study. Disability and Rehabilitation 2001;23 (8):325-35.

\section{Salo 2012 \{published data only\}}

Salo P, Ylonen-Kayra N, Hakkinen A, Kautiainen H, Malkia E, Ylinen J. Effects of long-term home-based exercise on health-related quality of life in patients with chronic neck pain: a randomized study with a 1-year follow-up. Disability and Rehabilitation 2012;34(23):1971-7.

Scholten-Peeters 2006 \{published data only\} Scholten-Peeters GG, Neeleman-van der Steen CW, van der Windt DA, Hendriks EJ, Verhagen AP, Oostendorp RA. Education by general practitioners or education and exercises by physiotherapists for patients with whiplashassociated disorders? A randomized clinical trial. Spine 2006;31(7):723-31.

Skillgate 2007 \{published data only\} Skillgate E, Vingård E, Alfredsson L. Naprapathic manual therapy or evidence-based care for back and neck pain: A randomized, controlled trial. Clinical Journal of Pain 2007; 23(5):431-9.

Skillgate 2010 \{published data only\} Skillgate E, Bohman T, Holm LW, Vingård E, Alfredsson L. The long-term effects of naprapathic manual therapy on back and neck pain - results from a pragmatic randomized controlled trial. BMC Musculoskeletal Disorders 2010;11:26.

Soderlund 2000 \{published data only\}

Soderlund A, Olerud C, Lindberg P. Acute whiplashassociated disorders (WAD): the effects of early mobilization and prognostic factors in long-term symptomatology. Clinical Rehabilitation 2000;14(5):457-67.

Song 2012 \{published data only\}

Song CH, Jang HJ, Lee KJ, Lee YW. Active exercise program in patients with nonspecific chronic neck pain: A randomized controlled trial. Pain practice 2012;

Proceedings of the 6th World Congress - World Institute of Pain;2012 Feb 4-6; Miami Beach:195-6.

Stewart 2007 \{published data only\}

Stewart MJ, Maher CG, Refshauge KM, Herbert RD, Bogduk N, Nicholas M. Randomized controlled trial of 
exercise for chronic whiplash-associated disorders. Pain 2007;128(1-2):59-68.

Storro 2004 \{published data only\}

Storrø S, Moen J, Svebak S. Effects on sick-leave of a multidisciplinary rehabilitation programme for chronic low back, neck or shoulder pain: comparison with usual treatment. Journal of Rehabilitation Medicine 2004;36(1): $12-6$.

Tan 2009 \{published data only\}

Tan EP, Tan ES, Ng BY. Efficacy of cognitive behavioural therapy for patients with chronic pain in Singapore. Annals of the Academy of Medicine, Singapore 2009;38(11):952-9.

Viljanen 2003 \{published data only\}

Viljanen M, Malmivaara A, Uitti J, Rinne M, Palmroos P, Laippala P. Effectiveness of dynamic muscle training, relaxation training, or ordinary activity for chronic neck pain: randomised controlled trial. BMJ 2003;327(7413): 475.

Yin 2006 \{published data only\} Yin XT, Wang JT, Hu XM, Yin W. [Mental status and psychotherapy in patients with cervical spondylosis after physiotherapy]. Chinese Journal of Clinical Rehabilitation 2006;10(46):28-30.

Ylinen 2003 \{published data only\}

Ylinen J, Takala EP, Nykänen M, et al. Both endurance training and strength training reduces disability and pain in chronic non-specific neck pain in women. Evidence-based Medicine 2003;8(6):184.

Yogitha 2010 \{published data only\}

Yogitha B, Nagarathna R, John E, Nagendra HR. Complimentary effect of yogic sound resonance relaxation technique in patients with common neck pain. International Journal of Yoga 2010;3(1):18-25.

Yogitha 2012 \{published data only\}

Yogitha B, John E. Efficacy of mind sound resonance technique in common neck pain. International Journal of Research in Ayurveda and Pharmacy 2012;3(2):227-33.

Zebis 2011 \{published data only\}

Zebis MK, Andersen LL, Pedersen MT, Mortensen P, Andersen CH, Pedersen MM, Boysen M, Roessler KK, Hannerz H, Mortensen OS, Sjøgaard G. Implementation of neck/shoulder exercises for pain relief among industrial workers: a randomized controlled trial. $B M C$ Musculoskeletal Disorders 2011;12:205.

\section{Additional references}

\section{Ariens 2001}

Ariëns GA, van Mechelen W, Bongers PM, Bouter LM, van der Wal G. Psychosocial risk factors for neck pain: a systematic review. American Journal of Industrial Medicine 2001;39(2):180-93.

Binder 2006

Binder A. Neck pain. Clinical Evidence 2006;15:1654-75.

Binder 2007

Binder A. Cervical spondylosis and neck pain. BMJ 2007; 334(7592):527-31.
Boutron 2005

Boutron I, Moher D, Tugwell P, Giraudeau B, Poiraudeau S, Nizard R, Ravaud P. A checklist to evaluate a report of a nonpharmacological trial (CLEAR NPT) was developed using consensus. Journal of Clinical Epidemiology 2005;58 (12):1233-40.

\section{Butler 2006}

Butler AC, Chapman JE, Forman EM, Beck AT. The empirical status of cognitive behavioral therapy: a review of meta-analyses. Clinical Psychology Review 2006;26(1):1731.

\section{Carroll 2008}

Carroll LJ, Hogg-Johnson S, van der Velde G, Haldeman S, Holm LW, Carragee EJ, Hurwitz EL, Côté P, Nordin M, Peloso PM, Guzman J, Cassidy JD. Course and prognostic factors for neck pain in the general population: results of the Bone and Joint Decade 2000-2010 Task Force on Neck Pain and Its Associated Disorders. Spine 2008;33(4 Suppl): S75-82.

\section{Cleland2008}

Cleland JA, Childs JD, Whitman JM. Psychometric properties of the Neck Disability Index and Numeric Pain Rating Scale in patients with mechanical neck pain. Arch Phys Med Rehabil 2008;89(1):69-74.

\section{Cotè 2008}

Côté P, van der Velde G, Cassidy JD, Carroll LJ, HoggJohnson S, Holm LW, Carragee EJ, Haldeman S, Nordin M, Hurwitz EL, Guzman J, Peloso PM. The burden and determinants of neck pain in workers: results of the Bone and Joint Decade 2000-2010 Task Force on Neck Pain and Its Associated Disorders. Journal of Manipulative and Physiological Therapeutics 2009;32(2 Suppl):S70-86.

\section{Croft 2001}

Croft PR, Lewis M, Papageorgiou AC, Thomas E, Jayson MI, Macfarlane GJ, Silman AJ. Risk factors for neck pain: a longitudinal study in the general population. Pain 2001;93 (3):317-25.

\section{Duffy 2014}

Duffy S, Misso K, Noake C, Ross J, Stirk L. Supplementary searches of PubMed to improve currency of MEDLINE and MEDLINE In-Process searches via OvidSP. Kleijnen Systematic Reviews Ltd, York. Poster presented at the UK InterTASC Information Specialists' Sub-Group (ISSG) Workshop; 9 July 2014; Exeter: UK (2014) [accessed 6.8.14]. Available from: https://medicine.exeter.ac.uk/ media/universityofexeter/medicalschool/research/pentag/ documents/Steven 'Duffy ' ISSG ' Exeter ' 2014 ' poster' 1.pdf.

Egger 1997

Egger M, Davey Smith G, Schneider M, Minder C. Bias in meta-analysis detected by a simple, graphical test. $B M J$ 1997;315(7109):629-34.

Foster 2003

Foster NE, Pincus T, Underwood MR, Vogel S, Breen A, Harding G. Understanding the process of care for musculoskeletal conditions-why a biomedical approach is inadequate. Rheumatology 2003;42(3):401-4. 
Furlan 2009

Furlan AD, Pennick V, Bombardier C, van Tulder M, Editorial Board Cochrane Back Review Group. 2009 updated method guidelines for systematic reviews in the Cochrane Back Review Group. Spine 2009;34(18): 1929-41.

\section{GRADEpro}

GRADEpro. Version on www.gradepro.org. McMaster University, 2014.

\section{Guzman 2008}

Guzman J, Hurwitz EL, Carroll LJ, Haldeman S, Cotè P, Carragee EJ, et al. A new conceptual model of neck pain: linking onset, course, and care: the Bone and Joint Decade 2000-2010 Task Force on Neck Pain and Its Associated Disorders. Spine 2008;33(4 Suppl):S14-23.

\section{Harbord 2006}

Harbord RM, Egger M, Sterne JA. A modified test for small-study effects in meta-analyses of controlled trials with binary endpoints. Statistics in Medicine 2006;25(20): 3443-57.

\section{Hazard 2012}

Hazard RG, Spratt KF, McDonough CM, Olson CM, Ossen ES, Hartmann EM, Carlson RJ, LaVoie J. Patientcentered evaluation of outcomes from rehabilitation for chronic disabling spinal disorders: the impact of personal goal achievement on patient satisfaction. Spine Journal 2012;12(12):1132-7.

\section{Henschke 2010}

Henschke N, Ostelo RW, van Tulder MW, Vlaeyen JW, Morley S, Assendelft WJ, Main CJ. Behavioural treatment for chronic low-back pain. Cochrane Database of Systematic Reviews 2010, Issue 7. [DOI: 10.1002/ 14651858.CD002014.pub3]

Higgins 2011

Higgins JPT, Green S (editors). Cochrane Handbook for Systematic Reviews of Interventions. The Cochrane Collaboration, 2011.

Hogg-Johnson 2008

Hogg-Johnson S, van der Velde G, Carroll LJ, Holm LW, Cassidy JD, Guzman J, et al. The burden and determinants of neck pain in the general population: the Bone and Joint Decade 2000-2010 Task Force on Neck Pain and Its Associated Disorders. Spine 2008;33(4 Suppl):S39-51.

Hoving 2001

Hoving JL, Gross AR, Gasner D, Kay T, Kennedy C, Hondras MA, Haines T, Bouter LM. A critical appraisal of review articles on the effectiveness of conservative treatment for neck pain. Spine 2001;26(2):196-205.

\section{Hurwitz 2008}

Hurwitz EL, Carragee EJ, van der Velde G, Carroll LJ, Nordin M, Guzman J, et al. Treatment of neck pain: noninvasive interventions: results of the Bone and Joint Decade 2000-2010 Task Force on Neck Pain and Its Associated Disorders. Spine 2008;33(4 Suppl):S123-52.
Huskinson 1974

Huskinson EC. Measurement of pain. Lancet 1974;2:112731.

Kori 1990

Kori KS, Miller RP, Todd DD. Kinesiophobia: a new view of chronic pain behaviour. Pain Management Nursing 1990; 3:35-43.

\section{Linton 2000b}

Linton Sj. A review of psychological risk factors in back and neck pain. Spine 2000;25(9):1148-56.

\section{Main 2008}

Main CJ, Sullivan MJL, Watson PJ. Pain Management: Practical Applications of the Biopsychosocial Perspective in Clinical and Occupational Settings. 2nd Edition. Edinburgh: Churchill Livingstone Elsevier, 2008.

\section{Malmivaara 2006}

Malmivaara A, Koes BW, Bouter LM, van Tulder MW. Applicability and clinical relevance of results in randomized controlled trials: the Cochrane review on exercise therapy for low back pain as an example. Spine 2006;31(13): 1405-9.

\section{Monticone 2013}

Monticone M, Ferrante S, Rocca B, Baiardi P, Farra FD, Foti C. Effect of a long-lasting multidisciplinary program on disability and fear-avoidance behaviors in patients with chronic low back pain: results of a randomized controlled trial. Clinical Journal of Pain 2013;29(11):929-38.

\section{Monticone 2014}

Monticone M, Ambrosini E, Rocca B, Magni S, Brivio F, Ferrante S. A multidisciplinary rehabilitation programme improves disability, kinesiophobia and walking ability in subjects with chronic low back pain: results of a randomised controlled pilot study. European Spine Journal 2014;23(10): 2105-13.

\section{Morley 2011}

Morley S. Efficacy and effectiveness of cognitive behaviour therapy for chronic pain: progress and some challenges. Pain 2011;152(3 Suppl):S99-106.

\section{Pincus 2002}

Pincus T, Vlaeyen JW, Kendall NA, Von Korff MR, Kalauokalani DA, Reis S. Cognitive-behavioral therapy and psychosocial factors in low back pain: directions for the future. Spine 2002;27(5):E133-8.

\section{Pincus 2006}

Pincus T, Vogel S, Burton AK, Santos R, Field AP. Fear avoidance and prognosis in back pain: a systematic review and synthesis of current evidence. Arthritis \& Rheumatism 2006;54(12):3999-4010.

\section{Revman}

Review Manager (RevMan). Version 5.3. Copenhagen: The Nordic Cochrane Centre, The Cochrane Collaboration, 2014. 


\section{Sullivan 1995}

Sullivan MJ, Bishop SR, Pivik J. The pain catastrophizing scale: development and validation. Psychological Assessment 1995;7:524-32.

\section{Turk 1984}

Turk DC, Flor H. Etiological theories and treatments for chronic back pain. II. Psychological models and interventions. Pain 1984;19(3):209-33.

\section{van Tulder 2003}

van Tulder M, Furlan A, Bombardier C, Bouter L, Editorial Board Cochrane Back Review Group. Updated method guidelines for systemic reviews in the Cochrane Collaboration Back Review Group. Spine 2003;28(12): $1290-9$.

\section{Vernon 1991}

Vernon H, Mior S. The Neck Disability Index: a study of reliability and validity. Journal of Manipulative and Physiological Therapeutics 1991;14(7):409-15.

\section{Vlaeyen 1995}

Vlaeyen JW, Kole-Snijders AM, Boeren RG, van Eek H. Fear of movement/(re)injury in chronic low back pain and its relation to behavioural performance. Pain 1995;62(3): $363-72$.

\section{Vlaeyen 2000}

Vlaeyen JW, Linton SJ. Fear-avoidance and its consequences in chronic musculoskeletal pain: a state of the art. Pain 2000;85(3):317-32.

\section{Vlaeyen 2005}

Vlaeyen JW, Morley S. Cognitive-behavioral treatments for chronic pain: what works for whom?. Clinical Journal of Pain 2005;21 (1):1-8.

\section{Ware 1992}

Ware JE, Sherbourne CD. The MOS 36-item short-form health survey (SF-36). I. Conceptual framework and item selection.. Medical Care 1992;30(6):437-83.

\section{Wheeler 1999}

Wheeler AH, Goolkasian P, Baird AC, Darden BV 2nd. Development of the Neck Pain and Disability Scale: item analysis, face, and criterion-related validity. Spine 1999;24 (13):1290-4.

\section{Young2009}

Young BA, Walker MJ, Strunce JB, Boyles RE, Whitman JM, Childs JD. Responsiveness of the Neck Disability Index in patients with mechanical neck disorders. Spine Journal 2009;9(10):802-8.

\section{Young2010}

Young IA, Cleland JA, Michener LA, Brown C. Reliability, construct validity, and responsiveness of the neck disability index, patient-specific functional scale, and numeric pain rating scale in patients with cervical radiculopathy. American Journal of Physical Medicine \& Rehabilitation 2010;89(10): 831-9.

* Indicates the major publication for the study 


\section{CHARACTERISTICS OF STUDIES}

\section{Characteristics of included studies [ordered by study ID]}

\section{Dunne 2012}

\begin{tabular}{ll}
\hline Methods & RCT; "randomly assigned" \\
\hline Participants & $\begin{array}{l}26 \text { patients, aged } 20 \text { to } 49 \text { years with chronic WAD grade II or III meeting the diagnos- } \\
\text { tic criteria for current MVC-related PTSD. Participants were excluded if they had (1) } \\
\text { cervical spine fractures, (2) serious head injury or burns, (3) previous history of NP or } \\
\text { headaches requiring treatment, (4) insufficient comprehension of English to complete } \\
\text { measures, or (5) if they were receiving current treatment for a major psychiatric disorder } \\
\text { (i.e., psychological or pharmacological treatment). 3 patients were lost at post-assessment } \\
\text { but all subjects were included in the analysis (intention-to-treat). The control group was } \\
\text { not involve in the follow-up assessment }\end{array}$ \\
\hline
\end{tabular}

Interventions

CBT treatment (I): 10 weekly 1-hour sessions of individually trauma-focused CBT based on the Australian Guidelines for the treatment of PTSD (cognitive strategies, coping self-talk, cognitive restructuring, psychoeducation, anxiety management strategies and relapse prevention strategies; $(\mathrm{n}=13)$

Reference treatment $(\mathrm{R})$ : waiting list control $(\mathrm{n}=13)$

Outcomes

No significant changes were noted for pain intensity over time or between groups at post-assessment

Concerning disability (NDI), greater improvements were found for (I) compared to (R) at post-assessment evaluation; at 6 month follow-up, treatment effects were maintained for CBT group. Greater reductions were found from pre-to post assessment for (I) compared with (R) in several subscales of SF-36, treatment effects were maintained at follow-up for physical role, bodily pain, general health, social functioning, and mental health subscales

Regarding self-report mental health measures, improvements were noted in both groups over time; at post assessment there were greater reductions for (I) compared to (R); at 6 month follow-up, treatment effects were maintained

Notes

Risk of bias

\begin{tabular}{|c|c|c|}
\hline Bias & Authors' judgement & Support for judgement \\
\hline $\begin{array}{l}\text { Random sequence generation (selection } \\
\text { bias) }\end{array}$ & Unclear risk & $\begin{array}{l}\text { Quote: "Participants were randomly assigned to } 1 \text { of } 2 \\
\text { conditions." } \\
\text { Comment: Method of sequence generation is not de- } \\
\text { scribed. }\end{array}$ \\
\hline Allocation concealment (selection bias) & Unclear risk & Not described. \\
\hline Blinding of participants & High risk & $\begin{array}{l}\text { No mention about blinding but blinding of participants } \\
\text { is not feasible due to the nature of the intervention }\end{array}$ \\
\hline
\end{tabular}


Dunne 2012 (Continued)

\begin{tabular}{|c|c|c|}
\hline $\begin{array}{l}\text { Blinding of personnel/ care providers (per- } \\
\text { formance bias) }\end{array}$ & Unclear risk & Not described. \\
\hline $\begin{array}{l}\text { Blinding of outcome assessment (detection } \\
\text { bias) } \\
\text { self-reported measures }\end{array}$ & High risk & $\begin{array}{l}\text { Self-reported outcome measures were collected with the } \\
\text { knowledge of the intervention received since participants } \\
\text { were not blinded }\end{array}$ \\
\hline $\begin{array}{l}\text { Incomplete outcome data (attrition bias) } \\
\text { All outcomes }\end{array}$ & Low risk & $\begin{array}{l}3 \text { subjects were lost at post-assessment }(12 \%) ; 1 \text { further } \\
\text { participant was lost at follow-up }(15 \%)\end{array}$ \\
\hline Selective reporting (reporting bias) & Low risk & $\begin{array}{l}\text { All of the outcome measures described in the Methods } \\
\text { section are reported in the Results section }\end{array}$ \\
\hline Group similarity at baseline (selection bias) & Low risk & $\begin{array}{l}\text { Quote: "Baseline comparisons showed no significant dif- } \\
\text { ferences between the groups on any variable that may con- } \\
\text { found the results including sociodemographic variables, } \\
\text { medical history, MVC details, average pain intensity, med- } \\
\text { ication use, and self-report measures." }\end{array}$ \\
\hline Cointerventions (performance bias) & Unclear risk & Not described. \\
\hline Compliance (performance bias) & Low risk & $\begin{array}{l}\text { Quote: "At post-assessment, } 85 \% \text { of participants in the } \\
\text { treatment condition ( } 11 \text { of } 13 \text { participants) had completed } \\
\text { all } 10 \text { sessions." }\end{array}$ \\
\hline Intention-to-treat-analysis & Low risk & $\begin{array}{l}\text { Quote: "Treatment effects were assessed using the intent-to } \\
\text { treat sample... Missing data were replaced with the value } \\
\text { for that variable at the preceding assessment and as there } \\
\text { was minimal missing data findings closely mirrored those } \\
\text { for treatment completers." }\end{array}$ \\
\hline $\begin{array}{l}\text { Timing of outcome assessments (detection } \\
\text { bias) }\end{array}$ & High risk & $\begin{array}{l}\text { Quote: "All participants completed a post-assessment at } \\
10 \text { to } 12 \text { weeks after the first assessment session and indi- } \\
\text { viduals in the treatment group also completed a 6-month } \\
\text { follow-up assessment using the same procedure and mea- } \\
\text { sures as the initial assessment." } \\
\text { Comment: One of the two groups did not perform follow- } \\
\text { up assessment }\end{array}$ \\
\hline
\end{tabular}

\section{Gustavsson 2006}

Methods

Participants
Randomised controlled pilot study. "Sealed envelopes were prepared by the second author prior to the enrolment of patients to the study. Group allocation was carried out with the help of permuted blocks of 2, 4 and 8 individuals sequentially located at random.”

37 patients, mean age (range) in (I): 43 (36-54); (R): 36 (24.5-48.5), with musculoskeletal $\mathrm{NP}$ of long-lasting duration (i.e. more than 3 months)

The patients were excluded if they had neurological symptoms or cervical facet joint 
pathology, insufficient knowledge of Swedish, a learning disability, medical history of psychotic disorders, were under treatment for a malignant disease, were pregnant or had previously received the relaxation treatment program designed for the intervention group. 4 patients withdrew from the study before the 7-week follow-up assessment and were excluded from the analysis. A further 4 participants were lost at the 20 -week followup assessment

Interventions

CBT treatment (I): The program contained 7 1.5-hour sessions, over a period of 7 weeks. The sessions consisted of applied relaxation training, 4 body awareness exercises and theoretical information about anatomy, aetiology, physiology of pain and stress, and pain and stress management. The relaxation training was largely derived from the method of applied relaxation. The rationale was that the patient was taught an active coping skill to prevent or control pain $(\mathrm{n}=18)$

Reference treatment (R): the 7 training sessions did not follow a standardized treatment procedure. The type of treatment, frequency of visits and duration of contact were left to the discretion of the physiotherapists and their patients. The relaxation training was not applied $(\mathrm{n}=19)$

Outcomes

The (I) group compared to the (R) group reported better ability to control pain (CSQ ability to control pain, $\mathrm{P}=$ value 0.003 ) and better ability to decrease pain (CSQ - ability to reduce pain, $\mathrm{P}$ value 0.003 ) by use of coping strategies at 20 -week follow-up. The (I) group reported a lower work-related fear of future neck injury than the (R) group (FABQ, P value 0.009 ) at 20 -week follow-up. The (I) group reported a lower HADS - Anxiety sum score than the $(\mathrm{R})$ group both at the 7-week follow-up (P value 0.023 ) and 20-week follow-up (P value 0.001). There were no statistically significant differences between groups regarding healthcare utilization, pain and analgesics, disability, pattern of coping strategies, fear and avoidance (TSK) or single questions regarding sleep

Notes

Risk of bias

Bias Authors' judgement Support for judgement

Random sequence generation (selection Low risk bias)

Quote: "the participants were assigned randomly to either the intervention program AR or to TAU. A physiotherapy-assistant who was not involved in the AR or the TAU administered the questionnaires and the opening of envelopes containing group allocation. [...] Group allocation was carried out with the help of permuted blocks of 2,4 and 8 individuals sequentially located at random.”

Allocation concealment (selection bias) Low risk
Quote: “These sealed envelopes were prepared by the second author prior to the enrolment of patients to the study." 


\section{Gustavsson 2006 (Continued)}

\begin{tabular}{|c|c|c|}
\hline Blinding of participants & High risk & $\begin{array}{l}\text { No mention about blinding but blinding of } \\
\text { participants is not feasible due to the nature } \\
\text { of the intervention }\end{array}$ \\
\hline
\end{tabular}

Blinding of personnel/ care providers (per- Unclear risk

Not described.

formance bias)

Blinding of outcome assessment (detection Unclear risk

Not described.

bias)

self-reported measures

Incomplete outcome data (attrition bias) Low risk

All outcomes

The percentages of withdrawals were about $11 \%$ and $22 \%$ at 7 -week and 20 -week follow-ups, respectively

Selective reporting (reporting bias) Low risk

All of the outcome measures described in the Methods section are reported in the Results section

Group similarity at baseline (selection bias) High risk

Quote: "The AR group was older, had a longer duration of neck pain and a higher average number of days of sick-leave as well as a larger number of healthcare visits, during the 3 months preceding the study than the TAU group. The AR group also had a higher consumption of pain-reducing medication both with regard to neck pain as well as to pain from other parts of the body. At baseline, the TAU group reported a better ability to control pain (CSQ) compared with the AR group."

\begin{tabular}{|c|c|c|}
\hline Cointerventions (performance bias) & Unclear risk & Not described. \\
\hline Compliance (performance bias) & Low risk & $\begin{array}{l}\text { Quote: "The type of treatment, frequency } \\
\text { of visits and duration of contact were left to } \\
\text { the discretion of the physiotherapists and } \\
\text { their patients." [...] "Attendance at group- } \\
\text { sessions among AR participants was high. } \\
\text { Nine [out of } 18 \text { ] participants attended all } 7 \\
\text { sessions. None of the participants attended } \\
\text { less than } 5 \text { sessions ( } 70 \% \text { of sessions). The } \\
\text { TAU group received an average of } 11 \text { treat- } \\
\text { ment sessions (ranging from } 2 \text { to } 32 \text { ). Six } \\
\text { [out of } 19 \text { ] participants in the TAU group } \\
\text { had completed their treatment at } 7 \text {-week } \\
\text { follow-up and } 6 \text { were still in treatment at } \\
\text { the } 20 \text {-week follow-up." }\end{array}$ \\
\hline
\end{tabular}



described.

Intention-to-treat-analysis $\quad$ High risk

Quote: "Data were analysed for all participants who completed treatment (on treatment analysis)."

Comment: Intention-to-treat analysis was not performed.

Timing of outcome assessments (detection Low risk bias)

Monticone 2012

Methods

Participants

Interventions

Outcomes

Notes
Randomised, parallel-group controlled trial; randomly assigned using a computerised procedure

80 patients, mean age \pm SD in $(\mathrm{I}): 54.97 \pm 13.83$ years; $(\mathrm{R}): 44.20 \pm 11.44$ years; with diagnosis of chronic non-specific NP. The exclusion criteria were cognitive impairment, all causes of specific NP, previous participated in a cognitive-behavioural intervention for low back pain. 5 patients in (R) dropped out (4 at post-treatment assessment - T2; 1 at 12-month follow-up - T3) because of economic difficulties (2), personal problems (2) or logistic problems (1); patients who did not complete the assessment were not included in the analysis

CBT treatment (I): number of sessions (median and range) 10 (6-12). Each session consisted of the same programme delivered to the control group (R) plus cognitivebehavioural therapy based on correct re-learning and cognitive reconditioning, physical and psychosocial recovery to modify mistaken fears, catastrophising beliefs and inappropriate thinking $(\mathrm{n}=40)$

Reference treatment (R): number of sessions (median and range) 10 (5-11). Each session consisted of multimodal approach, including passive and active mobilisation of the neck, exercises aimed at improving postural control, strengthening muscles and stretching (n $=40)$

No significant differences between groups were observed concerning disability (NPDS), pain (NRS) and quality of life (SF-36) at T2. In both groups there were improvements in all outcomes over time; disability remained stable until T3 in (I) while slightly worsened in (R); pain at T3 slightly worsened in both groups, SF-36 domains showed a linear increase in (I) between T1 and T3 compared to (R), these changes were not clinically significant

\section{Risk of bias}


Monticone 2012 (Continued)

\begin{tabular}{l|l|l}
\hline Bias & Authors' judgement & Support for judgement \\
\hline $\begin{array}{l}\text { Random sequence generation (selection } \\
\text { bias) }\end{array}$ & Low risk & $\begin{array}{l}\text { Quote: "Randomisation was performed } \\
\text { centrally using a computerised procedure" }\end{array}$ \\
\hline Allocation concealment (selection bias) & High risk & $\begin{array}{l}\text { Quote: "the randomisation list was man- } \\
\text { aged by the principal investigator who in- } \\
\text { formed the physiotherapist involved about } \\
\text { the treatment assignment." }\end{array}$ \\
\hline Blinding of participants & High risk & $\begin{array}{l}\text { Quote: “The patients were partially } \\
\text { blinded as they were unaware of the hy- } \\
\text { pothesised differences between the groups, } \\
\text { but they were aware of what treatment they } \\
\text { were participating in." } \\
\text { Comment: Patients were aware of their } \\
\text { treatment allocation, thus they could not } \\
\text { be considered blinded }\end{array}$ \\
\hline
\end{tabular}

Blinding of personnel/ care providers (per- Unclear risk

Not described.

formance bias)

Blinding of outcome assessment (detection High risk bias)

self-reported measures

Self-reported outcome measures were collected with the knowledge of the intervention received since participants were not blinded

Incomplete outcome data (attrition bias) Low risk

All outcomes

Quote: "Five patients in the PT group dropped out (four at T2 and one at T3) because of economic difficulties (2), personal problems (2) or logistic problems (1), leaving a total of 75 completers (94\%).”

Selective reporting (reporting bias) Low risk

All of the outcome measures described in the Methods section are reported in the Results section

Group similarity at baseline (selection bias) Low risk

Quote: "We did not find any differences between groups, except for age and marital status. Hence, these variables were used as covariates in the subsequent analyses."

Cointerventions (performance bias) Low risk

Quote: "The patients were asked to avoid any additional treatments (e.g. pain killers, NSAIDs, physical modalities, etc.) and their family doctors were asked to avoid referrals for other treatments while the participants were undergoing the rehabilitation programmes and during the follow-up pe- 
Monticone 2012 (Continued)

riod."

Compliance (performance bias) Low risk $\quad$ Quote: "The patients included underwent the following number of sessions (median and range): ten (6-12) for the PTcb group and ten (5-11) for the PT group"

Intention-to-treat-analysis

Low risk

Intention-to-treat analysis was performed as specified in Figure 1

Timing of outcome assessments (detection Low risk bias)

Quote: "The questionnaires were completed before treatment (T1), at the end of treatment (T2) and 12 months later (T3).

Pato 2010

$\begin{array}{ll}\text { Methods } & \text { RCT, 'randomly allocated' }\end{array}$

Participants

87 patients, mean age \pm SD in (I): $41.6 \pm 11.95$ years $(\mathrm{R}): 39.1 \pm 12.35$ years; with diagnosis of WAD injury grade I or II (QTF Classification) and persistent NP or headache 6 to 12 months after accident. The exclusion criteria were: injuries to other areas of the body during the accident, actual head injury, previous brain injury, previous neurologic deficits, previous whiplash injury, pre-existing NP, or previous neck surgery

Interventions

CBT treatment (I): all patients received twice weekly for 8 weeks (16 sessions) CBT (n $=40)$ and were randomly assigned to one of following additional treatments: infiltration $(\mathrm{n}=16)$, physiotherapy $(\mathrm{n}=14)$, medication $(\mathrm{n}=14)$. CBT focused on pain aspects, teaching control of pain, stress reduction, and chronic pain management techniques. Specific skills taught during the sessions were imagery, cognitive therapy for stressful situations, progressive muscle relaxation training, and application of guided mastery for stress/pain management. In the infiltration group, tender points were found by palpation or movement and each point was infiltrated with an IM injection of bupivacaine $0.25 \%$. In the physiotherapy group, patients received massage, learned relaxation techniques of myogelotic muscles, and were instructed in a detailed program of isometric and low intensity active isotonic training of their neck muscles, which they had to regularly practice at home. In the medication group, patients received $200 \mathrm{mg}$ flurbiprofen

Reference treatment (R): patients were randomly assigned to: infiltration group $(n=14)$ , physiotherapy group $(n=15)$, medication group $(n=14)$, without CBT $(n=43)$

14 patients dropped out during follow-up and were not included in the analysis

Outcomes

Primary outcome measures were: subjective outcome rating (free of symptoms, improved, unchanged, worse), pain rating (McGill pain questionnaire, VAS), and working capacity. A significantly higher rate of recovery (free of symptoms; $23 \%$ vs $9 \%$ ) and improvement ( $53 \%$ vs $42 \%$ ) was achieved by the (I) group when compared to $(\mathrm{R})$ group (P value 0 . 024). There was a gender difference (P value 0.01$)$ in the (I) group, where CBT was effective only in women ( $\mathrm{P}$ value 0.004 for women, $\mathrm{P}$ value 0.69 for men). Among the $26(36 \%)$ patients without any treatment efficacy after 2 months, 4 improved during the following 6 months without further treatment: 3 women in the (R) medication group

Cognitive-behavioural treatment for subacute and chronic neck pain (Review)

Copyright @ 2015 The Cochrane Collaboration. Published by John Wiley \& Sons, Ltd. 
Pato 2010 (Continued)

and 1 man in the (R) infiltration group. A gender-dependent efficacy was detected in several ways: depending on gender but not on treatment modality, 33 women (73\%) and only 14 men (50\%) improved after treatment ( $P$ vaue 0.047$)$. The gender-dependent difference persisted over the following 6 months without therapy; however, it was no longer significant. After 2 months of treatment, pain intensity was improved with all treatments (VAS: P value 0.01 , P value 0.003 , and P value 0.000 , and McGill total: $P$ value $0.004, P$ value 0.122 , and $P$ value 0.014 for infiltration, medication, and physiotherapy respectively with and without $\mathrm{CBT}$ ). Working ability improved overall (P value 0.023 ) , in the infiltration group ( $\mathrm{P}$ value 0.016 ), and in the physiotherapy group ( $\mathrm{P}$ value 0 . 035), but not in the medication group. CBT had a favourable influence overall (P value $0.003)$

Secondary outcome measures were: Health Assessment Questionnaire, Well-Being Scale, and cognitive ability (Cognitive Failures Questionnaire). Comparing results of the WellBeing Scale, only a short-term effect was found, with a difference between patients with and without CBT after 8 weeks (P value 0.036 ) but no longer after 6 months. There were no differences in the Cognitive Failures Questionnaire and the Health Assessment Questionnaire between the different treatment groups, with or without CBT, at any time

Notes

Risk of bias

\begin{tabular}{|c|c|c|}
\hline Bias & Authors' judgement & Support for judgement \\
\hline $\begin{array}{l}\text { Random sequence generation (selection } \\
\text { bias) }\end{array}$ & Unclear risk & $\begin{array}{l}\text { Quote: "Patients were first randomised to } 1 \text { of } 3 \text { treat } \\
\text { ment groups: local anaesthetic infiltration, physiotherapy } \\
\text { or medication, and stratified according to gender, age, and } \\
\text { education (restricted randomization)." } \\
\text { Comment: It is not specified how the randomised sequence } \\
\text { was generated }\end{array}$ \\
\hline Allocation concealment (selection bias) & Unclear risk & Not described. \\
\hline
\end{tabular}

Blinding of participants High risk

No mention about blinding but blinding of participants is not feasible due to the nature of intervention

Blinding of personnel/ care providers (per- Unclear risk Not described.

formance bias)

Blinding of outcome assessment (detection High risk

bias)

self-reported measures

Self-reported outcome measures were collected with the knowledge of the intervention received since participants were not blinded

Incomplete outcome data (attrition bias) Low risk

About $20 \%$ of participants was lost at follow-up.

All outcomes

Selective reporting (reporting bias)

High risk

Outcome measures evaluated at T3 are not reported.

Group similarity at baseline (selection bias) Low risk

Groups were similar at baseline.

Cognitive-behavioural treatment for subacute and chronic neck pain (Review)

Copyright @ 2015 The Cochrane Collaboration. Published by John Wiley \& Sons, Ltd. 
Pato 2010 (Continued)

\begin{tabular}{l|ll}
\hline Cointerventions (performance bias) & Unclear risk & Not described. \\
\hline Compliance (performance bias) & Unclear risk & Not described. \\
\hline Intention-to-treat-analysis & High risk & $\begin{array}{l}\text { Only the patients who performed the follow-up assess- } \\
\text { ments were involved in the analysis }\end{array}$ \\
\hline $\begin{array}{l}\text { Timing of outcome assessments (detection } \\
\text { bias) }\end{array}$ & Low risk & $\begin{array}{l}\text { Quote: "Evaluations were performed immediately after the } \\
\text { 8-week study treatment period (T2), then, at 3 (T3) and } \\
6 \text { months (T4) later." }\end{array}$ \\
\hline
\end{tabular}

\section{Pool 2010}

\begin{tabular}{ll} 
Methods & RCT, computer-generated random list \\
\hline Participants & 146 patients; mean age \pm SD in (I): $44.5 \pm 12.0$ years; (R): $45.6 \pm 11.1$ years; with \\
diagnosis of subacute non-specific NP. The exclusion criterion was specific NP; patients \\
with WAD were included unless they had an unsettled insurance claim during the intake \\
period \\
At 13 weeks 3 patients of $(\mathrm{I})$ and 5 patients of $(\mathrm{R})$ dropped out, at 52 weeks a further \\
2 patients of $(\mathrm{I})$ and 1 patient of $(\mathrm{R})$ dropped out. Analysis was performed according to \\
the intention-to-treat principle
\end{tabular}

Interventions

CBT treatment (I): maximum 18 sessions (30 minutes each) of behavioural graded activity program. The core elements of the program are: (1) decrease in pain behaviour and increase in "healthy" behaviour, (2) improvement of function and no focus on pain reduction, (3) the patient is responsible for the treatment and has an active role $(\mathrm{n}=71)$ Reference treatment (R): maximum 6 sessions (from 30 to 45 minutes each) of manual therapy treatment that consisted of a combination of manipulative therapy, specific mobilization techniques, exercises and advice $(n=75)$

Outcomes

At 52 weeks, the (I) group scored slightly better in GPE, NRS and NDI measurements: the GPE expressed as an odds ratio was $0.76(0.21-2.68)$, the NRS expressed as a regression coefficient or mean difference was $0.99(0.15-1.83)$ points, and the NDI expressed as a mean difference was $2.42(0.52-4.32)$ points. The only statistically significant overall effect was found on the NDI in favour of the (I) group. This effect was present at all follow-up points

Secondary outcome measures were: the Pain Coping and Cognition List, the 4 DSQ, the TSK, the SF-36 and the Graded Chronic Pain Scale. There was no statistically significant overall difference in effect between the two interventions. Only somatisation, a domain within the 4 DSQ, showed a significant difference in favour of the (I) group at 52 weeks

Notes

Risk of bias

Bias

Authors' judgement

Support for judgement

Cognitive-behavioural treatment for subacute and chronic neck pain (Review)

Copyright @ 2015 The Cochrane Collaboration. Published by John Wiley \& Sons, Ltd. 
Pool 2010 (Continued)

\begin{tabular}{|c|c|c|}
\hline $\begin{array}{l}\text { Random sequence generation (selection } \\
\text { bias) }\end{array}$ & Low risk & $\begin{array}{l}\text { Quote: "After the baseline measurement the } \\
\text { patients were randomly assigned either to the } \\
\text { BGA program or to MT. The treatment allo- } \\
\text { cation was concealed, through the use of num- } \\
\text { bered, opaque, and sealed envelopes, based on } \\
\text { a computer-generated list, and prepared by an } \\
\text { independent person before the start of the in- } \\
\text { clusion period." }\end{array}$ \\
\hline Allocation concealment (selection bias) & Low risk & $\begin{array}{l}\text { Quote: "The treatment allocation was con- } \\
\text { cealed, through the use of numbered, opaque, } \\
\text { and sealed envelopes." }\end{array}$ \\
\hline Blinding of participants & High risk & $\begin{array}{l}\text { Quote: "The patients were aware of the treat- } \\
\text { ment they received." }\end{array}$ \\
\hline $\begin{array}{l}\text { Blinding of personnel/ care providers (per- } \\
\text { formance bias) }\end{array}$ & Unclear risk & Not described. \\
\hline $\begin{array}{l}\text { Blinding of outcome assessment (detection } \\
\text { bias) } \\
\text { self-reported measures }\end{array}$ & High risk & $\begin{array}{l}\text { Self-reported outcome measures were collected } \\
\text { with the knowledge of the intervention re- } \\
\text { ceived since participants were not blinded }\end{array}$ \\
\hline $\begin{array}{l}\text { Incomplete outcome data (attrition bias) } \\
\text { All outcomes }\end{array}$ & Low risk & $\begin{array}{l}\text { The percentages of withdrawals were about } \\
4 \%, 5 \%, 14 \% \text {, and } 8 \% \text { at } 6,13,26 \text {, and } 52 \\
\text { weeks after randomisation, respectively }\end{array}$ \\
\hline Selective reporting (reporting bias) & High risk & $\begin{array}{l}\text { Some of the outcome measures described in } \\
\text { the Methods were not reported in the Results } \\
\text { section }\end{array}$ \\
\hline Group similarity at baseline (selection bias) & Low risk & $\begin{array}{l}\text { Quote: "The baseline characteristics of the pa- } \\
\text { tients in the two groups were very similar." }\end{array}$ \\
\hline Cointerventions (performance bias) & Unclear risk & Not described. \\
\hline Compliance (performance bias) & Unclear risk & Not described. \\
\hline Intention-to-treat-analysis & Low risk & $\begin{array}{l}\text { Quote: "The statistical analyses were per- } \\
\text { formed according to the intention-to-treat } \\
\text { principle." }\end{array}$ \\
\hline $\begin{array}{l}\text { Timing of outcome assessments (detection } \\
\text { bias) }\end{array}$ & Low risk & $\begin{array}{l}\text { Quote: "the patients completed questionnaires } \\
\text { at } 6,13,26 \text {, and } 52 \text { weeks after randomization. } \\
\text { " }\end{array}$ \\
\hline
\end{tabular}

Cognitive-behavioural treatment for subacute and chronic neck pain (Review) 
Methods

Participants
RCT, 'randomly assigned; for allocation a computer-generated list of random numbers was used'

191 patients, mean age \pm SD in (I): $36.4 \pm 12.2$ years; $(R 1): 35.1 \pm 12.0$ years; $(R 2): 40.4$ \pm 12.4 years; with diagnosis of WAD grades I-II attributed to an MVC approximately 2 months earlier. The inclusion criteria were: (1) fulfilled the QTF classification of WAD grades I or II, (2) no related hospitalisation after the MVC, (3) no indication of loss of consciousness after the MVC, (4) symptoms associated with injuries to areas other than the neck were either absent or relatively minor, (5) no current substance abuse, and (6) significant fear of neck-specific movements (defined as fear ratings of at least 4 of 10 on 3 or more of the PFActS-C). 18 patients (11 in (I) group; 3 in (R1) group; and 4 in (R2) group) dropped out and were not involved in the analysis

Interventions

CBT treatment (I): educational booklet plus 3 biweekly skill training and exposure therapy (imaginal and in vivo desensitization) sessions in one-on-one format $(\mathrm{n}=70)$

Reference treatment (R1): education provided with a booklet containing basic information about MCVs, whiplash injuries and associated pain problems $(\mathrm{n}=57)$

Reference treatment (R2): educational booklet plus 3 biweekly educational presentations in one-on-one format (2 hours sessions). Sessions included a physician, a psychologist and a physical therapist who reviewed and expanded on information contained in the booklet. The physician focused on anatomical and neurological aspects of whiplash injury and pain, and medications. The psychologist focused on stress and pain recovery after MVCs, relaxation, strategies for coping with stress and anxiety. The physical therapist addressed pain and body mechanics, sleep hygiene, activities regulation and pacing, gradual exposure activities and flare up management $(n=64)$

Outcomes

Differences in treatment completion rates among groups, caused by participants dropped out in (I) group $(\mathrm{n}=11)$ compared to the $(\mathrm{R} 1)$ group $(\mathrm{n}=3)$ and $(\mathrm{R} 2)$ group $(\mathrm{n}=4)$, were not statistically significant (P value 0.076 )

Concerning the primary outcome, the (I) group fared significantly better on the NDI (0-100) at post-treatment (10 days after the third session) compared to the (R1) group (mean value of 18.9 vs 24.4; P value 0.019). Regarding the PFActS-C (0-720), the (I) group evidenced significantly lower fear levels compared to the (R1) group (mean value of 77.0 vs 158.1; P value < 0.001). Lower pain severity (Multidimensional Pain Inventory, $0-6)$ was reported by the (I) group, compared to both the (R1) group (mean value of 1.5 vs 2.3 , P value $<0.001$ ) and the (R2) group (mean value of 1.5 vs 2.0 , P value 0 . 039). Post hoc tests on the Chronic Pain Self-Efficacy Scale revealed that the (I) group demonstrated greater self-efficacy at post-treatment when compared to the (R1) group only (mean value of 261.9 vs 240.0 ; P value 0.024 ). In terms of PTSD symptoms at post-treatment, post hoc tests only indicated significantly lower scores for the (I) group compared to the (R1) group

Notes

\section{Risk of bias}

\section{Bias}

Authors' judgement
Support for judgement 
Robinson 2013 (Continued)

\begin{tabular}{|c|c|c|}
\hline $\begin{array}{l}\text { Random sequence generation (selection } \\
\text { bias) }\end{array}$ & Low risk & $\begin{array}{l}\text { Quote: "Specifically, when a block of } 6 \text { par- } \\
\text { ticipants was found to be eligible, a com- } \\
\text { puter-generated list of random numbers } \\
\text { was used for allocation of the participants } \\
\text { to } 1 \text { of the } 3 \text { treatment groups. This process } \\
\text { was repeated for each newly eligible block } \\
\text { of } 6 \text { participants. However, the enrolment } \\
\text { rates varied somewhat, leading to unequal } \\
\text { numbers within groups." }\end{array}$ \\
\hline Allocation concealment (selection bias) & Unclear risk & Not described. \\
\hline Blinding of participants & High risk & $\begin{array}{l}\text { No mention about blinding but blinding of } \\
\text { participants is not feasible due to the nature } \\
\text { of intervention }\end{array}$ \\
\hline $\begin{array}{l}\text { Blinding of personnel/ care providers (per- } \\
\text { formance bias) }\end{array}$ & Unclear risk & Not described. \\
\hline $\begin{array}{l}\text { Blinding of outcome assessment (detection } \\
\text { bias) } \\
\text { self-reported measures }\end{array}$ & Unclear risk & Not described. \\
\hline
\end{tabular}

Incomplete outcome data (attrition bias) Low risk All outcomes

Selective reporting (reporting bias) Low risk

Group similarity at baseline (selection bias) Low risk

Cognitive-behavioural treatment for subacute and chronic neck pain (Review)

Copyright $\odot 2015$ The Cochrane Collaboration. Published by John Wiley \& Sons, Ltd.

Intention-to-treat-analysis High risk
About $9 \%$ of the participants dropped out of the study before post-assessment

All of the outcome measures described in the Methods section are reported in the Results section

A small and marginally significant effect was observed for differences in age among the groups. Otherwise, groups were equivalent on all the baseline variables

Quote: "Participants in the IB group continued their present care..."

Comment: Participants within the IB group could be involved in additional treatments and no guarantees about the similarity between co-interventions was provided

$\begin{array}{lll}\text { Compliance (performance bias) } & \text { Unclear risk } & \text { Not described. }\end{array}$

Only the participants who completed the treatment were involved in the analysis 
Robinson 2013 (Continued)

Timing of outcome assessments (detection Low risk bias)
Quote: "All participants were provided a comprehensive, 3-hour initial evaluation consisting of physical and psychological assessments, including all measures described earlier."

Soderlund 2001

\begin{tabular}{ll}
\hline Methods & RCT; 'a balanced randomised block procedure' \\
\hline Participants & 33 patients, mean age in (I): 37.7 years; (R): 43.5 years, with diagnosis of WAD grade \\
& $\begin{array}{l}\text { I-III according to The QTF Classification. The exclusion criteria were: a history of } \\
\text { neck injury before the actual whiplash injury, age }<18 \text { and }>60 \text { years, difficulty with } \\
\text { understanding written Swedish }\end{array}$
\end{tabular}

Interventions

CBT treatment (I): patients underwent 12 individual sessions (median $=11$ ) which included learning of basic physical and psychological skills, application and generalization of these basic skills in everyday activities, and a phase for maintenance of these skills. A functional behaviour analysis approach was used to highlight the problem behaviours and to establish treatment goals. The general treatment goals were to change the problem behaviours and recognise the factors that perpetuate muscular dysfunction. All skills training would be done at home. The basic skills phase included coping strategies, relaxation training and reeducation of a balanced cervicothoracic posture based on cervicothoracic muscular stabilisation techniques suggested by Sweeney. Further, exercises aimed at increasing neck range of motion, coordination, and endurance of neck muscles as well as reeducation of normal humeroscapular rhythm was included $(n=16)$

Reference treatment $(\mathrm{R})$ : patients underwent 12 individual sessions (median $=6$ ) of exercises designed to enhance muscular stabilisation of neck and shoulder mobility with stretching and coordination of head movements, and exercises to maintain body posture and arm muscle strength. Patients were given oral or written information and were expected to practice exercises at home. The treatment could also include pain-relieving methods like relaxation, TENS, acupuncture and heat $(\mathrm{n}=17)$

Outcomes

PDI, pain intensity (NRS) and cervical rotation (ROM) were used for comparing treatment groups; the SES and the CSQ were used to compare patients with high and low self-efficacy

Results showed no significant differences between (I) and (R) groups over time in disability, pain intensity, or in any of the physical measures. Self-experienced benefits of the treatment reported with global questions at post-treatment and follow-up were analysed. The results showed that the (I) group perceived themselves as having significantly less pain than the $(\mathrm{R})$ group at post-treatment $\left(\mathrm{Chi}^{2} 6.5\right.$, df $2, \mathrm{P}$ value $\left.<0.05\right)$. At the 3 month follow-up, patients' perceived ability to perform daily activities differed significantly between groups $\left(\mathrm{Chi}^{2} 10.27\right.$, df 3 , P value $\left.<0.05\right)$ in favour of the (I) group. Patients were asked if they applied what they had learned in order to manage or prevent $\mathrm{NP}$; the results showed significantly better long-term compliance for the experimental group $\left(\mathrm{Chi}^{2}\right.$ 6.4, df 2, P value < 0.05).

There were significant positive effects for the merged (I) and (R) group over time regarding disability (PDI; $\mathrm{F}(2,58) 6.41, \mathrm{P}$ value $<0.01$ ), pain intensity (NRS; $\mathrm{F}(2,60) 4.35$, P 
value $<0.05)$, and two physical measures, that is, head posture $(\mathrm{F}(2,60) 7.77$, P value $<0.001$ ) and neck range of motion in flexion/extension (Wilk's Lambda $(4,26) 0.61, \mathrm{P}$ value $<0.01)$

Notes

Risk of bias

\begin{tabular}{l|l|l}
\hline Bias & Authors' judgement & Support for judgement \\
\hline $\begin{array}{l}\text { Random sequence generation (selection } \\
\text { bias) }\end{array}$ & Unclear risk & $\begin{array}{l}\text { Quote: "After informed consent 33 patients } \\
\text { were assigned in two different intervention } \\
\text { groups, that is, an experimental and a com- } \\
\text { parison group, by a balanced randomised } \\
\text { block procedure." } \\
\text { Comment: It is not described how the ran- } \\
\text { dom sequence was generated }\end{array}$ \\
\hline Allocation concealment (selection bias) & Unclear risk & $\begin{array}{l}\text { Quote: "After informed consent 33 patients } \\
\text { were assigned in two different intervention } \\
\text { groups, that is, an experimental and a com- } \\
\text { parison group, by a balanced randomised } \\
\text { block procedure." } \\
\text { Comment: It is not described who the al- } \\
\text { location was performed }\end{array}$ \\
\hline
\end{tabular}

Quote: "Patients were asked what kind of treatment they had had and if they understood the purpose and principles of the treatment."

Comment: Patients could not be blinded.

Blinding of personnel/ care providers (per- Unclear risk Not described.

formance bias)

Blinding of outcome assessment (detection High risk bias)

self-reported measures
Quote: "The self-report measures below were mailed to all subjects and collected by the experimenter"

Comment: It is not clear if the experimenter was blinded. Anyway all subjects were not blinded

Only one participant did not complete the treatment.

All of the outcome measures described in the Methods section are reported in the Results section 
Soderlund 2001 (Continued)

\begin{tabular}{|c|c|c|}
\hline \multirow[t]{2}{*}{ Group similarity at baseline (selection bias) } & \multirow[t]{2}{*}{ Low risk } & \multirow{2}{*}{$\begin{array}{l}\text { Quote: "There were no differences between } \\
\text { groups in the demographic data. To cover } \\
\text { motivational aspects five questions were } \\
\text { used in a self-report form. There were no } \\
\text { differences in these treatment expectations. } \\
\text { " } \\
\text { Comment: The characteristics of the } \\
\text { groups were similar at baseline }\end{array}$} \\
\hline & & \\
\hline Cointerventions (performance bias) & Unclear risk & Not described. \\
\hline Compliance (performance bias) & Low risk & $\begin{array}{l}\text { Quote: "One patient from the comparison } \\
\text { group did not comply with the treatment } \\
\text { and was therefore excluded in group com- } \\
\text { parisons." }\end{array}$ \\
\hline Intention-to-treat-analysis & High risk & $\begin{array}{l}\text { Quote: "One patient from the comparison } \\
\text { group did not comply with the treatment } \\
\text { and was therefore excluded in group com- } \\
\text { parisons." } \\
\text { Comment: Authors did not perform inten- } \\
\text { tion to treat analysis because one patient } \\
\text { was excluded }\end{array}$ \\
\hline $\begin{array}{l}\text { Timing of outcome assessments (detection } \\
\text { bias) }\end{array}$ & Low risk & $\begin{array}{l}\text { Quote: "Physical measures, measures of } \\
\text { disability, pain intensity, coping, and in- } \\
\text { dividual characteristics (i.e., self efficacy) } \\
\text { were collected pre- and posttreatment and } \\
\text { at the three-month follow-up." }\end{array}$ \\
\hline
\end{tabular}

Taimela 2000

Methods

RCT, "randomly assigned into one of the three interventions, the randomization was performed in blocks of three stratified by sex, age, and severity of the disorder based on pain drawing"

Participants

76 patients; mean age \pm SD in (I): women $44.0 \pm 8.4$ years, men $38.8 \pm 7.6$ years; $(\mathrm{R} 1)$ : women $44.8 \pm 9.0$ years, men $36.0 \pm 8.0$ years; $(\mathrm{R} 2)$ : women $47.1 \pm 16.8$, men 43.2 \pm 11 .0. The inclusion criterion was non specific recurrent or chronic NP (longer than 3 months). The exclusion criteria were: neural tissue involvement, severe disorders of the cervical spine, other severe diseases preventing physical loading, a recent major operation, acute infection, and refusal to cooperate. 11 patients dropped out at 3 months and a further 3 patients dropped out at 12 months. Analysis was performed according to the intention-to-treat principle

Interventions

CBT treatment (I): 24 treatments, two sessions per week, 45 minutes each, during 12 weeks. The treatment contained (1) cervicothoracic stabilization, (2) relaxation training, (3) behavioural support, (4) eye fixation exercises, and (5) seated wobble-board training

Cognitive-behavioural treatment for subacute and chronic neck pain (Review)

Copyright @ 2015 The Cochrane Collaboration. Published by John Wiley \& Sons, Ltd. 
Taimela 2000 (Continued)

$(\mathrm{n}=26)$

Reference treatment (R1): patients attended a lecture about NP and its consequences, received written information about neck exercises plus practical training (in smaller groups twice with 1 week interval) for home exercises $(n=25)$

Reference treatment (R2): patients attended one lecture about NP and its consequences, received written information about neck exercises to be applied at home and at the workplace. $(\mathrm{n}=25)$

Outcomes

3 month after treatment self-experienced total benefit (from 1, very much harm, to 5 , very much benefit) was highest in the (I) group (mean score of 4.6) compared to (R1) group (mean score of 3.8) and (R2) group (mean score of 3.3); a similar difference was noted at 12 months. Differences between the groups in favour of the (I) group were recorded in reduction in neck symptoms and improvement in general health at 3 months, and the differences were still visible at 12 months. An improvement in self-reported working ability in favour of the (I) group was seen at 3 months and this difference remained at the 12-month follow-up. VAS pain intensity score after the intervention at 3 months were significantly lower in the (I) and (R1) groups compared to the (R2) group. No statistically significant differences between the groups were noted at 12 months. No statistically discernible differences were noted among the groups in the reduction of physical impairment or FABQ score

There were no statistically significant differences in Cervical Mobility and Pressure Pain Threshold except for Pressure Pain Threshold in the trapezius and elevator scapula muscle areas which increased in the (R1) group at 3 months, but no statistically discernible group differences were seen at 12 months

Notes

Risk of bias

Bias

Authors' judgement

Support for judgement

Random sequence generation (selection Unclear risk bias)

\section{Unclear risk}

Quote: "After the baseline measurements, the subject was randomly assigned into one of the three interventions. The randomization was performed in blocks of three stratified by sex, age, and severity of the disorder based on pain drawing."

Comment: It is not described how the random sequence was generated

\footnotetext{
Allocation concealment (selection bias) Unclear risk
}

Quote: "After the baseline measurements, the subject was randomly assigned into one of the three interventions. The randomization was performed in blocks of three stratified by sex, age, and severity of the disorder based on pain drawing."

Comment: It is not described who and how the allocation was performed 
Taimela 2000 (Continued)

\begin{tabular}{l|l} 
Blinding of participants & High risk \\
& $\begin{array}{l}\text { Quote: "The study was a randomized, sin- } \\
\text { gle-blind trial of three interventions. Mea- } \\
\text { surements were obtained before the ran- } \\
\text { domization, after the intervention period } \\
\text { of } 3 \text { months, and at } 12 \text { months. Researchers } \\
\text { performing measurements and interviews } \\
\text { were kept blinded to the interventions." } \\
\text { Comment: If it is single blind and re- } \\
\text { searchers were blinded, the participants } \\
\text { were not blinded }\end{array}$ \\
\hline
\end{tabular}

Blinding of personnel/ care providers (per- High risk formance bias)

Quote: "The study was a randomized, single-blind trial of three interventions. Measurements were obtained before the randomization, after the intervention period of 3 months, and at 12 months. Researchers performing measurements and interviews were kept blinded to the interventions." Comment: If it is single blind and researchers were blinded, the care providers were not blinded

Blinding of outcome assessment (detection High risk bias)

self-reported measures

Self-reported outcome measures were collected with the knowledge of the intervention received since participants were not blinded

Incomplete outcome data (attrition bias) Low risk All outcomes

Quote: "The withdrawal rate was 14\% (11 cases) at 3 months and $18 \%$ (14 cases) at 12 months."

Selective reporting (reporting bias) High risk

Some of the outcome measures described in the Methods were not reported in the Results section

Group similarity at baseline (selection bias) Low risk

Quote: "No statistically discernible differences were recorded in pain location, pain frequency, or use of medication between the treatment groups.”

\begin{tabular}{lll}
\hline Cointerventions (performance bias) & Unclear risk & Not described. \\
\hline Compliance (performance bias) & Unclear risk & Not described. \\
\hline Intention-to-treat-analysis & Low risk & $\begin{array}{l}\text { Quote: “The x2 test with cross-tabulation } \\
\text { tables was used in the intention-to-treat } \\
\text { analyses." }\end{array}$
\end{tabular}

Cognitive-behavioural treatment for subacute and chronic neck pain (Review) 
Taimela 2000 (Continued)

Timing of outcome assessments (detection Low risk bias)
Quote: “After signing a written informed consent, all patients answered the same questionnaire and underwent the same measurement protocol three times: before and after the intervention and at 12 months (Figure 1)."

Vonk 2009

Methods

Participants

Interventions
RCT. 'computer-generated randomization scheme'

139 patients, mean age \pm SD in $(\mathrm{I}): 45.7 \pm 12.1$ years; $(\mathrm{R}): 45.7 \pm 12.7$ years; with diagnosis of non-specific NP. The exclusion criteria were: diagnosis of a specific disorder, physical/manual therapy treatment during the previous six months, chronic disease or undergoing surgery in the near future. 12 and 18 patients in the (R) and (I) groups, respectively, dropped out at 9 weeks. The number of drop-outs increased to 24 and 23 in the (R) and (I) groups, respectively, at 52 weeks. The analyses were carried out according to the intention-to-treat principle

CBT treatment (I): behaviour graded activity program. The duration of the treatment was about 30 minutes and patients could received up to 18 treatments. The treatment was according to a biopsychosocial model. During the treatment, patients discussed their beliefs about pain following the pain model and defined personal aims and baseline levels of activities in order to systematically increase them throughout graded exercises. Patients learned to manage their pain and relapses period $(n=68)$

Reference treatment (R): conventional exercise composed of exercises and physiotherapy techniques (i.e. massage, mobilization, traction). The duration of the treatment was about 30 minutes and patients could received up to 18 treatments $(n=71)$

Outcomes

The primary outcome was GPE: GPE for recovery of complaints and GPE for recovery of functioning in daily activities. At 4 weeks, the (R) group showed significantly more recovery of complaints compared to the (I) group (odds ratio $0.25,95 \%$ CI 0.06 to 0 . 99). At 9 weeks, recovery of complaints was similar for both groups. Thereafter, recovery stabilized in the (R) group, whereas in the (I) group it increased until follow-up at 26 weeks. The pattern of recovery in daily functioning was similar in both groups. No significant differences between treatments were found

Secondary outcomes were physical and psychological measurements. For the physical outcomes, no significant differences were found between the two groups at any time point of measurement. However, for the severity of the main complaint, pain severity, and impediment, both treatments showed a clinically significant improvement ( $>2$ points), which was maintained until 52 weeks follow-up and was even enhanced for impediment. For the psychosocial outcomes the (I) group showed significantly higher improvements compared to (R) only for catastrophising and pain self-efficacy at the end of the treatment period ( 9 weeks), and for pain self-efficacy at 26 weeks of follow-up. All other secondary measures were not significantly different 
Vonk 2009 (Continued)

\section{Risk of bias}

\begin{tabular}{|c|c|c|}
\hline Bias & Authors' judgement & Support for judgement \\
\hline $\begin{array}{l}\text { Random sequence generation (selection } \\
\text { bias) }\end{array}$ & Low risk & $\begin{array}{l}\text { Quote: "An independent examiner us- } \\
\text { ing a computer-generated randomisation } \\
\text { schema performs randomisation." }\end{array}$ \\
\hline Allocation concealment (selection bias) & Low risk & $\begin{array}{l}\text { Quote: "An independent examiner us- } \\
\text { ing a computer-generated randomisation } \\
\text { schema performs randomisation." } \\
\text { Comment: Randomisation was performed } \\
\text { by an independent examiner }\end{array}$ \\
\hline Blinding of participants & High risk & $\begin{array}{l}\text { Althought authors wrote that the "patients } \\
\text { were blinded for treatment allocation", due } \\
\text { to the nature of the intervention patients } \\
\text { could not be considered as blinded }\end{array}$ \\
\hline
\end{tabular}

Blinding of personnel/ care providers (per- High risk formance bias)

Quote in Vonk 2004: “The physiotherapists are not blinded for allocation, but the physiotherapists from each treatment group are kept strictly separate and are not involved in the outcome measurement"; Quote in Vonk 2009: "Physiotherapists were not blinded but were not involved in the outcome measurement."

Blinding of outcome assessment (detection High risk

bias)

self-reported measures

Incomplete outcome data (attrition bias) High risk All outcomes

Selective reporting (reporting bias) Low risk

Group similarity at baseline (selection bias) Low risk
Self-reported outcome measures were collected and participants were not blinded

$21 \%$ dropouts at 9 weeks; $31 \%$ dropouts at 52 weeks.

All of the outcome measures described in the Methods section are reported in the Results section

Quote: "Baseline demographics and patient characteristics were well balanced between the two groups."

Quote: "We also examined medicine use, number of side effects (e.g. headache, dizziness, etc.) and additional treatments used, all as reported by the patients...No differences between treatments were found."

Comment: Co-interventions were similar 
Vonk 2009 (Continued)

between groups.

\begin{tabular}{|c|c|c|}
\hline Compliance (performance bias) & Unclear risk & $\begin{array}{l}\text { Quote: "The therapist decided the number } \\
\text { of treatments but the patient also had the } \\
\text { option to stop treatment. The mean num- } \\
\text { ber of treatments received was } 6.6(3.0) \text { in } \\
\text { BGA and } 11.2(4.1) \text { in CE." } \\
\text { Comment: Not sufficient information to } \\
\text { judge. }\end{array}$ \\
\hline Intention-to-treat-analysis & Low risk & $\begin{array}{l}\text { Quote: "All analyses were carried out ac- } \\
\text { cording to the intention-to-treat principle. } \\
\text { " }\end{array}$ \\
\hline $\begin{array}{l}\text { Timing of outcome assessments (detection } \\
\text { bias) }\end{array}$ & Low risk & $\begin{array}{l}\text { Quote: "Outcome of intervention will be } \\
\text { assessed at } 4 \text { and } 9 \text { weeks after randomisa- } \\
\text { tion; however, if the treatment is not fin- } \\
\text { ished at } 9 \text { weeks, the patients will receive } \\
\text { an additional questionnaire...after finish- } \\
\text { ing the treatment. Follow-up assessments } \\
\text { are planned at } 26 \text { and } 52 \text { weeks after ran- } \\
\text { domization." }\end{array}$ \\
\hline
\end{tabular}

Wicksell 2008

Methods

Participants
RCT, randomly assigned with "sealed envelope containing a code for intervention or control"

21 patients, one participant in the (R) group withdrew from the study and was excluded from the treatment evaluations. Participants mean age \pm SD in (I): $48.2 \pm 7.8$ years; (R): $55.1 \pm 11.2$ years. People older than 20 years who reported being diagnosed with WAD and with pain duration of more than 3 months were recruited. Exclusion criteria were: pain correlated with an identified pathological process other than whiplash, coexisting psychiatric or psychosocial issues that were considered more relevant, having a reduced proficiency in speaking Swedish, suffering from major cognitive dysfunctions, and currently participating in another rehabilitation program based on CBT

Interventions

CBT treatment (I): 10 individual sessions (60 minutes each) over a period of 8 weeks; eight sessions were conducted by psychologists and two by a physician specializing in pain. The objective of CBT treatment was to improve the patients' functioning by increasing psychological flexibility and through the following steps: pain education, values assessment, shifting perspective, exposure, acceptance and defusion $(\mathrm{n}=11)$

Reference treatment (R): waiting list controls $(\mathrm{n}=10)$.

Outcomes

Primary outcome measures were: PDI and SWLS; there was a significant difference in PDI between the conditions in favour of the (I) group $(F(1,16) 12.6, P$ value 0.003$)$. The subsequent analysis of the (I) group showed an improvement over time. For SWLS, the (I) group improved significantly more than the $(\mathrm{R})$ group $(\mathrm{F}(1,16) 10.1$, P value 0 . 006). The separate analysis of the treatment group, including the 7 months follow-up 
Wicksell 2008 (Continued)

assessment, showed a statistically significant improvement $(\mathrm{F}(3,30) 11.1$, P value $<0$. 001)

Secondary outcome variables were the TSK), the IES, and the HADS. In addition, pain intensity and interference were also assessed. For TSK, the comparison between the conditions revealed a significant difference in favour of the (I) group. The separate analysis of the treatment group did not reach significance. For IES, the (I) group improved more than the (R) group, but differences between the groups just failed to reach significance. The analysis of the treatment group, however, illustrated a significant improvement over time. Although an improvement could be seen for the (I) group on HADS - Anxiety, neither the difference between the groups, nor the analysis of the treatment group over time reached significance. For HADS - Depression, a significant difference between groups, as well as significant improvements within the (I) group across time were seen. No change in pain intensity was obtained in any of the groups. With regard to pain interference, the (I) group performed better, although the difference seen between groups was just above significance. The analysis of treatment effects over time reached significance. Results on the PIPS Avoidance subscale showed a statistically significant difference between groups in favour of the (I) group $(\mathrm{F}(1,16) 24.6$, P value $<0.001)$. Similarly, a significant improvement was seen in the repeated measures analysis for the treatment group, $F(3,30)$ 27.5 , P value <.001). In addition, post hoc analyses illustrated that the effects seen in (I) were explained by the differences between pre- and post treatment assessments $(t(10) 8$. 82 , P value $<0.01$ ). The PIPS Fusion subscale showed a difference between the groups $(\mathrm{F}(1,16) 8.2$, $\mathrm{P}$ value 0.011$)$. Further analyses demonstrated significant improvements over time for $(\mathrm{I})(\mathrm{F}(3,30) 7.3$, P value 0.007$)$

Notes

Risk of bias

Bias

Random sequence generation (selection Unclear risk bias)
Authors' judgement

Allocation concealment (selection bias)
Low risk

\section{Support for judgement}

Quote: “A simple randomization technique was used with the 22 participants as a single block. After inclusion, a sealed envelope (prepared by a secretary who was unaware of the objective of the study) containing a code for "intervention" or "control" was opened, assigning the participant to either the treatment or the wait-list condition." Comment: it is not described how the random sequence was generated

Quote: "A simple randomization technique was used with the 22 participants as a single block. After inclusion, a sealed envelope (prepared by a secretary who was unaware of the objective of the study) containing a code for "intervention" or "control" was opened, assigning the participant to either the treatment." 
Wicksell 2008 (Continued)

\begin{tabular}{l|l|l}
\hline Blinding of participants & High risk & $\begin{array}{l}\text { No mention about blinding but blinding of } \\
\text { participants is not feasible due to the nature } \\
\text { of intervention }\end{array}$ \\
\hline $\begin{array}{l}\text { Blinding of personnel/ care providers (per- } \\
\text { formance bias) }\end{array}$ & Unclear risk & Not described. \\
\hline $\begin{array}{l}\text { Blinding of outcome assessment (detection } \\
\text { bias) } \\
\text { self-reported measures }\end{array}$ & High risk & $\begin{array}{l}\text { Self-reported outcome measures were col- } \\
\text { lected with the knowledge of the interven- } \\
\text { tion received since participants were not } \\
\text { blinded }\end{array}$ \\
\hline
\end{tabular}

Incomplete outcome data (attrition bias) Low risk

All outcomes

Quote: "During the course of treatment, one participant in the control group dropped out of the study."

Comment: Drop-out rate of 5\% and 10\% after the treatment phase ( 2 months) and at 4-month follow-up respectively

Selective reporting (reporting bias) Low risk

All of the outcome measures described in the Methods section are reported in the Results section

Group similarity at baseline (selection bias) Low risk

Quote: “Also, the treatment and control groups were comparable on all outcome and process measures at pretreatment assessments."

Comment: No differences between the two groups were observed at baseline (Table 1)

Cointerventions (performance bias) High risk

Quote: "An add-on design was adopted, meaning that all participants received TAU (e.g. medication, acupuncture, physiotherapy, naprapathy, osteopathy) during the course of the study."

Comment: The type of co-intervention was not controlled by the study design

\begin{tabular}{lll}
\hline Compliance (performance bias) & Unclear risk & Not described. \\
\hline Intention-to-treat-analysis & Low risk & $\begin{array}{l}\text { Quote: "Intent-to-treat analysis (i.e. in- } \\
\text { cluding the participant who dropped out } \\
\text { from the control group) did not reveal any } \\
\text { difference in results." }\end{array}$ \\
\hline
\end{tabular}

Timing of outcome assessments (detection High risk bias)
Quote: "After randomization, all participants completed questionnaires and daily ratings 1 week before treatment, immediately after the treatment phase $(2$ months 
after pretreatment assessments), and 4 months after the end of the treatment phase. In addition, the treatment group was assessed 7 months after the end of treatment."

Comment: One of the two groups did not perform follow-up assessment at 7 months

RCT: randomised controlled trial

WAD: whiplash associated disorders

PTSD: post traumatic stress disorder

NP: neck pain

CBT: cognitive-behavioural therapy

I: intervention treatment

$\mathrm{R}$ : reference treatment

NDI: Neck Disability Index

MVC: motor vehicle collision

CSQ: Coping Strategies Questionnaire

FABQ: Fear-Avoidance Beliefs Questionnaire

HADS: Hospital Anxiety and Depression Scale

SF-36: Short-Form Health Survey Questionnaire

TSK: Tampa Scale for Kinesiophobia

AR: Applied Relaxation

TAU: Treatment As Usual

SD: standard deviation

T2: post-treatment

T3: first follow-up

PT: physiotherapy alone

NSAID: nonsteroidal anti-inflammatory drugsPTcb: physiotherapy plus cognitive-behavioural

T1: before treatmentQTF: Quebec Task Force

IM: intramuscular

T4: second follow-up

NPDS: Neck Pain and Disability Scale

NRS: numerical rating scale

VAS: visual analogue scale

GPE: Global Perceived Effect

4 DSQ: 4 Dimensions of Psychological Symptomatology Questionnaire

BGA: behavioural graded activity program

MT: manual therapy

WAD: whiplash-associated disorders

PFActS-C: Pictorial Fear of Activities Scale - Cervical

IB: Informational Booklet

TENS: transcutaneous electric nerve stimulation

PDI: Pain Disability Index

ROM: range of motion

SES: Self-Efficacy Scale

CE: conventional exercise

SWLS: Satisfaction with Life Scale 
IES: Impact of Event Scale

PIPS: Psychological Inflexibility in Pain Scale

\section{Characteristics of excluded studies [ordered by study ID]}

\begin{tabular}{l|l}
\hline Study & Reason for exclusion \\
\hline Andersen 2008 & $\begin{array}{l}\text { The procedure employed was not considered a true cognitive-behavioural treatment as a general health } \\
\text { counselling was delivered }\end{array}$ \\
\hline Andersen 2012 & $\begin{array}{l}\text { The procedure employed was not considered a true cognitive-behavioural treatment as a general health } \\
\text { counselling (including information on diet, smoking, alcohol, physical exercise, workplace ergonomics, and } \\
\text { indoor climate) was delivered }\end{array}$ \\
\hline
\end{tabular}

Aslan Telci 2012 The procedure employed was not considered a true cognitive-behavioural treatment because subjects received an active home-based treatment including exercises and advice

Bablis 2008

The procedure employed was not considered a true cognitive-behavioural treatment as subjects were engaged in a neuro-emotional technique for the treatment of trigger point sensitivity

Bergstrom 2012 Mixed patient population with non-specific spinal pain. Unable to distinguish results for neck pain patients separately

Bernaards 2008 The procedure employed was not considered a true cognitive-behavioural treatment as a group-based interactive work style intervention aimed at improving work style behaviours was employed

Bissett 1985 The procedure employed was not considered a true cognitive-behavioural treatment as the subjects received electromyography biofeedback mediated muscle relaxation

Bronfort 2012 The procedure employed was not considered a true cognitive-behavioural treatment as complementary and alternative medicine were delivered

Bunketorp 2006 The procedure employed was not considered a true cognitive-behavioural treatment as the subjects received general health counselling

Busch 2011 Mixed patient population with non-specific spinal pain. Unable to distinguish results for neck pain patients separately

Cramer 2012

The procedure employed was not considered a true cognitive-behavioural treatment as Yoga techniques were used

Cramer 2013

The procedure employed was not considered a true cognitive-behavioural treatment as Yoga techniques were used

Cramer 2013a

The procedure employed was not considered a true cognitive-behavioural treatment as Yoga techniques were used 
(Continued) Dehner 2009
The procedure was not considered a true cognitive-behavioural treatment as physical techniques including
application of moist heat, classic massage, electrotherapy, soft-tissue treatment, trigger point treatment, joint
mobilisation were used

Ehrenborg $2010 \quad$ Mixed patient population with chronic neck and shoulder pain after whiplash. Unable to distinguish results for neck pain patients separately

Gale 2002 Mixed patient population with chronic head and neck pain. Unable to distinguish results for neck pain patients separately

Gustavsson 2010 The procedure was not considered a true cognitive-behavioural treatment because the subjects were engaged in a stress self-management group intervention

Gustavsson 2011 The procedure was not considered a true cognitive-behavioural treatment because the subjects were engaged in a stress self-management group intervention

Haugli 2003 Mixed patients population with localized and generalized chronic musculoskeletal pain. Unable to distinguish results for neck pain patients separately

Jensen $1995 \quad$ MIxed population. Unable to distinguish results for chronic neck pain patients separately

Jensen 1997 Mixed patient population with chronic neck and low-back pain. Unable to distinguish results for neck pain patients separately

Jensen 1998

Mixed patient population with chronic neck and low-back pain. Unable to distinguish results for neck pain patients separately

Jensen 2005 Mixed patient population with chronic neck and low-back pain. Unable to distinguish results for neck pain patients separately

Jorgensen $2011 \quad$ Mixed patient population with neck, shoulder, and low-back pain. Unable to distinguish results for neck pain patients separately

Klaber $2005 \quad$ Mixed patient population with sub-acute and chronic neck pain. Unable to distinguish results for neck pain patients separately

Klaber 2006

Mixed patient population with sub-acute and chronic neck pain and back pain. Unable to distinguish results for neck pain patients separately

Lindell 2008

Mixed patient population with sub-acute and chronic neck and back pain. Unable to distinguish results for neck pain patients separately

Linton 2000

Mixed patient population with acute and subacute spinal pain. Unable to distinguish results for neck pain patients separately

Linton 2001

The study included patients with acute or subacute spinal pain who perceived that they were at risk for developing a chronic problem 
(Continued)

\begin{tabular}{ll}
\hline Manca 2007 & $\begin{array}{l}\text { Mixed patient population with neck and low-back pain. Unable to distinguish results for neck pain patients } \\
\text { separately }\end{array}$ \\
\hline Marhold 2001 & $\begin{array}{l}\text { Mixed patient population with neck and low-back pain. Unable to distinguish results for neck pain patients } \\
\text { separately }\end{array}$ \\
\hline McLean 2013 & $\begin{array}{l}\text { Mixed patient population with sub-acute and chronic neck pain. Unable to distinguish results for neck pain } \\
\text { patients separately }\end{array}$ \\
\hline Michalsen 2012 & $\begin{array}{l}\text { The procedure employed was not considered a true cognitive-behavioural treatment as Yoga techniques were } \\
\text { used }\end{array}$ \\
\hline Mongini 2012 & $\begin{array}{l}\text { The procedure employed was not considered a true cognitive-behavioural treatment as a simple educational } \\
\text { intervention was delivered }\end{array}$ \\
\hline Persson 2001 & $\begin{array}{l}\text { The procedure employed was not considered a true cognitive-behavioural treatment as physical interventions } \\
\text { including physiotherapy and collars were used }\end{array}$ \\
\hline Salo 2012 & $\begin{array}{l}\text { The procedure employed was not considered a true cognitive-behavioural treatment as physical and educa- } \\
\text { tional programs were delivered }\end{array}$ \\
\hline
\end{tabular}

Scholten-Peeters 2006 The procedure employed was not considered a true cognitive-behavioural treatment because education and advice were delivered

Skillgate 2007 The procedure employed was not considered a true cognitive-behavioural treatment as advice on how to cope with pain were delivered

Skillgate 2010 The procedure employed was not considered a true cognitive-behavioural treatment because the subjects were engaged in naprapathic manual therapy

Soderlund $2000 \quad$ Mixed patient population with acute whiplash-associated disorders. Unable to distinguish results for neck pain patients separately

Song 2012 The procedure employed was not considered a true cognitive-behavioural treatment because active exercises including stability, strengthening, and proprioceptive training along with an educational program were delivered

Stewart 2007

The procedure employed was not considered a true cognitive-behavioural treatment as subjects received standardised education, reassurance, and encouragement to resume light activity

Storro $2004 \quad$ Mixed patient population with neck and shoulder pain. Unable to distinguish results for neck pain patients separately

Tan 2009

Mixed patient population with chronic pain. Unable to distinguish results for neck pain patients separately

Viljanen 2003

The procedure employed was not considered a true cognitive-behavioural treatment as only relaxation techniques were used 
(Continued)

\begin{tabular}{l|l} 
Yin 2006 & Patients were not affected by chronic or sub-acute neck pain \\
\hline Ylinen 2003 & $\begin{array}{l}\text { The procedure employed was not considered a true cognitive-behavioural treatment as strength and en- } \\
\text { durance training were delivered }\end{array}$
\end{tabular}
durance training were delivered

Yogitha 2010

The procedure employed was not considered a true cognitive-behavioural treatment because a Yoga-like technique called mind sound resonance was delivered

Yogitha 2012

The procedure employed was not considered a true cognitive-behavioural treatment as Yoga techniques were used

Zebis 2011

The procedure employed was not considered a true cognitive-behavioural treatment as subjects were engaged in cervical strength training at high-intensity 
DATA ANDANALYSES

Comparison 1. CBT versus other types of treatment (subacute NP)

\begin{tabular}{lcccc} 
Outcome or subgroup title & $\begin{array}{c}\text { No. of } \\
\text { studies }\end{array}$ & $\begin{array}{c}\text { No. of } \\
\text { participants }\end{array}$ & Statistical method & Effect size \\
\hline 1 Pain (short-term follow-up) & 2 & 265 & Std. Mean Difference (IV, Fixed, 95\% CI) & $-0.24[-0.48,0.00]$ \\
2 Disability (short-term follow-up) & 2 & 265 & Std. Mean Difference (IV, Fixed, 95\% CI) & $-0.12[-0.36,0.12]$ \\
\hline
\end{tabular}

\section{Comparison 2. CBT versus no treatment (chronic NP)}

\begin{tabular}{|c|c|c|c|c|}
\hline Outcome or subgroup title & $\begin{array}{l}\text { No. of } \\
\text { studies }\end{array}$ & $\begin{array}{c}\text { No. of } \\
\text { participants }\end{array}$ & Statistical method & Effect size \\
\hline 1 Pain (short-term follow-up) & 3 & 89 & Std. Mean Difference (IV, Fixed, 95\% CI) & $-0.58[-1.01,-0.16]$ \\
\hline 2 Disability (short-term follow-up) & 2 & 46 & Std. Mean Difference (IV, Fixed, 95\% CI) & $-0.61[-1.21,-0.01]$ \\
\hline $\begin{array}{l}3 \text { Kinesiophobia (short-term } \\
\text { follow-up) }\end{array}$ & 2 & 46 & Mean Difference (IV, Random, 95\% CI) & $-6.69[-13.91,0.53]$ \\
\hline 4 Distress (short-term follow-up) & 2 & 46 & Std. Mean Difference (IV, Fixed, 95\% CI) & $-0.41[-0.99,0.18]$ \\
\hline $\begin{array}{l}5 \text { Quality of life (short-term } \\
\text { follow-up) }\end{array}$ & 2 & 46 & Std. Mean Difference (IV, Fixed, 95\% CI) & $-0.93[-1.54,-0.31]$ \\
\hline
\end{tabular}

Comparison 3. CBT versus other types of treatment (chronic NP)

\begin{tabular}{|c|c|c|c|c|}
\hline Outcome or subgroup title & $\begin{array}{l}\text { No. of } \\
\text { studies }\end{array}$ & $\begin{array}{c}\text { No. of } \\
\text { participants }\end{array}$ & Statistical method & Effect size \\
\hline 1 Pain (short-term follow-up) & 3 & 212 & Std. Mean Difference (IV, Fixed, 95\% CI) & $-0.06[-0.33,0.21]$ \\
\hline $\begin{array}{l}2 \text { Pain (intermediate-term } \\
\text { follow-up) }\end{array}$ & 2 & 168 & Mean Difference (IV, Random, 95\% CI) & $-0.89[-2.73,0.94]$ \\
\hline 3 Disability (short-term follow-up) & 2 & 168 & Std. Mean Difference (IV, Fixed, 95\% CI) & $-0.10[-0.40,0.20]$ \\
\hline $\begin{array}{l}4 \text { Disability (intermediate-term } \\
\text { follow-up) }\end{array}$ & 2 & 168 & Std. Mean Difference (IV, Fixed, 95\% CI) & $-0.24[-0.54,0.07]$ \\
\hline $\begin{array}{l}5 \text { Kinesiophobia } \\
\text { (intermediate-term follow-up) }\end{array}$ & 2 & 168 & Std. Mean Difference (IV, Fixed, 95\% CI) & $-0.39[-0.69,-0.08]$ \\
\hline $\begin{array}{l}6 \text { Depression (short-term } \\
\text { follow-up) }\end{array}$ & 2 & 168 & Std. Mean Difference (IV, Fixed, 95\% CI) & $-0.43[-0.74,-0.12]$ \\
\hline $\begin{array}{l}7 \text { Depression (intermediate-term } \\
\text { follow-up) }\end{array}$ & 2 & 168 & Std. Mean Difference (IV, Fixed, 95\% CI) & $-0.29[-0.60,0.01]$ \\
\hline 8 Coping (short-term follow-up) & 2 & 168 & Std. Mean Difference (IV, Random, 95\% CI) & $-0.28[-0.72,0.16]$ \\
\hline $\begin{array}{l}9 \text { Coping (intermediate-term } \\
\text { follow-up) }\end{array}$ & 2 & 168 & Std. Mean Difference (IV, Random, 95\% CI) & $-0.07[-0.84,0.71]$ \\
\hline
\end{tabular}


Comparison 4. CBT in addition to another intervention versus the other intervention alone (chronic NP)

\begin{tabular}{lcccc} 
Outcome or subgroup title & $\begin{array}{c}\text { No. of } \\
\text { studies }\end{array}$ & $\begin{array}{c}\text { No. of } \\
\text { participants }\end{array}$ & Statistical method & Effect size \\
\hline 1 Pain (short-term follow-up) & 3 & 185 & Std. Mean Difference (IV, Random, 95\% CI) & $-0.36[-0.73,0.02]$ \\
2 Disability (short-term follow-up) & 3 & 185 & Std. Mean Difference (IV, Random, 95\% CI) & $-0.10[-0.56,0.36]$ \\
\hline
\end{tabular}

\section{Analysis I.I. Comparison I CBT versus other types of treatment (subacute NP), Outcome I Pain (short- term follow-up).}

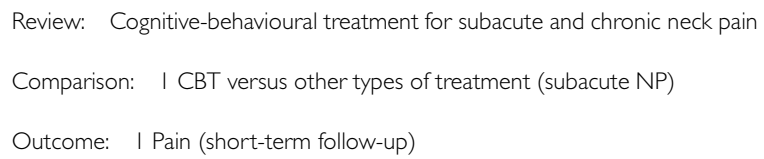

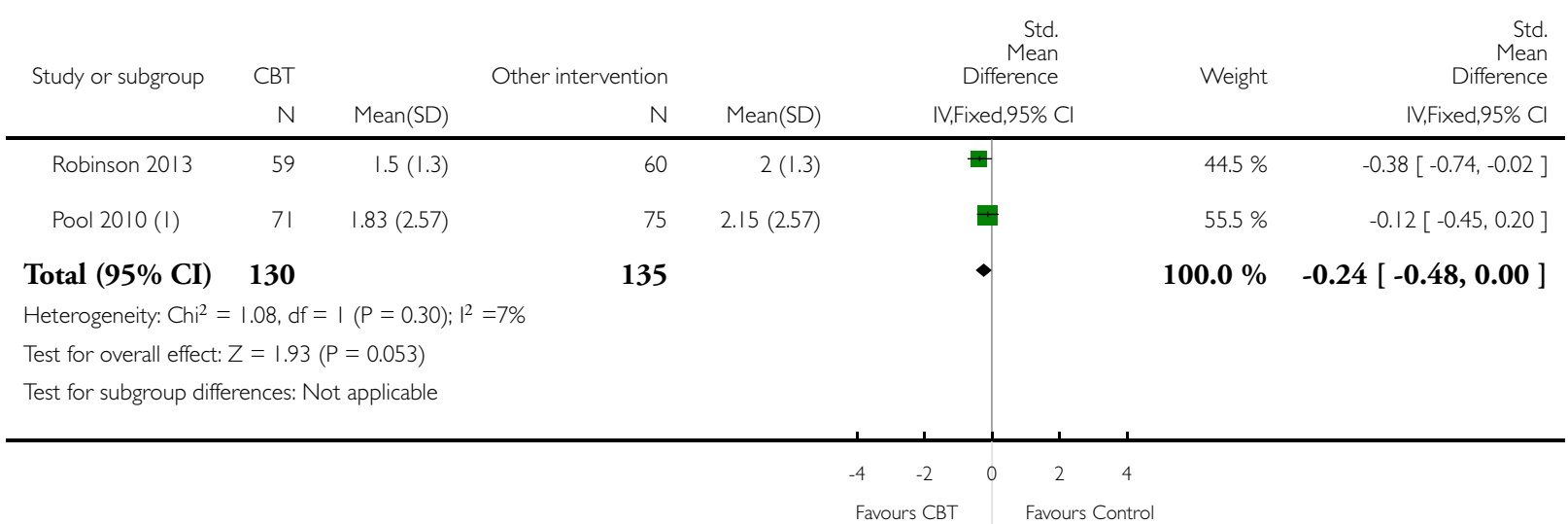

( I) Standard deviations was derived from 95\% confidence intervals that relate to the differences between means in the two groups. 


\section{Analysis I.2. Comparison I CBT versus other types of treatment (subacute NP), Outcome 2 Disability} (short-term follow-up).

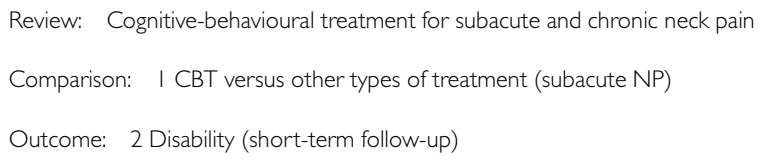

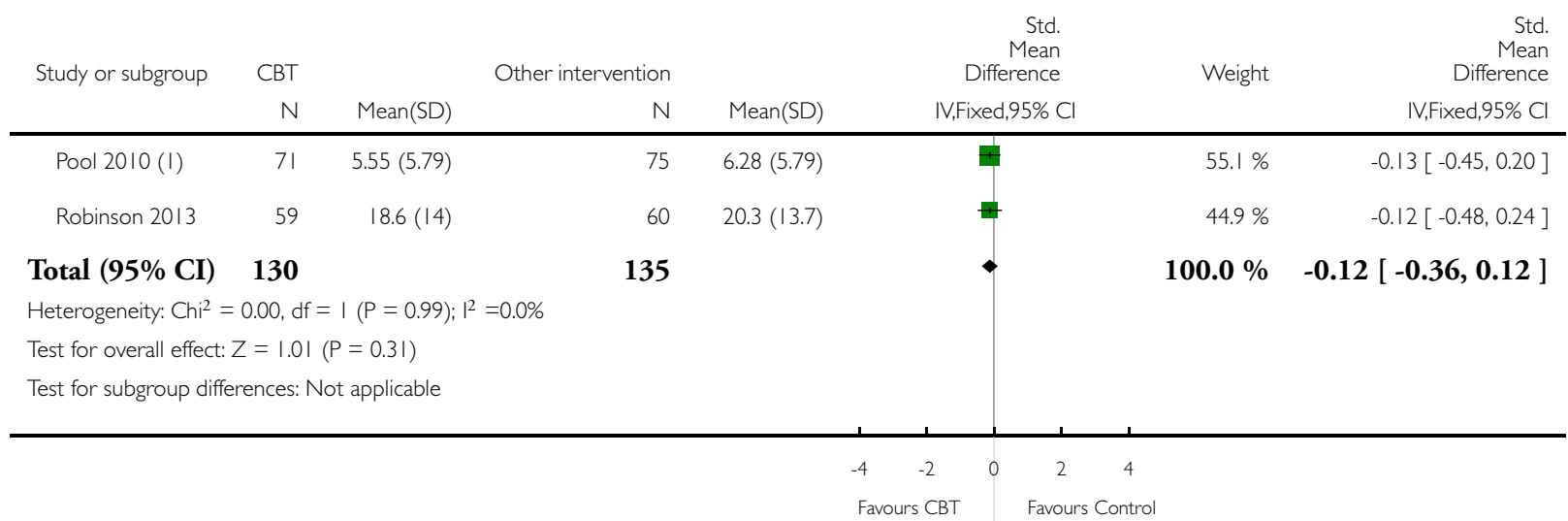

( I) Standard deviations was derived from 95\% confidence intervals that relate to the differences between means in the two groups. 


\section{Analysis 2.I. Comparison 2 CBT versus no treatment (chronic NP), Outcome I Pain (short-term follow-up).}

Review: Cognitive-behavioural treatment for subacute and chronic neck pain

Comparison: 2 CBT versus no treatment (chronic NP)

Outcome: I Pain (short-term follow-up)

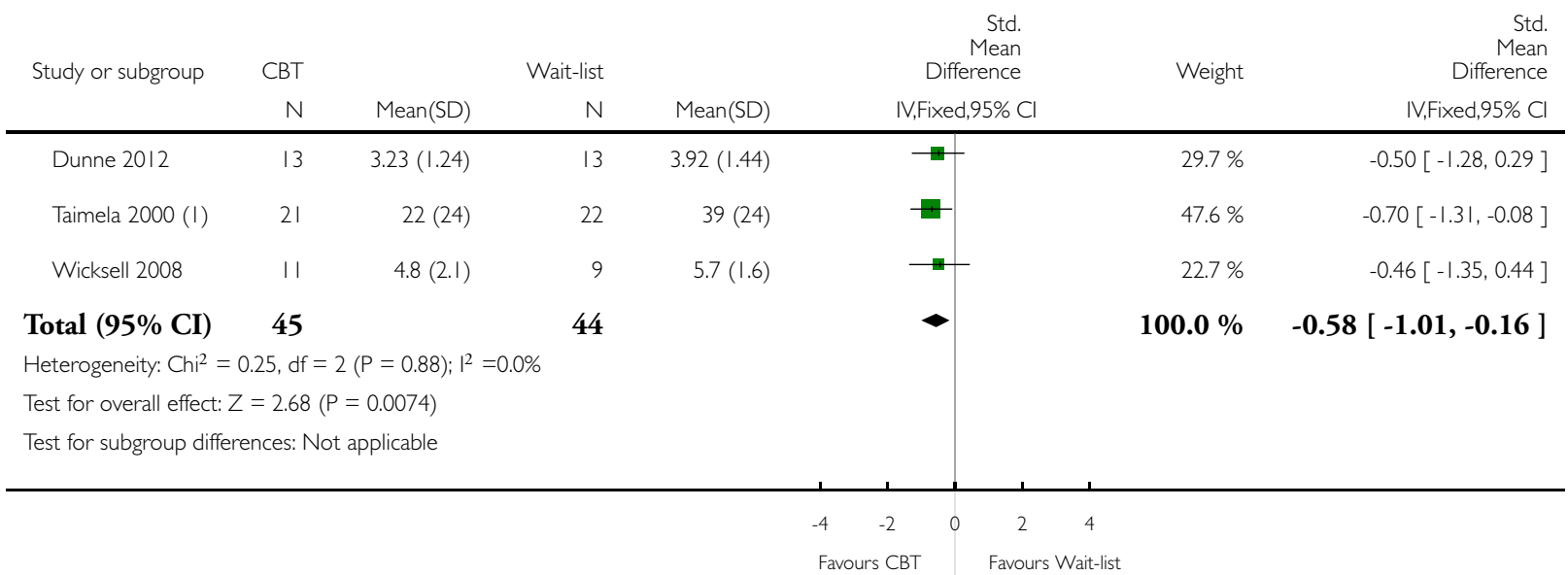

(I) The values of SD of the two groups have been derived from the SD of all groups combined at I2-month follow-up. 
Analysis 2.2. Comparison 2 CBT versus no treatment (chronic NP), Outcome 2 Disability (short-term follow-up).

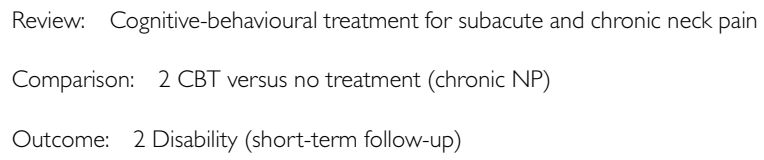

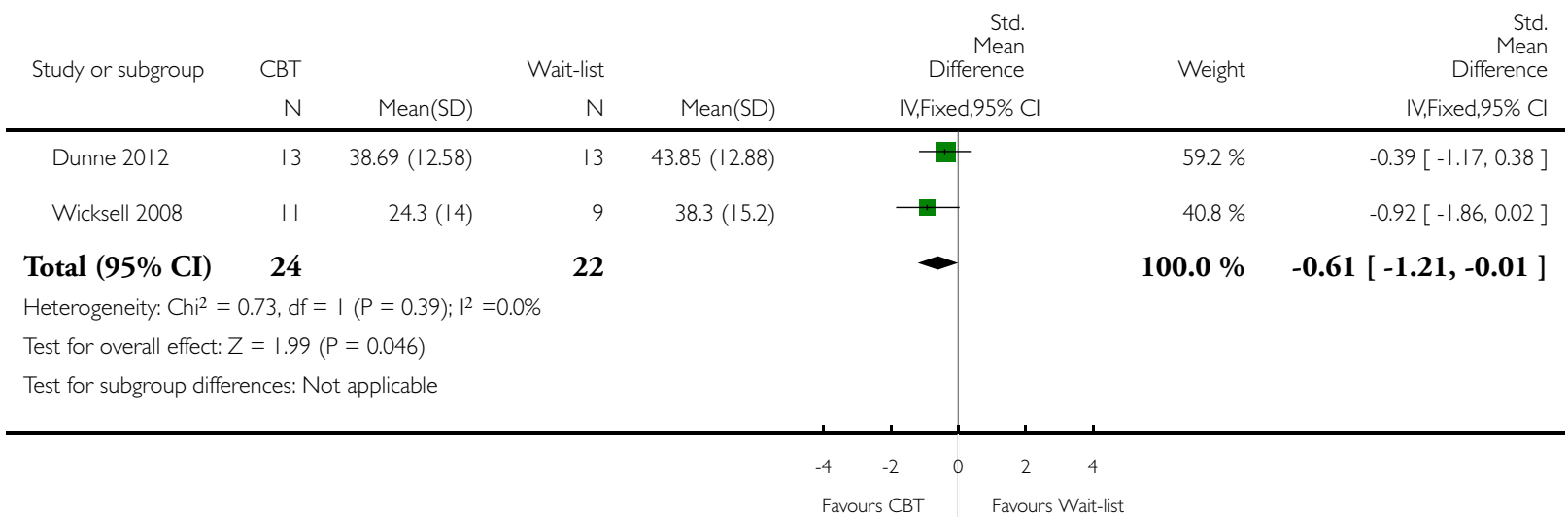

\section{Analysis 2.3. Comparison 2 CBT versus no treatment (chronic NP), Outcome 3 Kinesiophobia (short-term} follow-up).

Review: Cognitive-behavioural treatment for subacute and chronic neck pain

Comparison: 2 CBT versus no treatment (chronic NP)

Outcome: 3 Kinesiophobia (short-term follow-up)

\begin{tabular}{|c|c|c|c|c|c|c|c|c|c|}
\hline \multirow{3}{*}{$\begin{array}{l}\text { Study or subgroup } \\
\text { Dunne } 2012\end{array}$} & \multirow{3}{*}{$\begin{array}{r}\text { CBT } \\
N\end{array}$} & \multirow{3}{*}{\multicolumn{2}{|c|}{$\frac{\text { Wait-list }}{N}$}} & \multirow{3}{*}{$\frac{\text { Mean(SD) }}{42.84(4.18)}$} & \multirow{2}{*}{\multicolumn{3}{|c|}{$\begin{array}{c}\text { Mean } \\
\text { Difference } \\
\text { IV,Random,95\% Cl }\end{array}$}} & \multirow[t]{2}{*}{ Weight } & \multirow{2}{*}{$\begin{array}{r}\text { Mean } \\
\text { Difference } \\
\text { IV,Random,95\% Cl }\end{array}$} \\
\hline & & & & & & & & & \\
\hline & & & & & $\because$ & & & $58.9 \%$ & $-3.61[-6.91,-0.31]$ \\
\hline Wicksell 2008 & 11 & $29(6.1)$ & 9 & $40.1(9.2)$ & $\sqrt{4}$ & & & $41.1 \%$ & $-11.10[-18.11,-4.09]$ \\
\hline Total $(95 \% \mathrm{CI})$ & 24 & & 22 & & 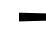 & & & $100.0 \%$ & $-6.69[-13.91,0.53]$ \\
\hline \multicolumn{10}{|c|}{ Heterogeneity: $\mathrm{Tau}^{2}=20.24 ; \mathrm{Chi}^{2}=3.59, \mathrm{df}=\mathrm{I}(\mathrm{P}=0.06) ; \mathrm{I}^{2}=72 \%$} \\
\hline \multicolumn{10}{|c|}{ Test for overall effect: $Z=1.82(P=0.069)$} \\
\hline \multicolumn{10}{|c|}{ Test for subgroup differences: Not applicable } \\
\hline & & & & & -4 & -2 & 0 & 4 & \\
\hline \multicolumn{10}{|c|}{ Favours CBT } \\
\hline
\end{tabular}

Cognitive-behavioural treatment for subacute and chronic neck pain (Review) 


\section{Analysis 2.4. Comparison 2 CBT versus no treatment (chronic NP), Outcome 4 Distress (short-term}

follow-up).

Review: Cognitive-behavioural treatment for subacute and chronic neck pain

Comparison: 2 CBT versus no treatment (chronic NP)

Outcome: 4 Distress (short-term follow-up)

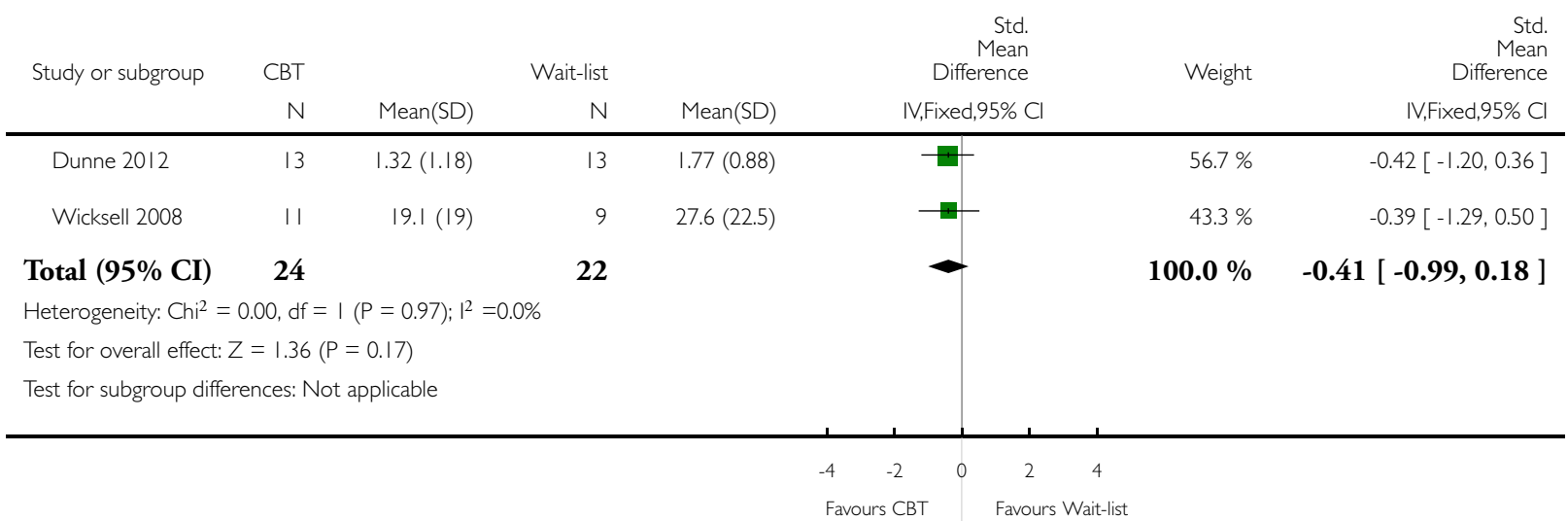




\section{Analysis 2.5. Comparison 2 CBT versus no treatment (chronic NP), Outcome 5 Quality of life (short-term follow-up).}

Review: Cognitive-behavioural treatment for subacute and chronic neck pain

Comparison: 2 CBT versus no treatment (chronic NP)

Outcome: 5 Quality of life (short-term follow-up)

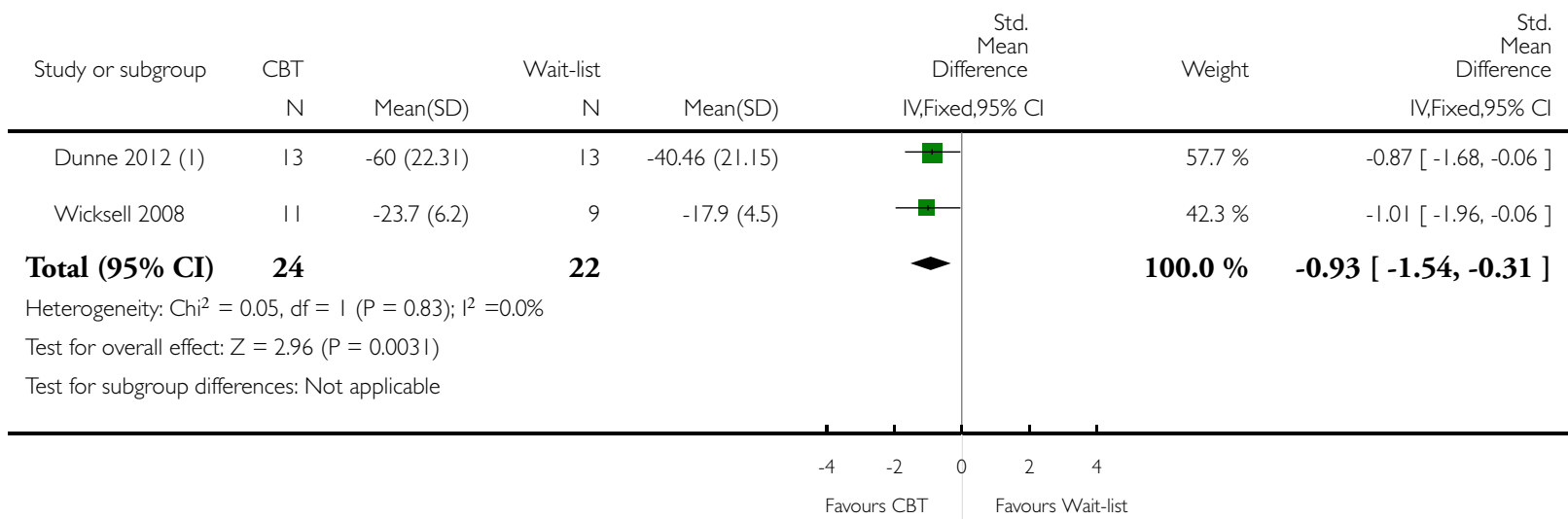

(I) The General Health sub-scale of SF-36 has been reported.

Analysis 3.I. Comparison 3 CBT versus other types of treatment (chronic NP), Outcome I Pain (shortterm follow-up).

Review: Cognitive-behavioural treatment for subacute and chronic neck pain

Comparison: 3 CBT versus other types of treatment (chronic NP)

Outcome: I Pain (short-term follow-up)

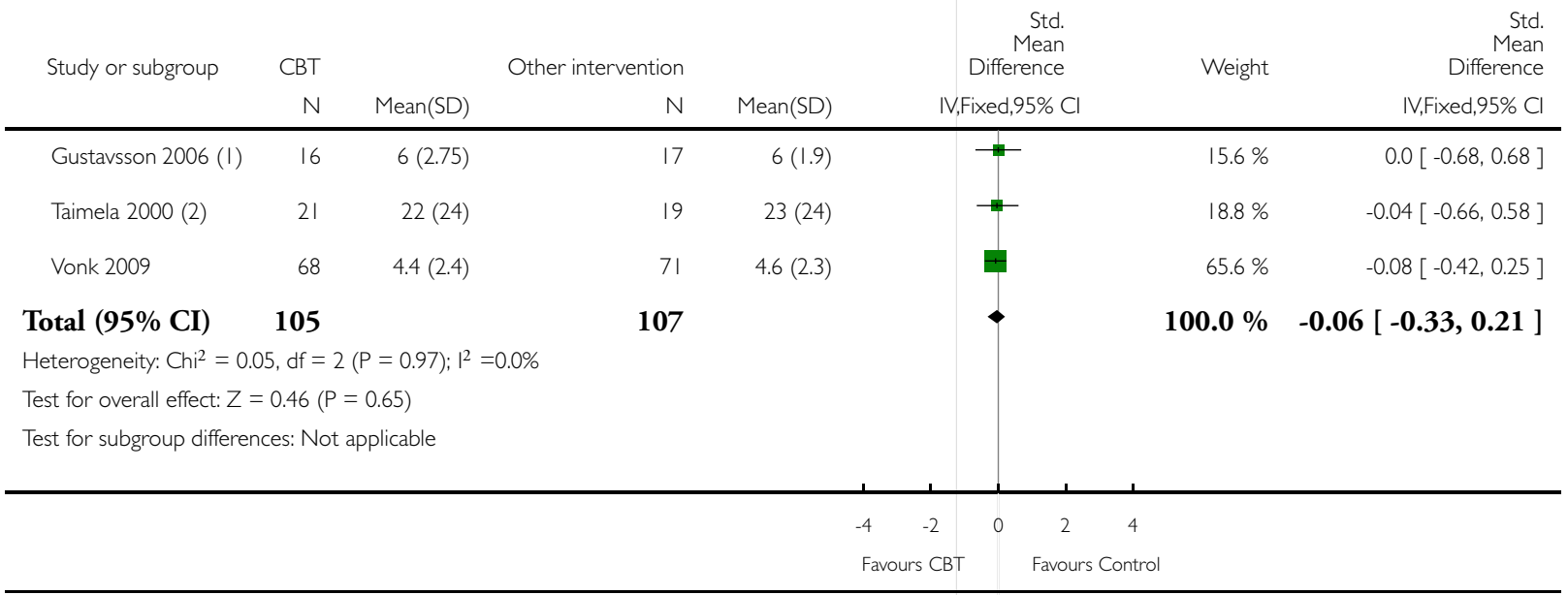

Cognitive-behavioural treatment for subacute and chronic neck pain (Review)

Copyright @ 2015 The Cochrane Collaboration. Published by John Wiley \& Sons, Ltd. 
(I) Median value as been considered as mean value; SD has been estimated as half of the interquartile range.

(2) The values of SD of the two groups have been derived from the SD of all groups combined at I2-month follow-up.

Analysis 3.2. Comparison 3 CBT versus other types of treatment (chronic NP), Outcome 2 Pain (intermediate-term follow-up).

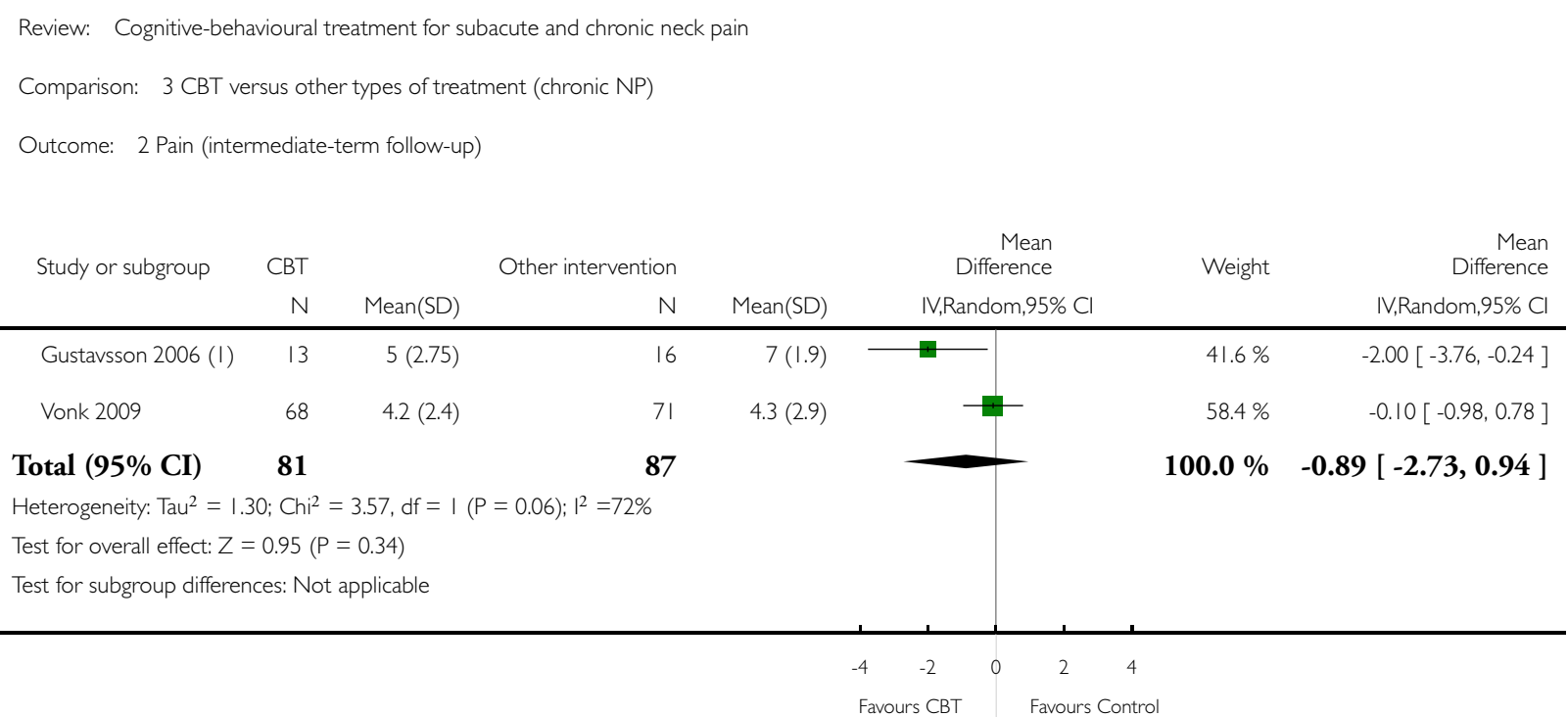

(I) Median value as been considered as mean value; SD has been estimated as half of the interquartile range. 


\section{Analysis 3.3. Comparison 3 CBT versus other types of treatment (chronic NP), Outcome 3 Disability}

(short-term follow-up).

Review: Cognitive-behavioural treatment for subacute and chronic neck pain

Comparison: 3 CBT versus other types of treatment (chronic NP)

Outcome: 3 Disability (short-term follow-up)

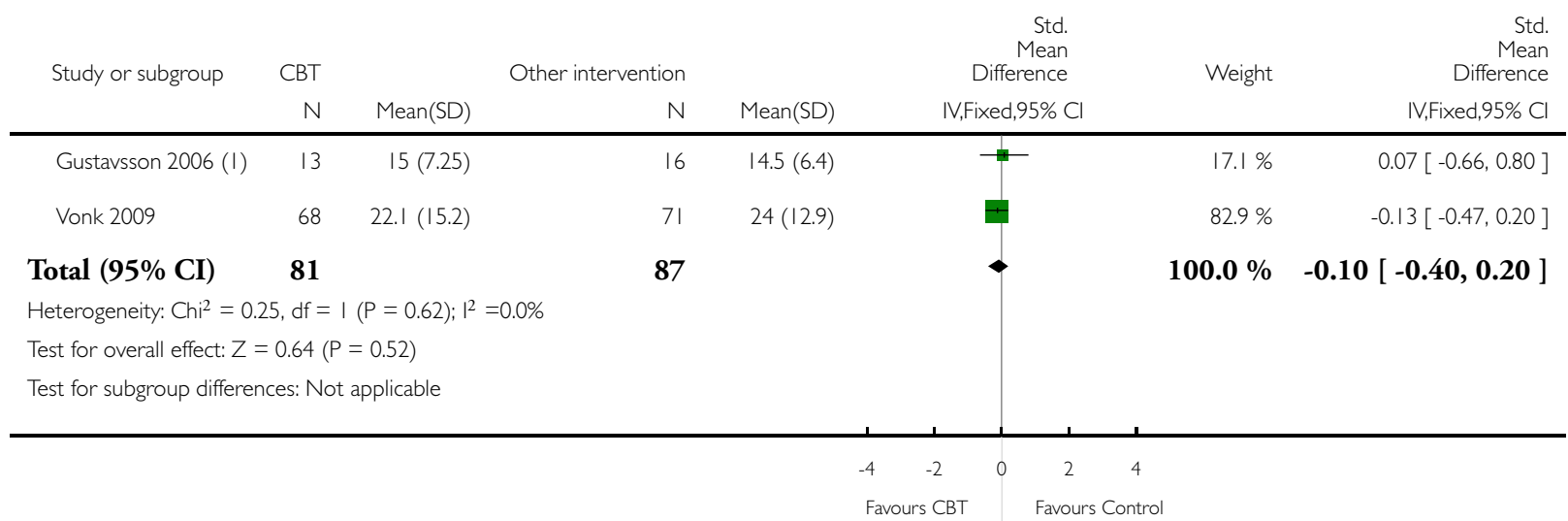

(I) Median value as been considered as mean value; SD has been estimated as half of the interquartile range. 
Analysis 3.4. Comparison 3 CBT versus other types of treatment (chronic NP), Outcome 4 Disability (intermediate-term follow-up).

Review: Cognitive-behavioural treatment for subacute and chronic neck pain

Comparison: 3 CBT versus other types of treatment (chronic NP)

Outcome: 4 Disability (intermediate-term follow-up)

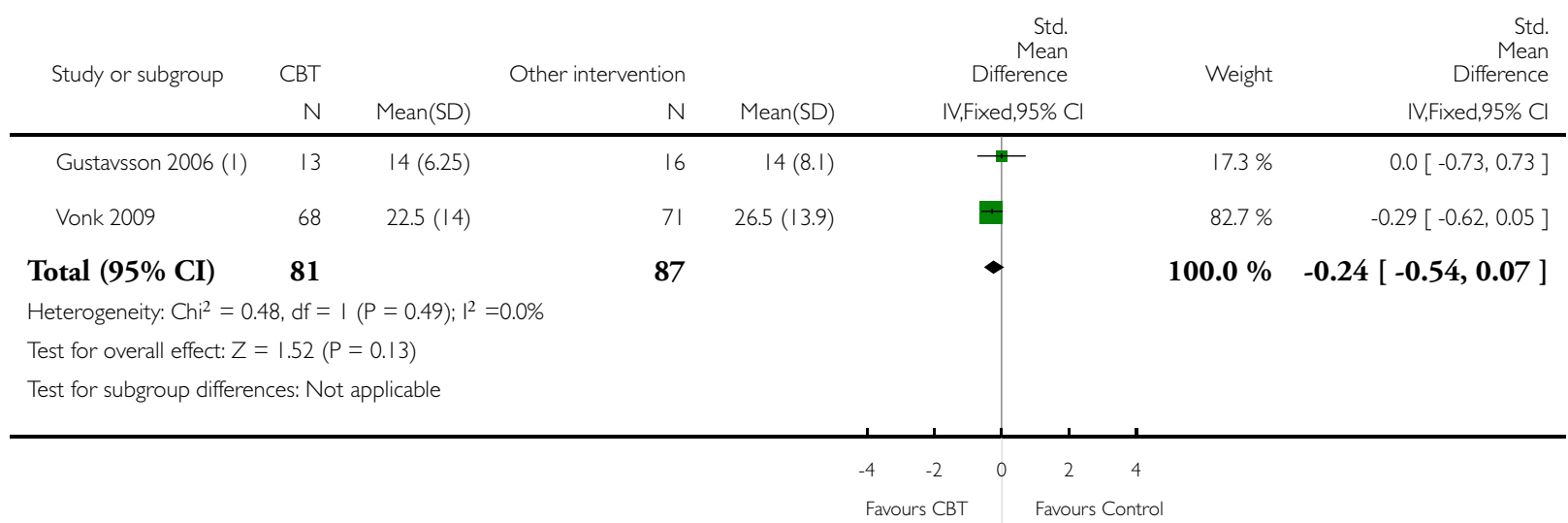

( I) Median value as been considered as mean value; SD has been estimated as half of the interquartile range. 


\section{Analysis 3.5. Comparison 3 CBT versus other types of treatment (chronic NP), Outcome 5 Kinesiophobia}

(intermediate-term follow-up).

Review: Cognitive-behavioural treatment for subacute and chronic neck pain

Comparison: 3 CBT versus other types of treatment (chronic NP)

Outcome: 5 Kinesiophobia (intermediate-term follow-up)

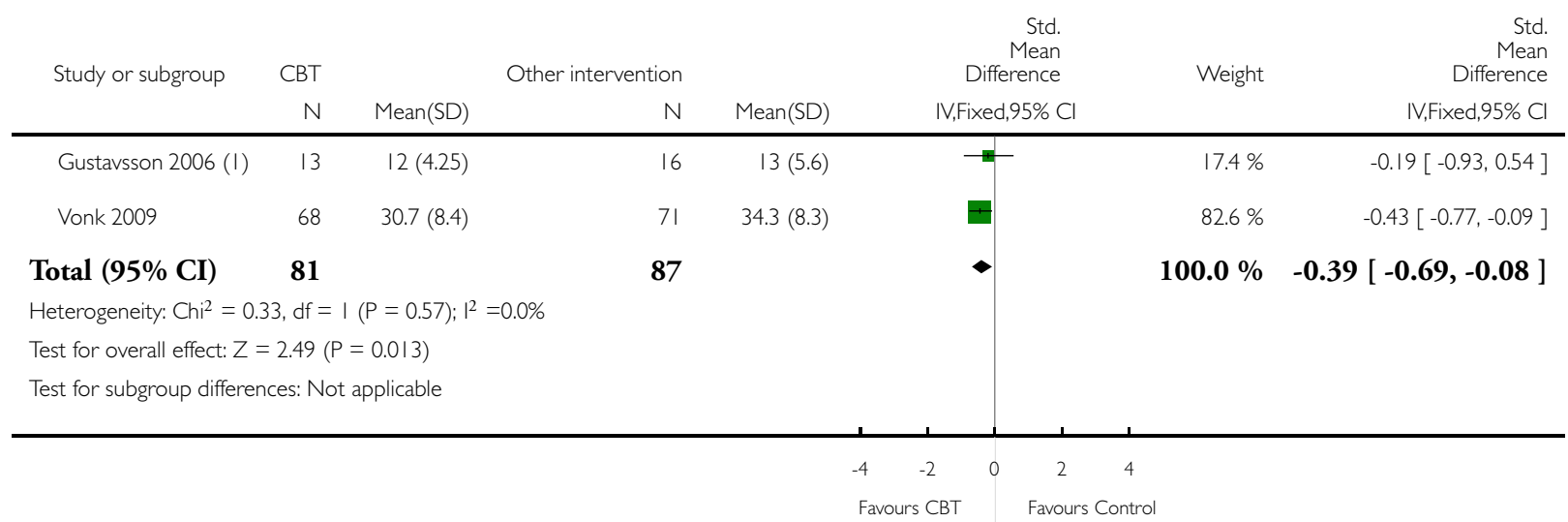

(I) Median value as been considered as mean value; SD has been estimated as half of the interquartile range. 


\section{Analysis 3.6. Comparison 3 CBT versus other types of treatment (chronic NP), Outcome 6 Depression}

(short-term follow-up).

Review: Cognitive-behavioural treatment for subacute and chronic neck pain

Comparison: 3 CBT versus other types of treatment (chronic NP)

Outcome: 6 Depression (short-term follow-up)

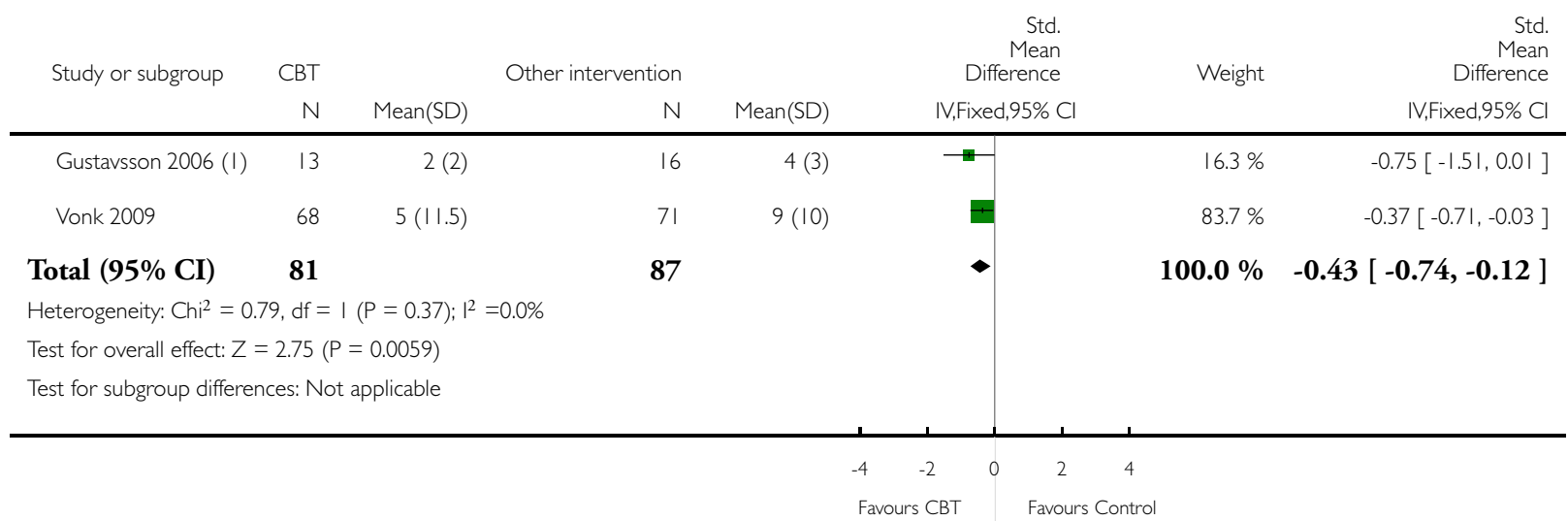

( I) Median value as been considered as mean value; SD has been estimated as half of the interquartile range. 


\section{Analysis 3.7. Comparison 3 CBT versus other types of treatment (chronic NP), Outcome 7 Depression}

(intermediate-term follow-up).

Review: Cognitive-behavioural treatment for subacute and chronic neck pain

Comparison: 3 CBT versus other types of treatment (chronic NP)

Outcome: 7 Depression (intermediate-term follow-up)

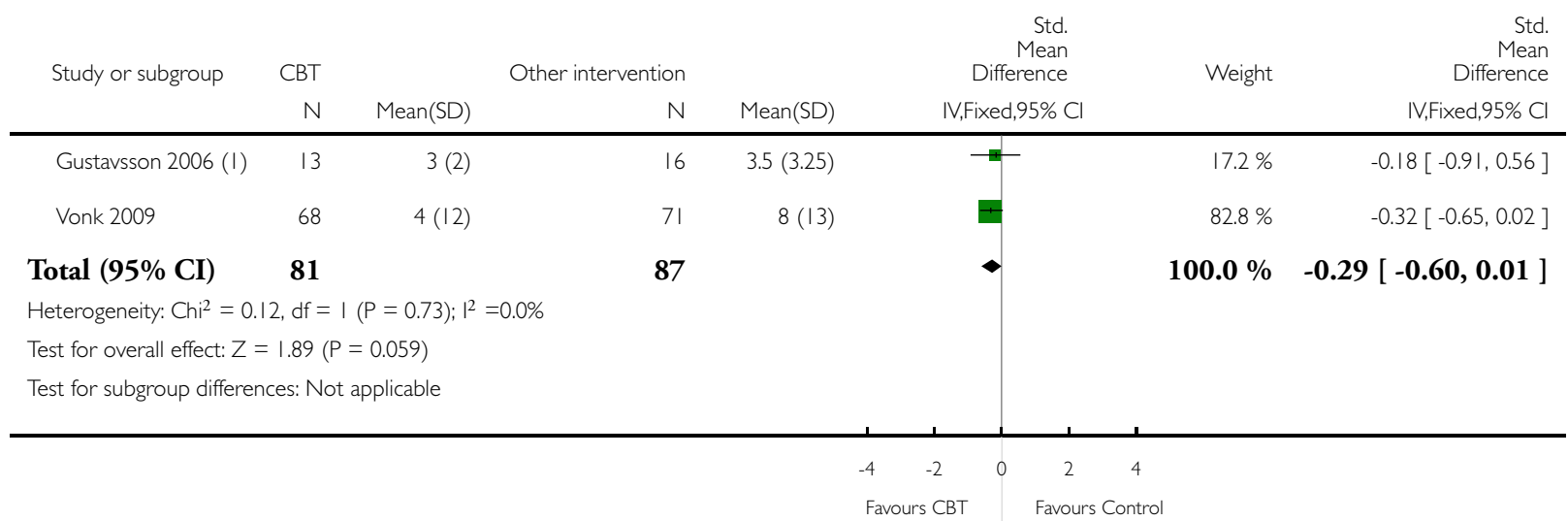

(I) Median value as been considered as mean value; SD has been estimated as half of the interquartile range. 
Analysis 3.8. Comparison 3 CBT versus other types of treatment (chronic NP), Outcome 8 Coping (shortterm follow-up).

Review: Cognitive-behavioural treatment for subacute and chronic neck pain

Comparison: 3 CBT versus other types of treatment (chronic NP)

Outcome: 8 Coping (short-term follow-up)

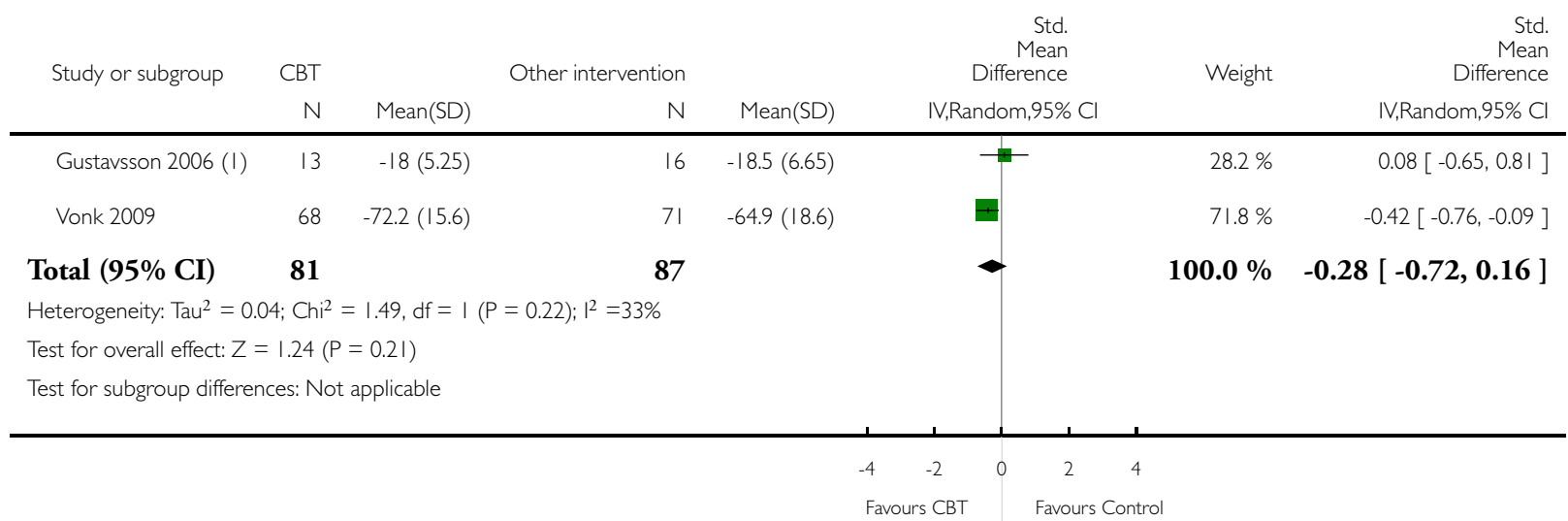

(I) Median value as been considered as mean value; SD has been estimated as half of the interquartile range. 


\section{Analysis 3.9. Comparison 3 CBT versus other types of treatment (chronic NP), Outcome 9 Coping (intermediate-term follow-up).}

Review: Cognitive-behavioural treatment for subacute and chronic neck pain

Comparison: 3 CBT versus other types of treatment (chronic NP)

Outcome: 9 Coping (intermediate-term follow-up)

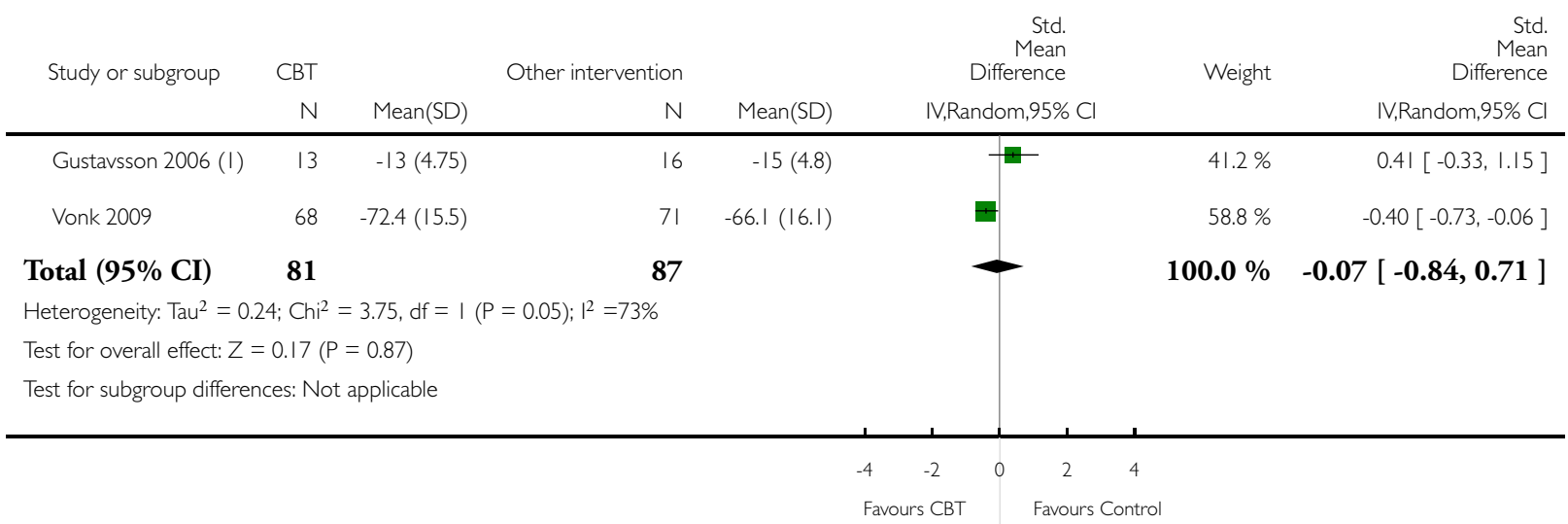

(I) Median value as been considered as mean value; SD has been estimated as half of the interquartile range.

Analysis 4.I. Comparison 4 CBT in addition to another intervention versus the other intervention alone (chronic NP), Outcome I Pain (short-term follow-up).

Review: Cognitive-behavioural treatment for subacute and chronic neck pain

Comparison: 4 CBT in addition to another intervention versus the other intervention alone (chronic NP)

Outcome: I Pain (short-term follow-up)

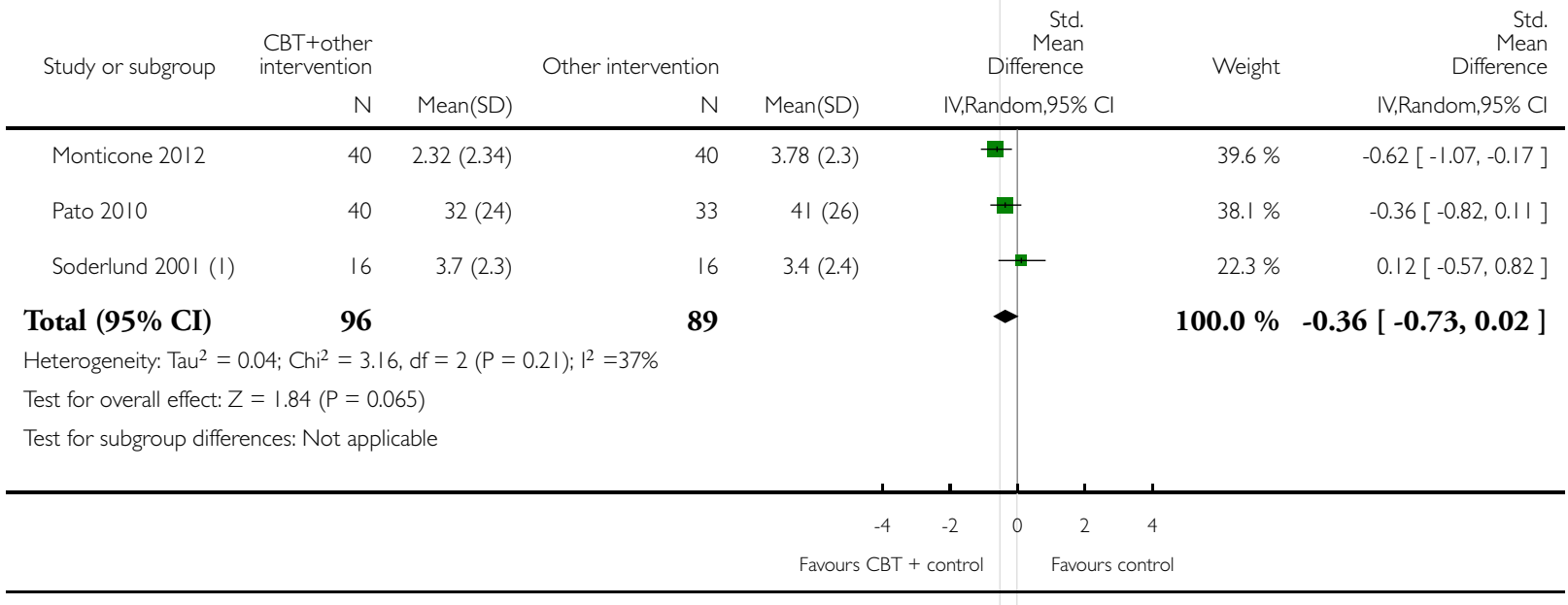

Cognitive-behavioural treatment for subacute and chronic neck pain (Review)

Copyright @ 2015 The Cochrane Collaboration. Published by John Wiley \& Sons, Ltd. 
Analysis 4.2. Comparison 4 CBT in addition to another intervention versus the other intervention alone (chronic NP), Outcome 2 Disability (short-term follow-up).

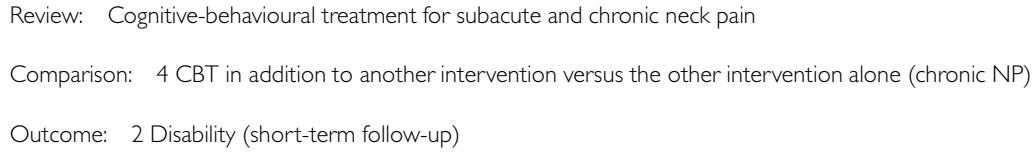

\begin{tabular}{|c|c|c|c|c|c|c|c|}
\hline \multirow[t]{2}{*}{ Study or subgroup } & \multirow{2}{*}{$\begin{array}{r}\text { CBT + } \\
\text { Other } \\
\text { intervention } \\
\mathrm{N}\end{array}$} & \multicolumn{3}{|c|}{ Other intervention } & \multirow{2}{*}{$\begin{array}{r}\text { Std. } \\
\text { Mean } \\
\text { Difference } \\
\text { IV,Random,95\% Cl }\end{array}$} & \multirow[t]{2}{*}{ Weight } & \multirow{2}{*}{$\begin{array}{r}\text { Std } \\
\text { Mean } \\
\text { Difference } \\
\text { IV,Random,95\% C }\end{array}$} \\
\hline & & Mean(SD) & $N$ & Mean(SD) & & & \\
\hline Monticone 2012 & 40 & $32.39(22.66)$ & 40 & $43.53(22.35)$ & + & $38.0 \%$ & $-0.49[-0.94,-0.05]$ \\
\hline Pato 2010 & 40 & $5.1(6)$ & 33 & $5.1(4)$ & & $37.0 \%$ & $0.0[-0.46,0.46]$ \\
\hline Soderlund 200I (I) & 16 & $26.3(17.5)$ & 16 & $20.2(15.7)$ & & $25.0 \%$ & $0.36[-0.34,1.06]$ \\
\hline
\end{tabular}

Total $(\mathbf{9 5 \%}$ CI)

\section{ADDITIONAL TABLES}

Table 1. Table 1. Results of clinical relevance assessment

\begin{tabular}{|c|c|c|c|c|c|}
\hline Study & Patients & Interventions & Relevant outcomes & Size of effect & Benefit/Harms \\
\hline Dunne 2012 & $\mathrm{Y}$ & $\mathrm{Y}$ & $\mathrm{Y}$ & $\mathrm{N}$ & $\mathrm{Y}$ \\
\hline Gustavsson 2006 & $\mathrm{Y}$ & Y & Y & $\mathrm{N}$ & Y \\
\hline Monticone 2012 & Y & Y & Y & $\mathrm{N}$ & Y \\
\hline Pato 2010 & $\mathrm{Y}$ & $\mathrm{Y}$ & Y & $\mathrm{N}$ & Y \\
\hline
\end{tabular}


Table 1. Table 1. Results of clinical relevance assessment (Continued)

\begin{tabular}{llllll}
\hline Pool 2010 & Y & Y & Y & N & Y \\
\hline Robinson 2013 & Y & Y & Y & N & Y \\
\hline Soderlund 2001 & Y & Y & Y & N & Y \\
\hline Taimela 2000 & Y & Y & Y & N & Y \\
\hline Vonk 2009 & Y & Y & Y & N & Y \\
\hline Wicksell 2008 & Y & N & Y & N & Y \\
\hline
\end{tabular}

\section{APPENDICES}

\section{Appendix I. Search strategies}

\section{CENTRAL}

Last searched November 20, 2014

\#1 MeSH descriptor: [Neck Pain] explode all trees

\#2 neck pain:ti,ab,kw (Word variations have been searched)

\#3 MeSH descriptor: [Brachial Plexus Neuritis] explode all trees

\#4 cervico brachial neuralgia:ti,ab,kw (Word variations have been searched)

\#5 MeSH descriptor: [Headache] this term only

\#6 Headache:ti,ab,kw (Word variations have been searched)

\#7 Cervicogenic headache:ti,ab,kw (Word variations have been searched)

\#8 Neckache:ti,ab,kw (Word variations have been searched)

\#9 Cervicalgia:ti,ab,kw (Word variations have been searched)

\#10 MeSH descriptor: [Spondylosis] explode all trees

\#11 MeSH descriptor: [Spondylolisthesis] explode all trees

\#12 spondylosis or spondylolysis or spondylolisthesis:ti,ab,kw (Word variations have been searched)

\#13 MeSH descriptor: [Spinal Osteophytosis] explode all trees

\#14 MeSH descriptor: [Intervertebral Disc Degeneration] explode all trees

\#15 MeSH descriptor: [Intervertebral Disc Displacement] explode all trees

\#16 MeSH descriptor: [Ossification of Posterior Longitudinal Ligament] explode all trees

\#17 MeSH descriptor: [Whiplash Injuries] explode all trees

\#18 whiplash:ti,ab,kw (Word variations have been searched)

\#19 Cervical Pain:ti,ab,kw (Word variations have been searched)

\#20 Cervicodynia:ti,ab,kw (Word variations have been searched)

\#21 Brachialgia:ti,ab,kw (Word variations have been searched)

\#22 brachial plexus neuritis:ti,ab,kw (Word variations have been searched)

\#23 rachialgia:ti,ab,kw (Word variations have been searched)

\#24 MeSH descriptor: [Radiculopathy] explode all trees

\#25 MeSH descriptor: [Polyradiculopathy] explode all trees

\#26 MeSH descriptor: [Neck Injuries] explode all trees

\#27 neck injur*:ti,ab,kw (Word variations have been searched)

Cognitive-behavioural treatment for subacute and chronic neck pain (Review)

Copyright @ 2015 The Cochrane Collaboration. Published by John Wiley \& Sons, Ltd. 
\#28 MeSH descriptor: [Torticollis] explode all trees \#29 MeSH descriptor: [Cervical Rib Syndrome] explode all trees

$\# 30 \# 1$ or $\# 2$ or \#3 or \#4 or \#5 or \#6 or \#7 or \#8 or \#9 or \#10 or \#11 or \#12 or \#13 or \#14 or \#15 or \#16 or \#17 or \#18 or \#19 or \# 20 or \#21 or \#22 or \#23 or \#24 or \#25 or \#26 or \#27 or \#28 or \#29

\#31 MeSH descriptor: [Behavior Therapy] explode all trees

\#32 behavior therapy:ti,ab,kw (Word variations have been searched) \#33 cognitive behav*:ti,ab,kw (Word variations have been searched) \#34 MeSH descriptor: [Conditioning, Operant] explode all trees \#35 operant conditioning:ti,ab,kw (Word variations have been searched)

\#36 respondent treatment:ti,ab,kw (Word variations have been searched)

\#37 behavioral therapy:ti,ab,kw (Word variations have been searched)

\#38 cognitive therapy:ti,ab,kw (Word variations have been searched)

\#39 cognitive treatment:ti,ab,kw (Word variations have been searched)

\#40 behavior treatment:ti,ab,kw (Word variations have been searched)

\#41 relaxation:ti,ab,kw (Word variations have been searched)

\#42 graded activity:ti,ab,kw (Word variations have been searched)

\#43 MeSH descriptor: [Reinforcement (Psychology)] explode all trees

\#44 MeSH descriptor: [Psychotherapy, Rational-Emotive] explode all trees

\#45 MeSH descriptor: [Reality Therapy] explode all trees

\#46 CBASP:ti,ab,kw (Word variations have been searched)

\#47 mindfulness:ti,ab,kw (Word variations have been searched)

\#48 functional analytic psychotherapy:ti,ab,kw (Word variations have been searched)

\#49 counseling:ti,ab,kw (Word variations have been searched)

\#50 biofeedback:ti,ab,kw (Word variations have been searched)

\#51 metacognitive therapy:ti,ab,kw (Word variations have been searched)

$\# 52 \# 31$ or \#32 or \#33 or \#34 or \#35 or \#36 or \#37 or \#38 or \#39 or \#40 or \#41 or \#42 or \#43 or \#44 or \#45 or \#46 or \#47 or \#48

or \#49 or \#50 or \#51

$\# 53$ \#30 and \#52 in Trials

\#54 \#53 Publication Year from 2013 to 2014, in Trials

\section{MEDLINE and MEDLINE In-Process \& Other Non-Indexed Citations}

Last searched November 20, 2014

1. randomized controlled trial.pt.

2. controlled clinical trial.pt.

3. randomized.ab.

4. placebo.ab,ti.

5. drug therapy.fs.

6. randomly.ab,ti.

7. trial.ab,ti.

8. groups.ab,ti.

9. or/1-8

10. (animals not (humans and animals)).sh.

11. 9 not 10

12. Neck Pain/

13. neck pain.ti,ab.

14. Brachial Plexus Neuritis/

15. cervico brachial neuralgia.mp.

16. Headache/

17. headache.ti,ab.

18. Cervicogenic headache.mp.

19. neckache.ti,ab.

20. cervicalgia.ti,ab.

Cognitive-behavioural treatment for subacute and chronic neck pain (Review)

Copyright @ 2015 The Cochrane Collaboration. Published by John Wiley \& Sons, Ltd. 
21. Spondylosis/ or Spondylolysis/ or Spondylolisthesis/

22. (spondylosis or spondylolysis).mp. or spondylolisthesis.ti,ab. [mp=title, abstract, original title, name of substance word, subject heading word, keyword heading word, protocol supplementary concept word, rare disease supplementary concept word, unique identifier]

23. spinal osteophytosis/

24. exp Intervertebral Disc Degeneration/

25. exp Intervertebral Disc Displacement/

26. "Ossification of Posterior Longitudinal Ligament"/

27. Whiplash Injuries/

28. whiplash.ti,ab.

29. cervical pain.ti,ab.

30. cervicodynia.ti,ab.

31. brachial plexus neuritis.mp.

32. rachialgia.ti,ab.

33. radiculopathy/

34. Polyradiculopathy/

35. Neck Injuries/

36. neck injur*.mp.

37. Torticollis/

38. cervicobrachial neuralgia.ti,ab.

39. Cervical Rib Syndrome/

40. or/12-39

41. Behavior Therapy/

42. Cognitive Therapy/

43. Relaxation Therapy/

44. behavior therapy.ti,ab.

45. Conditioning, Operant/

46. operant conditioning.ti,ab.

47. respondent treatment.ti,ab.

48. behavioral therapy.ti,ab.

49. behavioural therapy.ti,ab.

50. cognitive therapy.ti,ab.

51. cognitive treatment.ti,ab.

52. behavior treatment.ti,ab.

53. relaxation.ti,ab. or Relaxation/

54. graded activity.ti,ab.

55. "Reinforcement (Psychology)"/

56. Psychotherapy, Rational-Emotive/

57. Reality Therapy/

58. CBASP.mp.

59. mindfulness.mp.

60. functional analytic psychotherapy.mp.

61. counseling.mp.

62. biofeedback.mp.

63. metacognitive therapy.mp.

64. cognitive behav*.mp.

65. or/41-64

66. 11 and 40 and 65

67. limit 66 to $y r=2013-2014$

68. $\operatorname{limit} 66$ to ed $=20130717-20141120$

69. 67 or 68

Cognitive-behavioural treatment for subacute and chronic neck pain (Review)

Copyright $\odot 2015$ The Cochrane Collaboration. Published by John Wiley \& Sons, Ltd. 
Neck terms used in the July 2013 strategy. For the November 20th search (above), the MeSH terms Cervicalgia, Cervical pain, Cervicodynia, and Neckache (lines 21,31, 33 and 19) were removed as they map to the term Neck pain (line 12). Line 35 Brachialgia was also removed as it is not listed as a term in the MeSH database.

12 Neck Pain/

13 neck pain.ti,ab.

14 Brachial Plexus Neuritis/

15 cervico brachial neuralgia.mp.

16 Headache/

17 headache.ti,ab.

18 Cervicogenic headache.mp.

19 Neckache/

20 neckache.ti,ab.

21 Cervicalgia/

22 cervicalgia.ti,ab.

23 Spondylosis/ or Spondylolysis/ or Spondylolisthesis/

24 (spondylosis or spondylolysis).mp. or spondylolisthesis.ti,ab.

25 spinal osteophytosis/

26 exp Intervertebral Disc Degeneration/

27 exp Intervertebral Disc Displacement/

28 "Ossification of Posterior Longitudinal Ligament"/

29 Whiplash Injuries/

30 whiplash.ti,ab.

31 Cervical Pain/

32 cervical pain.ti,ab.

33 Cervicodynia/

34 cervicodynia.ti,ab.

35 Brachialgia/

36 brachial plexus neuritis.mp.

37 rachialgia.ti,ab.

38 radiculopathy/

39 Polyradiculopathy/

40 Neck Injuries/

41 neck injur*.mp.

42 Torticollis/

43 cervicobrachial neuralgia.ti,ab.

44 Cervical Rib Syndrome/

45 or/ $12-44$

\section{EMBASE}

Last searched November 20, 2014

1 neck pain/

2 neck pain.ti,ab.

3 cervicobrachial neuralgia/

4 cervico brachial neuralgia.ti,ab.

5 cervicobrachial neuralgia.ti,ab.

6 headache/

7 headache.ti,ab.

8 Cervicogenic headache.mp. or exp secondary headache/

9 Neckache.mp.

10 Cervicalgia.mp.

11 Spondylosis/ or Spondylolysis/ or Spondylolisthesis/

Cognitive-behavioural treatment for subacute and chronic neck pain (Review)

Copyright $\odot 2015$ The Cochrane Collaboration. Published by John Wiley \& Sons, Ltd. 
12 (spondylosis or spondylolysis).mp. or spondylolisthesis.ti,ab. [mp=title, abstract, subject headings, heading word, drug trade name, original title, device manufacturer, drug manufacturer, device trade name, keyword]

13 spinal osteophytosis.mp.

14 intervertebral disk degeneration/

15 intervertebral disk hernia/

16 ligament calcinosis/

17 whiplash injury/

18 whiplash.ti,ab.

19 Cervical Pain.mp.

20 Cervicodynia.mp.

21 brachialgia/

22 brachial plexus neuritis.mp. or exp brachial plexus neuropathy/

23 rachialgia.ti,ab.

24 exp radiculopathy/

25 neck injury/

26 Neck Injur*.mp.

27 torticollis/

28 or/1-27

29 behavior therapy/

30 cognitive therapy/

31 cognitive behav*.mp.

32 relaxation training/

33 behavior therapy.ti,ab.

34 instrumental conditioning/

35 operant conditioning.ti,ab.

36 respondent treatment.ti,ab.

37 behavioral therapy.ti,ab.

38 behavioural therapy.ti,ab.

39 cognitive therapy.ti,ab.

40 cognitive treatment.ti,ab.

41 behavior treatment.ti,ab.

42 relaxation.ti,ab.

43 graded activity.ti,ab.

44 reinforcement/

45 psychotherapy/

46 reality therapy/

47 CBASP.mp.

48 mindfulness.mp.

49 counseling/

50 counseling.ti,ab.

51 biofeedback.mp.

52 metacognitive therapy.mp.

53 or/29-52

5428 and 53

55 Clinical Article/

56 exp Clinical Study/

57 Clinical Trial/

58 Controlled Study/

59 Randomized Controlled Trial/

60 Major Clinical Study/

61 Double Blind Procedure/

62 Multicenter Study/

63 Single Blind Procedure/

Cognitive-behavioural treatment for subacute and chronic neck pain (Review)

Copyright $\odot 2015$ The Cochrane Collaboration. Published by John Wiley \& Sons, Ltd. 
64 Phase 3 Clinical Trial/

65 Phase 4 Clinical Trial/

66 crossover procedure/

67 placebo/

68 or $/ 55-67$

69 allocat\$.mp.

70 assign \$.mp.

71 blind \$.mp.

72 (clinic\$ adj25 (study or trial)).mp.

73 compar\$.mp.

74 control\$.mp.

75 cross?over.mp.

76 factorial $\$ . m p$.

77 follow?up.mp.

78 placebo $\$ . \mathrm{mp}$.

79 prospectiv\$.mp.

80 random $\$$.mp.

81 ((singl\$ or doubl\$ or trebl\$ or tripl\$) adj25 (blind\$ or mask\$)).mp.

82 trial.mp.

83 (versus or vs).mp.

84 or/69-83

8568 or 84

86 exp animals/ or exp invertebrate/ or animal experiment/ or animal model/ or animal tissue/ or animal cell/ or nonhuman/

87 human/ or normal human/ or human cell/

8886 and 87

8986 not 88

9085 not 89

9154 and 90

92 limit 91 to $\mathrm{yr}=2013-2014$

93 limit 91 to $\mathrm{em}=201329-201446$

9492 or 93

Previous RCT filter used in Jul 2013. For the search in November 2014 (above), lines 55 to 59 were removed and line 90 (line 85 above) was changed from "and" to "or".

55 random\$.tw.

56 placebo\$.mp.

57 double-blind.tw.

58 or $/ 55-57$

5954 and 58

60 Clinical Article/

61 exp Clinical Study/

62 Clinical Trial/

63 Controlled Study/

64 Randomized Controlled Trial/

65 Major Clinical Study/

66 Double Blind Procedure/

67 Multicenter Study/

68 Single Blind Procedure/

69 Phase 3 Clinical Trial/

70 Phase 4 Clinical Trial/

71 crossover procedure/

72 placebo/

73 or/ $60-72$

74 allocat\$.mp.

Cognitive-behavioural treatment for subacute and chronic neck pain (Review)

Copyright $\odot 2015$ The Cochrane Collaboration. Published by John Wiley \& Sons, Ltd. 
75 assign \$.mp.

76 blind $\$ . m p$.

77 (clinic\$ adj25 (study or trial)).mp.

78 compar $\$ . m p$.

79 control\$.mp.

80 cross?over.mp.

81 factorial\$.mp.

82 follow?up.mp.

83 placebo\$.mp.

84 prospectiv\$.mp.

85 random $\$ . m p$.

86 ((singl\$ or doubl\$ or trebl\$ or tripl\$) adj25 (blind\$ or mask\$)).mp.

87 trial.mp.

88 (versus or vs).mp.

89 or $/ 74-88$

9073 and 89

91 exp animals/ or exp invertebrate/ or animal experiment/ or animal model/ or animal tissue/ or animal cell/ or nonhuman/

92 human/ or normal human/ or human cell/

9391 and 92

9491 not 93

9590 not 94

9654 and 95

\section{CINAHL}

Last searched November 20, 2014

S79 S77 OR S78 32

S78 S76 AND EM 20130717-20141120

S77 S76 Limiters - Published Date: 20130701-20141131

S76 S28 AND S51 AND S75

S75 S52 OR S53 OR S54 OR S55 OR S56 OR S57 OR S58 OR S59 OR S60 OR S61 OR S62 OR S63 OR S64 OR S65 OR S66

OR S67 OR S68 OR S69 OR S70 OR S71 OR S72 OR S73 OR S74

S74 (MH "Biofeedback")

S73 (MH “Counseling”) OR “counseling”

S72 (MH "Counseling”) OR "counseling”

S71 "mindfulness"

S70 "CBASP"

S69 (MH "Reality Therapy")

S68 (MH "Reality Therapy")

S67 (MH "Reinforcement (Psychology)")

S66 "graded activity"

S65 "behavior treatment"

S64 "cognitive treatment"

S63 "cognitive therapy"

S62 "behavioural therapy"

S61 "behavioral therapy"

S60 "respondent treatment"

S59 "operant conditioning"

S58 (MH "Conditioning (Psychology)")

S57 "behavior therapy"

S56 "cognitive behav*"

S55 (MH "Relaxation") OR "relaxation"

S54 (MH "Simple Relaxation Therapy (Iowa NIC)")

Cognitive-behavioural treatment for subacute and chronic neck pain (Review)

Copyright $\odot 2015$ The Cochrane Collaboration. Published by John Wiley \& Sons, Ltd. 
S53 (MH "Cognitive Therapy") OR (MH “Cognitive Therapy (Iowa NIC) (Non-Cinahl)")

S52 (MH "Behavior Therapy")

S51 S29 OR S30 OR S31 OR S32 OR S33 OR S34 OR S35 OR S36 OR S37 OR S38 OR S39 OR S40 OR S41 OR S42 OR S43

OR S44 OR S45 OR S46 OR S47 OR S48 OR S49 OR S50

S50 "Cervical Rib Syndrome" OR (MH "Cervical Vertebrae")

S49 (MH "Torticollis")

S48 "neck injur*"

S47 (MH "Neck Injuries")

S46 (MH "Radiculopathy") OR (MH "Polyradiculopathy")

S45 "rachialgia"

S44 "Brachialgia"

S43 "cervicodynia"

S42 "Cervical Pain"

S41 "whiplash"

S40 (MH "Whiplash Injuries")

S39 "Ossification of Posterior Longitudinal Ligament"

S38 (MH "Intervertebral Disk") OR (MH "Intervertebral Disk Displacement")

S37 (MH "Spinal Osteophytosis")

S36 (MH "Spondylosis+")

S35 "cervicalgia"

S34 "neckache"

S33 (MH "Headache") OR "Headache"

S32 "cervico-brachial neuralgia"

S31 (MH "Brachial Plexus Neuritis")

S30 "neck pain"

S29 (MH "Neck Pain")

S28 S26 NOT S27

S27 (MH "Animals")

S26 S7 or S12 or S19 or S25

S25 S20 or S21 or S22 or S23 or S24

S24 volunteer*

S23 prospectiv*

S22 control*

S21 followup stud*

S20 follow-up stud*

S19 S13 or $S 14$ or $S 15$ or $S 16$ or $S 17$ or $S 18$

S18 (MH "Prospective Studies+")

S17 (MH "Evaluation Research+")

S16 (MH "Comparative Studies")

S15 latin square

S14 (MH "Study Design+")

S13 (MH "Random Sample")

S12 S8 or S9 or S10 or S11

S11 random*

S10 placebo*

S9 (MH "Placebos")

S8 (MH "Placebo Effect")

$\mathrm{S} 7 \mathrm{~S} 1$ or $\mathrm{S} 2$ or $\mathrm{S} 3$ or $\mathrm{S} 4$ or $\mathrm{S} 5$ or S6

S6 triple-blind

S5 single-blind

S4 double-blind

S3 clinical W3 trial

S2 "randomi?ed controlled trial*"

Cognitive-behavioural treatment for subacute and chronic neck pain (Review)

Copyright $\odot 2015$ The Cochrane Collaboration. Published by John Wiley \& Sons, Ltd. 


\section{S1 (MH "Clinical Trials+")}

\section{PsycINFO}

Last searched November 20, 2014

1. clinical trials/

2. controlled trial.mp.

3. RCT.mp.

4. (Random $\$$ adj 3 trial).mp. [mp=title, abstract, heading word, table of contents, key concepts, original title, tests \& measures]

5. (clin $\$$ adj3 trial).mp. [mp=title, abstract, heading word, table of contents, key concepts, original title, tests \& measures]

6. (sing $\$$ adj2 blind $\$$ ).mp. [mp=title, abstract, heading word, table of contents, key concepts, original title, tests \& measures]

7. (doub\$ adj2 blind\$).mp. [mp=title, abstract, heading word, table of contents, key concepts, original title, tests \& measures]

8. placebo.mp. or exp Placebo/

9. latin square.mp.

10. (random\$ adj2 assign\$).mp.

11. prospective studies/

12. (prospective adj stud\$).mp.

13. (comparative adj stud\$).mp.

14. treatment effectiveness evaluation/

15. (evaluation adj stud\$).mp.

16. exp Posttreatment Followup/

17. follow?up stud\$.mp.

18. or/1-17

19. neck pain.mp.

20. Cervico Brachial Neuralgia.mp. [mp=title, abstract, heading word, table of contents, key concepts, original title, tests \& measures]

21. Headache.mp. [mp=title, abstract, heading word, table of contents, key concepts, original title, tests \& measures]

22. headache/ (3328)

23. Cervicogenic headache.mp.

24. Neckache.mp.

25. Cervicalgia.mp.

26. Spondylosis.mp.

27. Spondylolysis.mp.

28. Spondylolisthesis.mp.

29. spinal osteophytosis.mp. [mp=title, abstract, heading word, table of contents, key concepts, original title, tests \& measures]

30. ((disc or disk) adj3 (degenerat $\$$ or displace $\$)$ ).mp. [mp=title, abstract, heading word, table of contents, key concepts, original title, tests $\&$ measures]

31. ossification of posterior longitudinal ligament.mp.

32. whiplash/

33. whiplash.mp.

34. Cervical Pain.mp.

35. Cervicodynia.mp.

36. Brachialgia.mp. [mp=title, abstract, heading word, table of contents, key concepts, original title, tests $\&$ measures]

37. brachial plexus neuritis.mp. [mp=title, abstract, heading word, table of contents, key concepts, original title, tests \& measures]

38. radiculopathy.mp. [mp=title, abstract, heading word, table of contents, key concepts, original title, tests $\&$ measures]

39. polyradiculopathy.mp. [mp=title, abstract, heading word, table of contents, key concepts, original title, tests $\&$ measures]

40. neck injur\$.mp. [mp=title, abstract, heading word, table of contents, key concepts, original title, tests \& measures]

41. torticollis.mp. [ $\mathrm{mp}=$ title, abstract, heading word, table of contents, key concepts, original title, tests $\&$ measures]

42. Cervical Rib Syndrome.mp. [mp=title, abstract, heading word, table of contents, key concepts, original title, tests $\&$ measures]

43. or $19-42$

44. exp behavior therapy/

45. cognitive therapy/

46. cognitive behav\$.mp.

Cognitive-behavioural treatment for subacute and chronic neck pain (Review)

Copyright @ 2015 The Cochrane Collaboration. Published by John Wiley \& Sons, Ltd. 
47. exp relaxation therapy/

48. (behavio?r adj2 (therapy or treatment)).mp. [mp=title, abstract, heading word, table of contents, key concepts, original title, tests \& measures]

49. (cognitive adj2 (therapy or treatment)).mp. [mp=title, abstract, heading word, table of contents, key concepts, original title, tests $\&$ measures]

50. relaxation/

51. relaxation.mp.

52. graded activity.mp.

53. exp reinforcement/

54. rational emotive behavior therapy/

55. reality therapy/

56. CBASP.mp.

57. mindfulness/

58. exp Analytical Psychotherapy/ or exp "Acceptance and Commitment Therapy"/

59. exp Counseling/ or counseling.mp.

60. exp Biofeedback/ or biofeedback.mp.

61. metacognitive therapy.mp.

62. or/44-61

63. 18 and 43 and 62

64. limit 63 to $\mathrm{yr}=2013-2014$

\section{Scopus}

Last searched November 20, 2014

( ( TITLE-ABS-KEY ( random*) AND SUBJAREA ( mult OR medi OR nurs OR vete OR dent OR heal ) ) OR ( TITLE-ABSKEY ( placebo*) AND SUBJAREA ( mult OR medi OR nurs OR vete OR dent OR heal ) ) OR ( TITLE-ABS-KEY ( group* ) AND SUBJAREA ( mult OR medi OR nurs OR vete OR dent OR heal ) ) OR ( TITLE-ABS-KEY ( trial*) AND SUBJAREA ( mult OR medi OR nurs OR vete OR dent OR heal ) ) ) AND ( ( TITLE-ABS-KEY ( neck pain ) AND SUBJAREA ( mult OR medi OR nurs OR vete OR dent OR heal ) ) OR ( TITLE-ABS-KEY-AUTH ( whiplash ) ) OR ( TITLE-ABS-KEY-AUTH ( neck injur* ) ) OR ( TITLE-ABS-KEY-AUTH ( neck injur*) ) ) AND ( ( TITLE-ABS-KEY-AUTH ( cognitive behav*) ) OR ( TITLE-ABS-KEYAUTH ( counseling ) ) OR ( TITLE-ABS-KEY-AUTH ( behav* therapy ) ) OR ( TITLE-ABS-KEY-AUTH ( behavior therapy ) ) OR ( TITLE-ABS-KEY-AUTH ( cognitive therapy ) ) ) AND ( LIMIT-TO ( PUBYEAR, 2014 ) OR LIMIT-TO ( PUBYEAR , 2013 ) )

\section{Web of Science}

Last searched November 20, 2014

\# 5 \#3 AND \#2 AND \#1

Refined by: PUBLICATION YEARS: ( 2013 OR 2014 )

Indexes=SCI-EXPANDED, SSCI, A\&HCI, CPCI-S, CPCI-SSH Timespan=All years

\# 4 \#3 AND \#2 AND \# 1

Indexes=SCI-EXPANDED, SSCI, A\&HCI, CPCI-S, CPCI-SSH Timespan=All years

\# 3 TOPIC: (cognitive behav*) OR TOPIC: (counseling) OR TOPIC: (behav* therapy) OR TOPIC: (cognitive therapy)

Indexes=SCI-EXPANDED, SSCI, A\&HCI, CPCI-S, CPCI-SSH Timespan=All years

\# 2 TOPIC: (neck pain) OR TOPIC: (whiplash) OR TOPIC: (neck injur*) OR TOPIC: (cervicogenic headache) OR TOPIC: (spondylosis)

Indexes=SCI-EXPANDED, SSCI, A\&HCI, CPCI-S, CPCI-SSH Timespan=All years

\# 1 TOPIC: (clinical trial*) OR TOPIC: (research design) OR TOPIC: (comparative stud*) OR TOPIC: (evaluation stud*) OR TOPIC: (controlled trial*) OR TOPIC: (follow-up stud*) OR TOPIC: (prospective stud*) OR TOPIC: (random*) OR TOPIC: (placebo*) OR TOPIC: ((single blind*)) OR TOPIC: ((double blind*))

Indexes=SCI-EXPANDED, SSCI, A\&HCI, CPCI-S, CPCI-SSH Timespan=All years

Cognitive-behavioural treatment for subacute and chronic neck pain (Review)

Copyright $\odot 2015$ The Cochrane Collaboration. Published by John Wiley \& Sons, Ltd. 


\section{PubMed}

Searched November 21, 2014

(((neck pain[Title/Abstract] OR whiplash[Title/Abstract] OR neck injur*[Title/Abstract] OR cervical radiculopathy[Title/Abstract])) AND (cognitive therapy[Title/Abstract] OR behavior* therapy[Title/Abstract] OR behaviour* therapy[Title/Abstract] OR relaxation[Title/Abstract] OR graded activity[Title/Abstract])) AND ((pubstatusaheadofprint OR publisher[sb] or pubmednotmedline[sb]))

\section{ClinicalTrials.gov}

Searched November 21, 2014

Search terms field: (neck pain AND (cognitive OR relaxation OR "graded activity"))

\section{WHO ICTRP}

Searched November 21, 2014

Basic search: Cognitive AND neck pain

\section{Appendix 2. Questions for clinical relevance}

1. Are the participants described in detail so that you can decide whether they are comparable with those that you see in your practice?

2. Are the interventions and treatment settings described well enough so that you can provide the same for your patients?

3. Were all clinically relevant outcomes measured and reported?

4. Is the size of the effect clinically important?

5. Are the likely treatment benefits worth the potential harms?

\section{Appendix 3. Criteria for assessing risk of bias for internal validity}

\section{Random sequence generation (selection bias)}

\section{Selection bias (biased allocation to interventions) due to inadequate generation of a randomised sequence}

Risk of selection bias is low if the investigators describe a random component in the sequence generation process, such as referring to a random number table, using a computer random number generator, coin tossing, shuffling cards or envelopes, throwing dice, drawing lots, minimising (minimisation may be implemented without a random element, and this is considered equivalent to being random). Risk of selection bias is high if the investigators describe a non-random component in the sequence generation process, such as sequence generated by odd or even date of birth, date (or day) of admission, hospital or clinic record number; or allocation by judgement of the clinician, preference of the participant, results of a laboratory test or a series of tests or availability of the intervention.

\section{Allocation concealment (selection bias)}

\section{Selection bias (biased allocation to interventions) due to inadequate concealment of allocations before assignment}

Risk of selection bias is low if participants and investigators enrolling participants could not foresee assignment because one of the following, or an equivalent method, was used to conceal allocation: central allocation (including telephone, web-based and pharmacycontrolled randomisation); sequentially numbered drug containers of identical appearance or sequentially numbered, opaque, sealed envelopes.

Risk of bias is high if participants or investigators enrolling participants could possibly foresee assignments and thus introduce selection bias, such as allocation based on using an open random allocation schedule (e.g. a list of random numbers); assignment envelopes used without appropriate safeguards (e.g. if envelopes were unsealed or non-opaque or not sequentially numbered); alternation or rotation; date of birth; case record number or other explicitly unconcealed procedures. 


\section{Blinding of participants}

\section{Performance bias due to knowledge of the allocated interventions by participants during the study}

Risk of performance bias is low if blinding of participants was ensured and it was unlikely that the blinding could have been broken; or if no blinding or incomplete blinding was provided, but the review authors judge that the outcome is not likely to be influenced by lack of blinding.

\section{Blinding of personnel/care providers (performance bias)}

\section{Performance bias due to knowledge of the allocated interventions by personnel/care providers during the study}

Risk of performance bias is low if blinding of personnel was ensured and it was unlikely that the blinding could have been broken; or if no blinding or incomplete blinding was provided, but the review authors judge that the outcome is not likely to be influenced by lack of blinding.

\section{Blinding of outcome assessor (detection bias)}

\section{Detection bias due to knowledge of the allocated interventions by outcome assessors}

Risk of detection bias is low if blinding of the outcome assessment was ensured and it was unlikely that the blinding could have been broken; or if no blinding or incomplete blinding was provided, but the review authors judge that the outcome is not likely to be influenced by lack of blinding, or:

- for participant-reported outcomes in which the participant was the outcome assessor (e.g. pain, disability): risk of bias for outcome assessors is low if risk of bias for participant blinding is low (Boutron 2005);

- for outcome criteria that are clinical or therapeutic events that will be determined by the interaction between participants and care providers (e.g. cointerventions, length of hospitalisation, treatment failure), in which the care provider is the outcome assessor: risk of bias for outcome assessors is low if risk of bias for care providers is low (Boutron 2005); and

- for outcome criteria that are assessed from data from medical forms: risk of bias is low if the treatment or adverse effects of the treatment could not be noticed in the extracted data (Boutron 2005).

\section{Incomplete outcome data (attrition bias)}

\section{Attrition bias due to amount, nature, or handling of incomplete outcome data}

Risk of attrition bias is low if no outcome data are missing; reasons for missing outcome data were unlikely to be related to the true outcome (for survival data, censoring unlikely to introduce bias); missing outcome data were balanced in numbers, with similar reasons for missing data across groups; for dichotomous outcome data, the proportion of missing outcomes compared with the observed event risk was not enough to have a clinically relevant impact on the intervention effect estimate; for continuous outcome data, the plausible effect size (difference in means or standardised difference in means) among missing outcomes was not enough to have a clinically relevant impact on observed effect size, or missing data were imputed using appropriate methods (if dropouts are very large, imputation using even "acceptable" methods may still suggest a high risk of bias) (van Tulder 2003). The percentage of withdrawals and dropouts should not exceed 20\% for short-term follow-up and 30\% for long-term follow-up and should not lead to substantial bias (these percentages are commonly used but arbitrary and are not supported by literature; van Tulder 2003).

Cognitive-behavioural treatment for subacute and chronic neck pain (Review) 


\section{Selective Reporting (reporting bias)}

\section{Reporting bias due to selective outcome reporting}

Risk of reporting bias is low if the study protocol is available and all of the study's prespecified (primary and secondary) outcomes that are of interest in the review have been reported in the prespecified way, or if the study protocol is not available, but it is clear that the published reports include all expected outcomes, including those that were prespecified (convincing text of this nature may be uncommon).

Risk of reporting bias is high if not all of the study's prespecified primary outcomes have been reported; one or more primary outcomes are reported using measurements, analysis methods or subsets of the data (e.g. subscales) that were not prespecified; one or more reported primary outcomes were not prespecified (unless clear justification for their reporting is provided, such as an unexpected adverse effect); one or more outcomes of interest in the review are reported incompletely so that they cannot be entered into a meta-analysis; or the study report fails to include results for a key outcome that would be expected to have been reported for such a study.

\section{Group similarity at baseline (selection bias)}

\section{Bias due to dissimilarity at baseline for the most important prognostic indicators}

Risk of bias is low if groups are similar at baseline for demographic factors, value of main outcome measure(s), and important prognostic factors (examples in the field of back and neck pain include duration and severity of complaints, vocational status, and percentage of participants with neurological symptoms; van Tulder 2003).

\section{Cointerventions (performance bias)}

\section{Bias because cointerventions were different across groups}

Risk of bias is low if no cointerventions were provided, or if cointerventions were similar between intervention and control groups (van Tulder 2003).

\section{Compliance (performance bias)}

\section{Bias due to inappropriate compliance with interventions across groups}

Risk of bias is low if compliance with the interventions was acceptable on the basis of reported intensity/dosage, duration, number, and frequency for both index and control intervention(s). For single-session interventions (e.g. surgery), this item is irrelevant (van Tulder 2003).

\section{Intention-to-treat-analysis}

Risk of bias is low if all randomly assigned participants were reported/analysed in the group to which they were allocated by randomisation.

\section{Timing of outcome assessments (detection bias)}

\section{Bias because important outcomes were not measured at the same time across groups}

Risk of bias is low if all important outcome assessments for all intervention groups were measured at the same time (van Tulder 2003).

Cognitive-behavioural treatment for subacute and chronic neck pain (Review)

Copyright $\odot 2015$ The Cochrane Collaboration. Published by John Wiley \& Sons, Ltd. 


\section{Other bias}

Bias due to problems not covered elsewhere

Risk of bias is low if the study appears to be free of other sources of bias not addressed elsewhere (e.g. study funding).

\section{CONTRIBUTIONS OFAUTHORS}

All authors contributed to draft, review, and edit the protocol and review.

All authors contributed to study selection.

Emilia Ambrosini, Roberta Fiorentini and Maddalena Restelli contributed to data extraction.

Marco Monticone and Emilia Ambrosini contributed to risk of bias assessment.

Marco Monticone and Silvia Gianola contributed to clinical relevance assessment.

Emilia Ambrosini and Lorenzo Moja contributed to data analysis.

All authors approved the final version of the protocol and review.

\section{DECLARATIONSOF INTEREST}

None.

\section{SOURCESOFS UPPORT}

\section{Internal sources}

- Editorial and administrative support of the Cochrane Back Review Group, Canada.

\section{External sources}

- No sources of support supplied

\section{DIFFERENCES BETWEEN PROTOCOLAND REVIEW}

The objectives of the review were expanded to include the three main comparisons that were investigated (CBT versus no treatment; CBT versus other treatment; CBT in addition to treatment).

Since publication of the protocol, we refined the types of intervention included in the review. Simple psychologically-oriented pain management strategies were not considered true cognitive-behavioural treatment. Therefore, studies involving these types of strategies were not considered eligible.

The investigation of clinical heterogeneity among studies was planned in the protocol, but was not carried out in the review due to the scarcity of studies, which did not allow for the performance of subgroup analyses. 


\section{Planned subgroup analyses and investigation of heterogeneity, as stated in the protocol}

Subgroup analyses would have explored heterogeneity due to study-level variables, such as population source and characteristics, and group-level variables such as CBT characteristics and type.

We would have assessed treatment effect differences according to gender and the particular type of CBT provided (individually designed or group-based designed program); delivery type (in-hospital treatment, home treatment, group supervision, individual supervision, psychologist based, rehabilitative teams based); dose/intensity; inclusion of additional interventions; time of outcome assessment (shortterm vs end of follow-up) and specific types of CBT (e.g. cognitive restructuring, imagery, attention diversion, relaxation techniques, operant treatment, pacing, graded exposure). Finally, in a subgroup analysis, we would have explored the possible interaction between treatment effect and the presence/absence of cervical radiculopathy or whiplash injury. Studies (or subgroups of participants within studies when data were stratified separately for participants with and without radiculopathy or whiplash injury) would have been divided into subgroups (e.g. with and without radiculopathy) and the effects of the covariatesanalysed. Studies mixing participants with and without the strata of interest would have been excluded.

Subgroup analyses would have been carried out when ten or more studies were retrieved in the data collection process, as it is unlikely that the investigation of heterogeneity would produce useful findings unless a substantial number of studies were identified (Higgins 2011). However, given that we expected to retrieve only a small number of studies, and given the potential value of identifying factors that differentiate between effective and ineffective CBT in terms of improvement in participant outcomes, we planned to try to offer at least a tentative view, with appropriate caveats, of the two characteristics that were most likely to affect success. These characteristics are "type of CBT" and "presence/absence of radiculopathy", which were selected by the review authors through a consensus approach, with agreement on the two factors judged most important and feasible to extract from published reports.

\section{NOT E S}

None. 